\title{
2005 NBCC-based Seismic Design of Gravity Retaining Walls
}

\author{
Submitted by \\ HASAN CHIKH MOHAMAD \\ B.Sc. Geotechnical Eng., Aleppo University, Syria
}

A thesis submitted to the Faculty of Graduate Studies \& Research in partial fulfilment of the requirements for the degree of Master of Applied Science in Engineering.

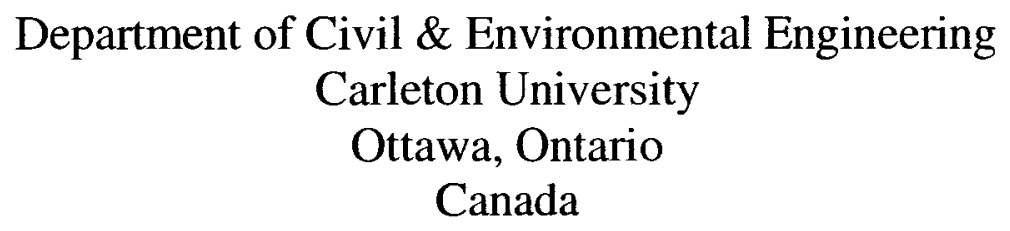

(C) Hasan Chikh Mohamad, 2006

Master of Applied Science in Civil Engineering is a joint program with University of Ottawa, administered by the Ottawa-Carleton Institute for Civil Engineering 


$\begin{array}{ll}\begin{array}{l}\text { Library and } \\ \text { Archives Canada }\end{array} & \begin{array}{l}\text { Bibliothèque et } \\ \text { Archives Canada }\end{array} \\ \begin{array}{l}\text { Published Heritage } \\ \text { Branch }\end{array} & \begin{array}{l}\text { Direction du } \\ \text { Patrimoine de l'édition }\end{array} \\ \begin{array}{l}\text { 395 Wellington Street } \\ \text { Ottawa ON K1A ON4 }\end{array} & \begin{array}{l}\text { 395, rue Wellington } \\ \text { Ottawa ON K1A ON4 } \\ \text { Canada }\end{array}\end{array}$

Your file Votre référence ISBN: 978-0-494-23333-7 Our file Notre référence ISBN: 978-0-494-23333-7

NOTICE:

The author has granted a nonexclusive license allowing Library and Archives Canada to reproduce, publish, archive, preserve, conserve, communicate to the public by telecommunication or on the Internet, loan, distribute and sell theses worldwide, for commercial or noncommercial purposes, in microform, paper, electronic and/or any other formats.

The author retains copyright ownership and moral rights in this thesis. Neither the thesis nor substantial extracts from it may be printed or otherwise reproduced without the author's permission.
AVIS:

L'auteur a accordé une licence non exclusive permettant à la Bibliothèque et Archives Canada de reproduire, publier, archiver, sauvegarder, conserver, transmettre au public par télécommunication ou par l'Internet, prêter, distribuer et vendre des thèses partout dans le monde, à des fins commerciales ou autres, sur support microforme, papier, électronique et/ou autres formats.

L'auteur conserve la propriété du droit d'auteur et des droits moraux qui protège cette thèse. $\mathrm{Ni}$ la thèse ni des extraits substantiels de celle-ci ne doivent être imprimés ou autrement reproduits sans son autorisation.
In compliance with the Canadian

Privacy Act some supporting forms may have been removed from this thesis.

While these forms may be included in the document page count, their removal does not represent any loss of content from the thesis.
Conformément à la loi canadienne sur la protection de la vie privée, quelques formulaires secondaires ont été enlevés de cette thèse.

Bien que ces formulaires aient inclus dans la pagination, il n'y aura aucun contenu manquant.

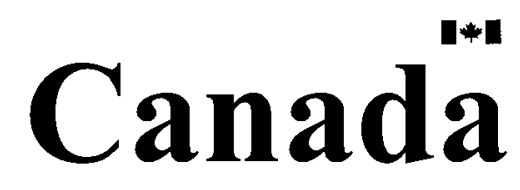




\begin{abstract}
The seismic provisions of the NBCC 2005 have introduced a lower hazard level ( $2 \%$ in 50 years probability of exceedance instead of $10 \%$ in 50 years). The peak ground accelerations have dramatically increased.

In this study, the developments of the seismic provisions pertaining to seismological, geotechnical and structural are thoroughly evaluated. By pursuing a reasonable rationale, the developments introduced for the structural design are applied to the seismic design of gravity retaining walls. In light of the previous application, a minimum factor of overstrength of 1.55 for a gravity retaining wall is obtained. Other factors, which increase the system overstrength, are also identified and quantified. Factors such as vegetation cover effect are only present in the retaining walls design. The use of 1.55 overstrength will maintain uniform performance in various parts of the country, and will bring about an improvement of the safety level performance for retaining walls.
\end{abstract}




\section{Acknowledgements}

The author is grateful for his research supervisor, Professor K. Tim Law for his sincere support, encouragement and his thoughtful suggestions and directions efforts throughout the research. At many stages in the proceeding of this study, the author has benefited from his advice, particularly so when exploring new ideas.

The author also is grateful to the faculty members in Civil \& Environmental Engineering Department at Carleton University especially Dr. Jag Humar and Dr. Siva Sivathayalan for their thoughtful discussions. Kind acknowledgment goes to Dr. Neal M. Holtz for his technical suggestions in Python computer program. Dr. Sai Vanapalli and Dr. Murat Saatcioglu from University of Ottawa and Mr. John Adams from GSC have overwhelmed this research with indirect thoughtful ideas and valuable discussion.

Thanks also go to Ottawa-Carleton Institute colleagues especially Mr. Tareq Salloum for his brave and persistent criticism of the exposition in various spots throughout the research. The author is also grateful for his family for their continuous support and endless love that was watching over him all the way to the end.

Finally, I would like to pass this research as a gift to all Canadians for their warm hospitality and kind welcome. 


\section{Table of Contents:}

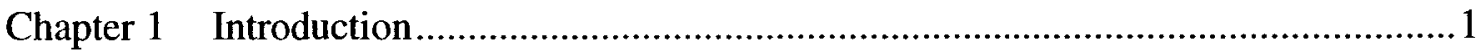

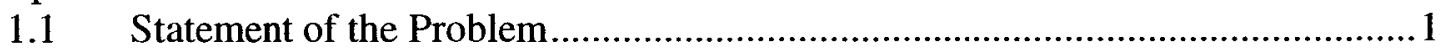

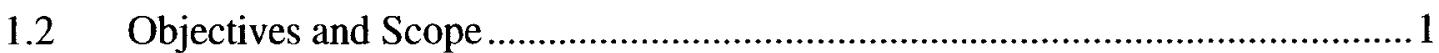

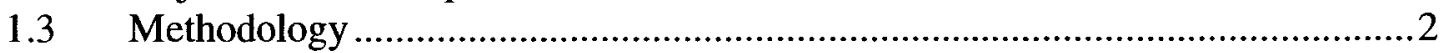

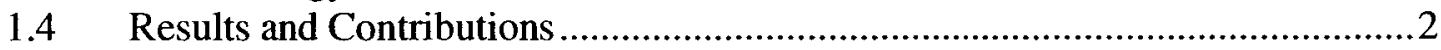

Chapter 2 Literature Review and Background ................................................... 4

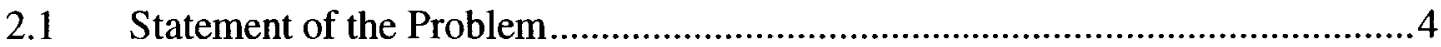

2.2 Developments of the Seismic Provisions of the NBCC ..................................5

2.2.1 Historical Development of Base Shear Equation.......................................5

2.2.2 Recent Developments of the NEHRP Recommended Provisions .............. 8

2.2.2.1 Development of the USGS Seismic Maps ......................................... 8

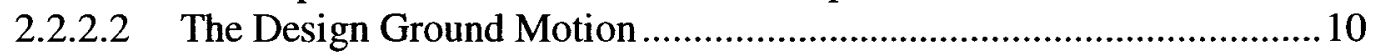

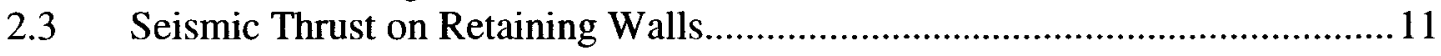

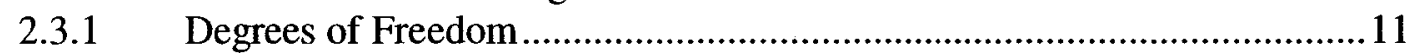

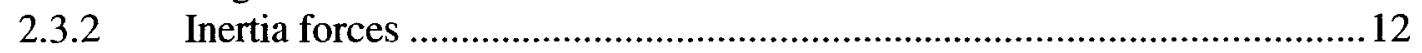

2.3.3 Pseudo-Static Methods................................................................... 14

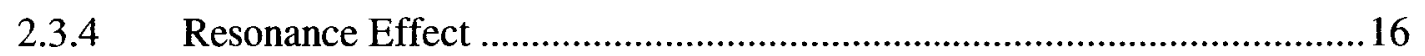

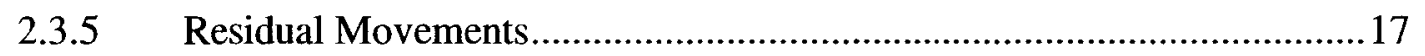

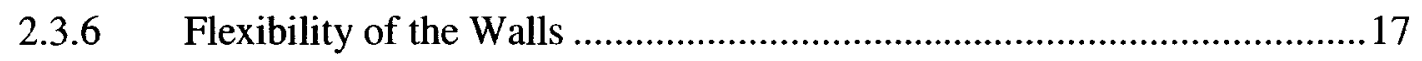

2.3.7 Secondary Importance of Longitudinal Loading .....................................19

2.3.8 Experimental Testing and Earthquake Reports....................................20

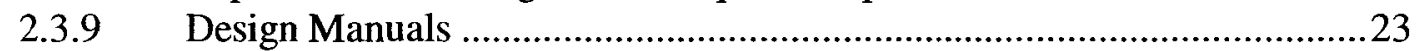

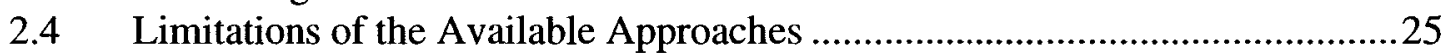

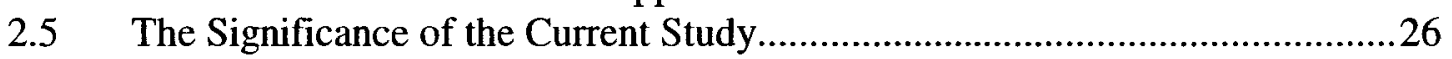

Chapter 3 Developments of the 2005 NBCC Seismic Provisions...............................22

3.1 Seismological Developments..............................................................28

3.1.1 New Model to Simulate the Wave Propagation and the Sources .............229

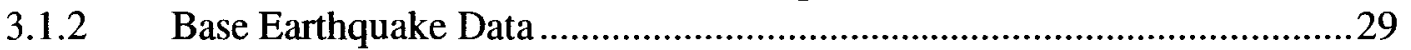

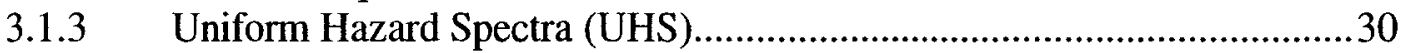

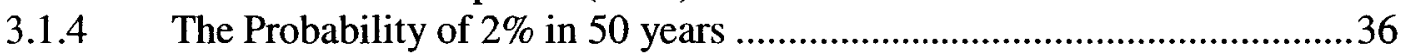

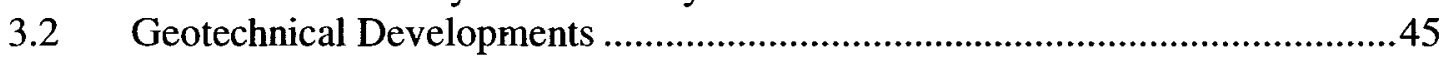

3.2.1 The Uniform Hazard Spectra UHS was developed for Site Class C ........45

3.2.2 Soil Effects Based on Natural Frequency ..............................................4

3.3 Structural Developments....................................................................53

3.3.1 Combining the Spectral Acceleration and the Foundation Factor .............55

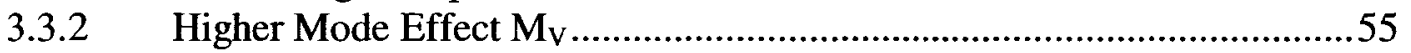

3.3.3 Ductility Modification Factor (R) .....................................................55

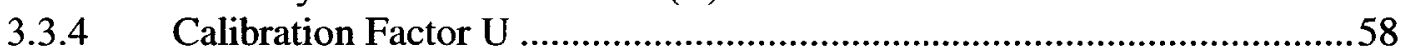

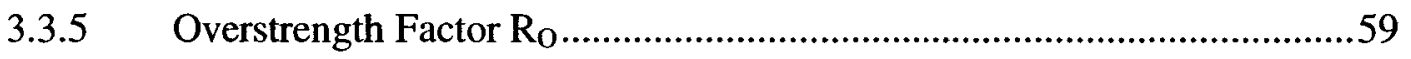

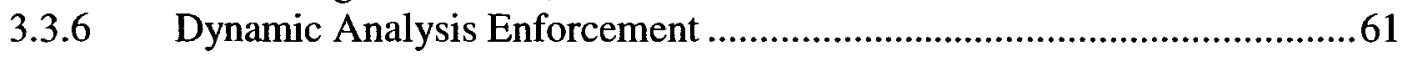

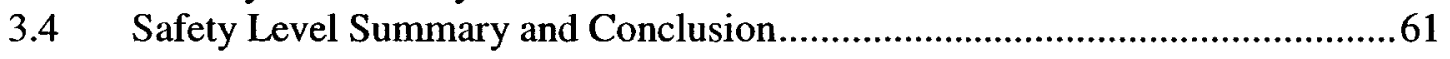

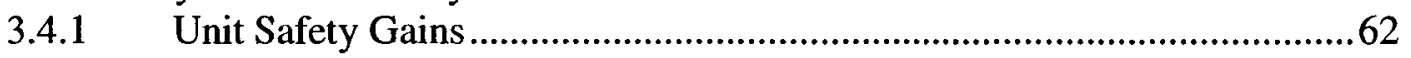

3.4.2 Average Safety Gain Improvements ...................................................63

3.4.3 The Result of the Safety Level Change ...............................................65 
Chapter 4 Seismic Design of Retaining Walls in Accordance with 2005 NBCC .........66

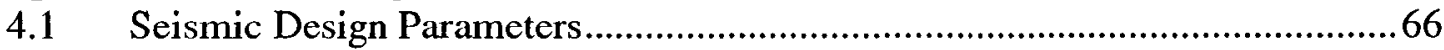

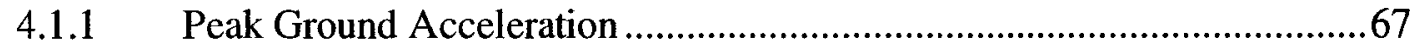

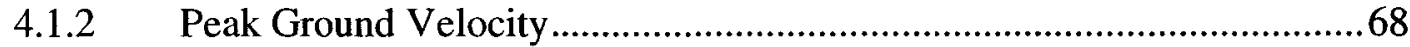

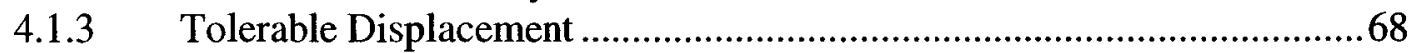

4.2 Limitation of the PGA to Quantify Ground Motions ...................................69

4.3 The Expected New Seismic Developments of Geotechnical Designs..............71

4.3.1 The Reduction of Hazard Level to $2 \%$ in 50 years .................................71

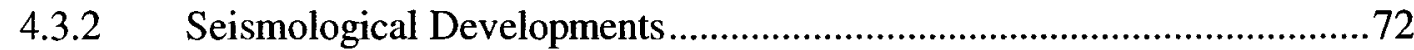

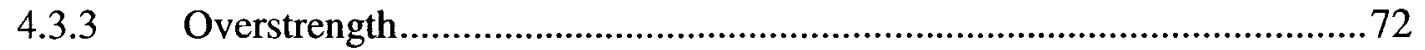

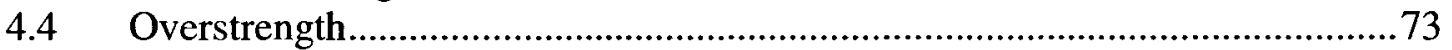

4.4.1 Overstrength in Structural Systems ....................................................73

4.4.2 Overstrength in Geotechnical Design .................................................77

4.4.3 Overstrength in Gravity Retaining Wall Design......................................77

4.4.4 The Overstrength in NEHRP Recommended Provisions ........................90

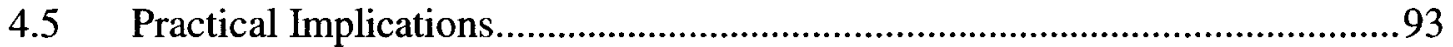

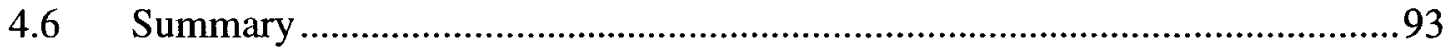

Chapter 5 Average Peak Ground Acceleration (APGA) ..........................................95

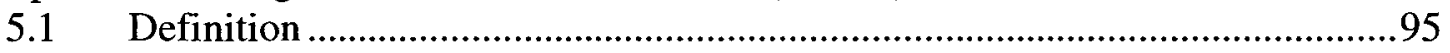

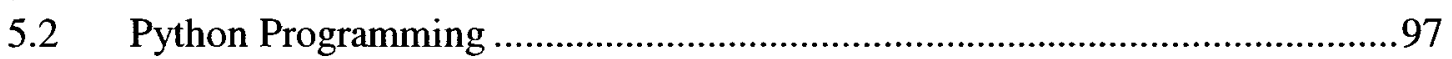

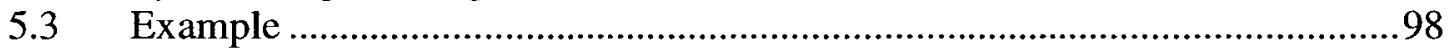

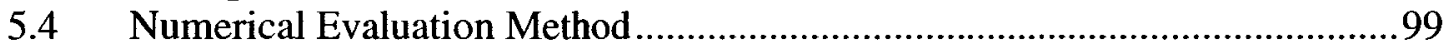

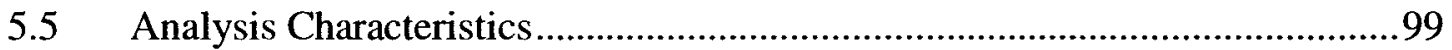

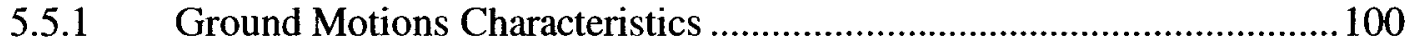

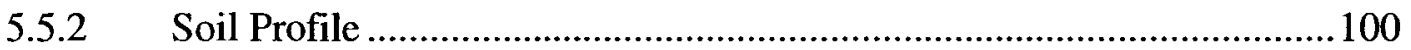

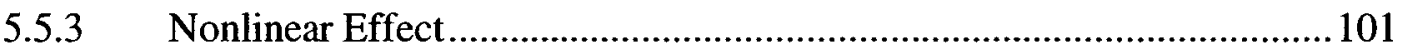

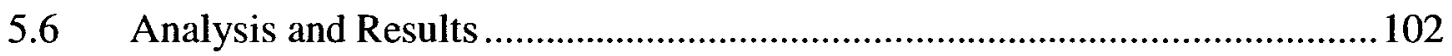

5.6.1 Threshold Level of 6\%, top 10\% Peaks with Simple Mean Value......... 103

5.6.2 Threshold Level of 20\%, top 10\% Peaks with Simple Mean Value....... 105

5.6.3 Threshold Level of $20 \%$, top $10 \%$ Peaks with RMS Combination

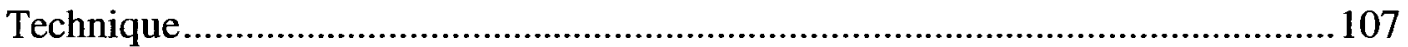

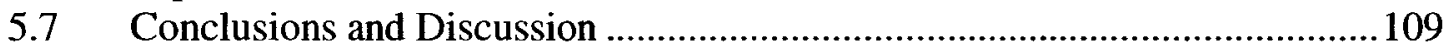

Chapter 6 The Performance of Retaining Walls.......................................................111

6.1 Numerical Study on Performance of Gravity Wall......................................112

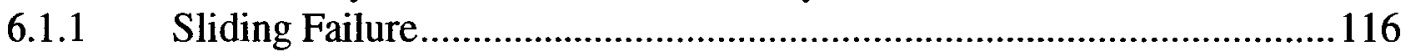

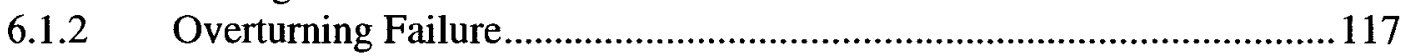

6.1.3 The Performance of the Retaining Wall ..............................................117

6.2 Discussion on the Retaining Wall Performance ............................................119

6.3 Uniform Performance According to 2005 NBCC ........................................121

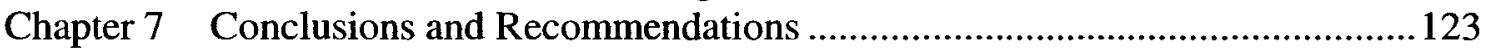

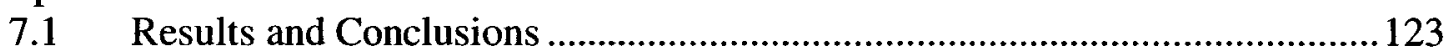

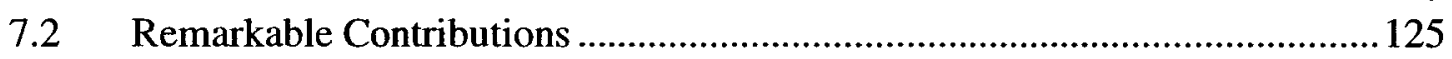

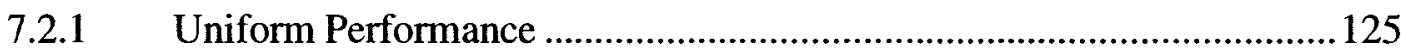

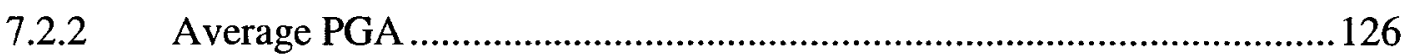

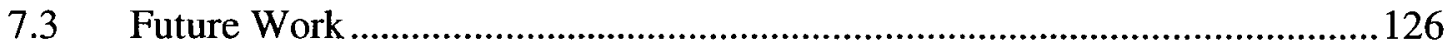

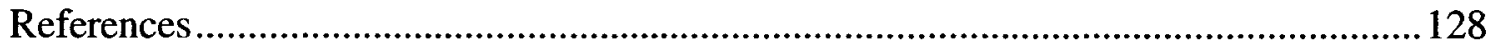




\section{List of Figures:}

Figure 2-1: Seismic hazard curves (after NEHRP 2003 Commentary) .............................

Figure 2-2: Three deformation modes and three degrees of freedom............................. 12

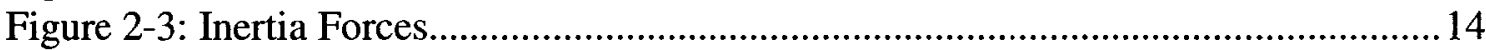

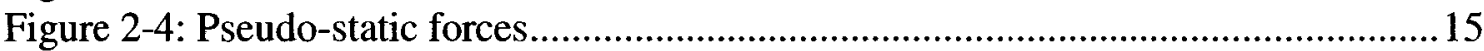

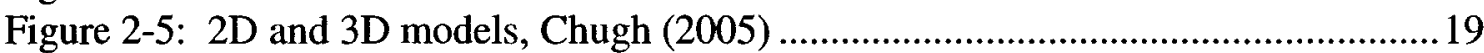

Figure 2-6: The locations of the walls and the strong ground motion stations (after Fang

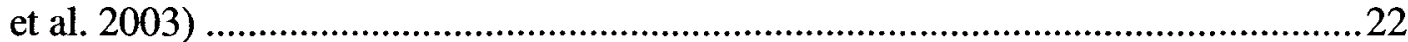

Figure 2-7: The difference between the driving component of the ground motion and the ground motion components in the surrounding stations .....................................23

Figure 3-1: Acceleration Response Spectrum of 2\% Damping, Treasure Island Record,

Loma Prieta earthquake

Figure 3-2: Uniform design hazard spectrum for Montréal (after Adams and Atkinson

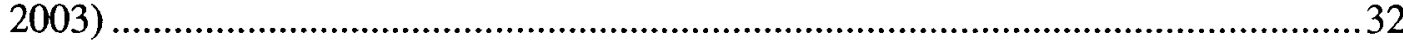

Figure 3-3: Arbitrary Spectral Acceleration Curve with two Fitting Curves ....................35

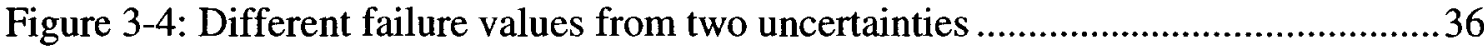

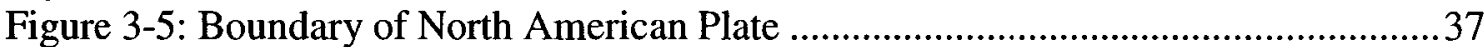

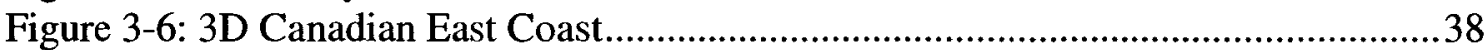

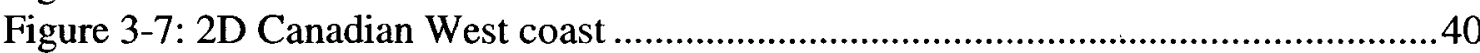

Figure 3-8: Seismic hazard curves of Montréal and Vancouver (after Adams and

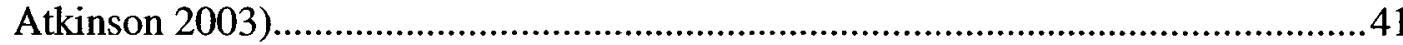

Figure 3-9: Two performances for two seismic hazard curves of different slopes...........42

Figure 3-10: Different performances at different hazard levels within the same seismic

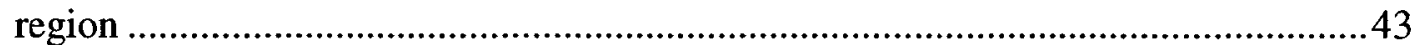

Figure 3-11: Uniform performance but different design levels similar to 2005 NBCC...43

Figure 3-12: Natural variation of a foundation factor................................................46

Figure 3-13: Errors from simulating the foundation factor; b) similar to 1995 NBCC

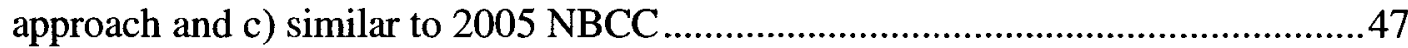

Figure 3-14: Selective damages in Mexico City earthquake of 1985 ..............................48

Figure 3-15: The differences between the natural and specified values of the foundation factors

Figure 3-16: The impact from the use of foundation factor in design on the nationwide costs and the nationwide failure risks ............................................................5. 52

Figure 3-17: "Two reference levels but the same failure probabilities in the two codes" 60

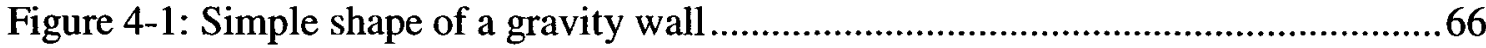

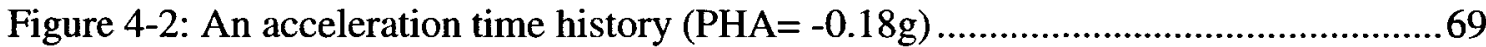

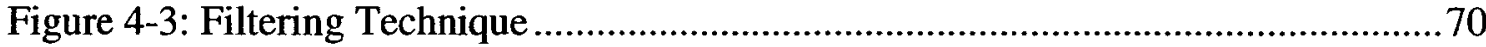

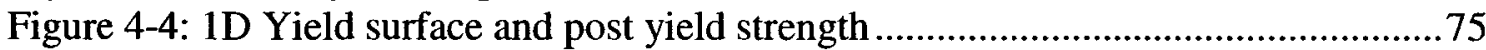

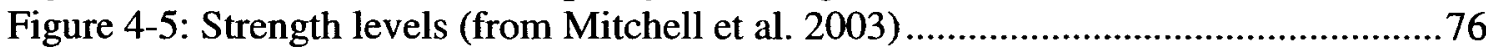

Figure 4-6: Standard geometries of a retaining wall (after Kaadan 2001) .......................79

Figure 4-7: Flexure Resistance, Concrete Design CSA Standard A23.3 (1994) ...............80

Figure 4-8: Nominal and factored resistance in structural and geotechnical systems ......82

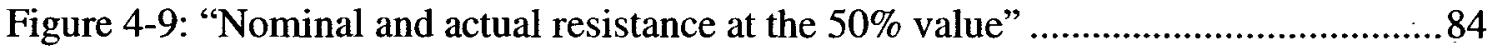

Figure 4-10: Chi-Chi Earthquake construction joint failure (Fang et al. 2003)................87 
Figure 4-11: Yielding differences between a structural system and a retaining wall system

Figure 4-12: Base shear coefficients for reinforced concrete ductile shear-wall (1995

NBCC case 12): (a) hard rock (site A); (b) very dense soil and soft rock (site C); and

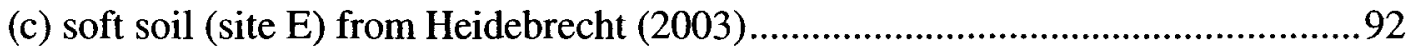

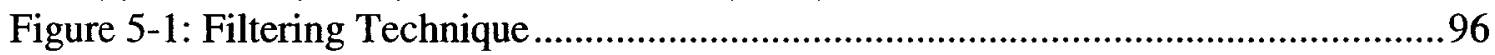

Figure 5-2: Soil Profile consists of 10 layer of $3 \mathrm{~m}$ thick laid on bedrock .....................101

Figure 5-3: Typical Modulus reduction function for sand (Seed and Idriss 1970).........102

Figure 5-4: Typical Damping function (Seed and Idriss 1970) .....................................102

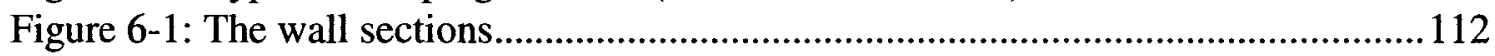

Figure 6-2: "A retaining wall designed based on M-O method" ....................................113

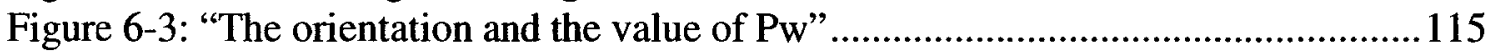

Figure 6-4: The wall-backfill external forces ........................................................116

Figure 6-5: The performance return period of the retaining wall .................................119

Figure 6-6: Performance PGAs for Different cities and different failure mechanisms, the first letter of G.S. is for wall type (gravity) and the second is for the failure type

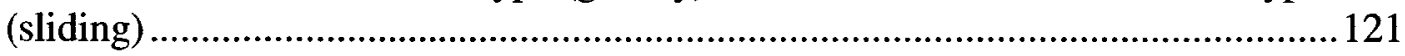




\section{List of Tables:}

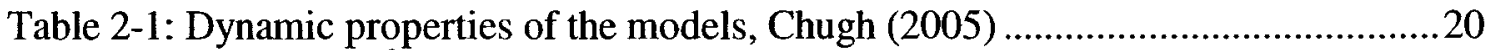

Table 2-2: PGAs $\left(\mathrm{cm} / \mathrm{s}^{2}\right)$ at three directions (after Fang et al. 2003) ..............................22

Table 3-1: 2005 NBCC design values (median values) for selected Canadian cities after

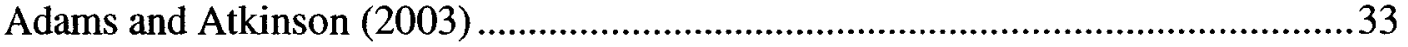

Table 3-2: Peak ground accelerations (Open File 4459 GSC, 2003) ...............................4

Table 3-3: Force Modification Factor (1995 NBCC) ..................................................56

Table 3-4: Ductility Modification Factor, $R_{d}$, and Overstrength Factor, $R_{0}$, (2005 NBCC)

Table 3-5: Ductility Modification Factor, $R_{d}$, and Overstrength Factor, $R_{o}$, (2005 NBCC)

(1)

Table 4-1: Applicable new developments on retaining wall design ..............................72

Table 4-2: "Resistance and load factors" (Taken from Canadian Foundation Manual 1993; Allen 1975; Becker 1996; Meyerhof 1993, 1995; Brinch Hansen 1953, 1956)

Table 4-3: Overstrength Factors for Cantilever Retaining Walls ................................89

Table 4-4: Overstrength Factors for Gravity Retaining Walls.......................................89

Table 4-5: Typical Range for Overstrength for Various Systems (NEHRP Commentary

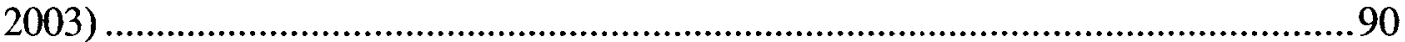

Table 4-6: Increase Ratio of the PGA values in the 2005 NBCC..................................91

Table 5-1: Ground motion characteristics...................................................................... 100

Table 5-2: Average Peak Ground Accelerations ......................................................... 103

Table 5-3: Soil responses with depth for the six ground motions.................................104

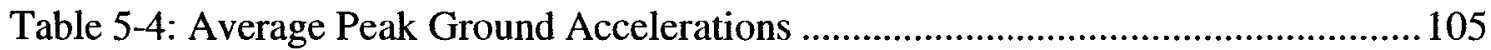

Table 5-5: Soil responses (Peak Shear Strain) with depth for the six ground motions .. 106

Table 5-6: Average Peak Ground Accelerations ....................................................... 107

Table 5-7: Soil responses (Peak Shear Strain) with depth for the six ground motions .. 108

Table 6-1: Centroids and Weights of the wall sections ...............................................114

Table 6-2: The performance return period of the wall..............................................118

Table 6-3: The performance return period of the retaining wall based on 1995 NBCC 120

Table 6-4: Performance PGAs for Different cities and different failure mechanisms based on $1995 \mathrm{NBCC}$.

Table 6-5: Design and performance PGAs for retaining walls in the $1995 \mathrm{NBCC}$ and the 2005 NBCC, the ratio is the introduced design PGA in the 2005 to the 1995 design PGA. 


\section{Chapter 1 Introduction}

\subsection{Statement of the Problem}

The new edition of the National Building Code of Canada (2005 NBCC) has introduced some remarkable changes. Lowering the hazard level from $10 \%$ in 50 years to $2 \%$ in 50 years is one of the main changes. For geotechnical designs, the Peak Ground Acceleration (PGA) is the main ground motion parameter that is used in design. Because of the change in seismicity level (hazard), the PGA has undergone a remarkable increase. For instance, the new PGA for Ottawa is $0.42 \mathrm{~g}$ whereas the previous value was $0.2 \mathrm{~g}$. Conventional techniques and methods used in seismic design of retaining walls will employ the new PGA guidelines associated with the new hazard level to determine the new seismic thrust on retaining walls. The employment of the new PGA may double the seismic forces in some places and may lead to doubling the design thicknesses of these walls.

\subsection{Objectives and Scope}

The main scope that initiates this study is simply to investigate the implications of the new seismic provisions on the design of retaining walls and find if there is a reasonable way to avoid direct use of the new PGA values in design.

Because of the unique challenges that are required to achieve the main target of this study, this research has to get involved in not only geotechnical engineering but also other disciplines including Structural Engineering, Earthquake Engineering, and Statistics. 


\subsection{Methodology}

The elements of this solution could be updated in further improvements based on the experience and the judgment of the leading professionals in the appropriate field. This unique solution will consist of five different steps:

1. The first step is to study, analyze, and interpret the scope of the historical developments of seismic provisions. The seismic provisions which are guidelines and recommendations for the seismic designs have been developed for years following similar rules. The latest edition of the seismic provisions is the outcome of accumulated developments.

2. The second step is to compile, study, and analyze the main studies available in the literature about the seismic thrust on retaining walls.

3. The third step is to trace the new seismic developments of the new 2005 NBCC seismic provisions, then identify any real increase in safety level.

4. The fourth step is to identify the similarities of the two design systems: the structural and the geotechnical designs.

5. The last step is to apply these structural changes of the seismic provisions to similar models in the geotechnical system. The last process will satisfy the approximation in engineering applications and represent the best answer.

\subsection{Results and Contributions}

The results of this study are applicable to the seismic design of retaining walls. In addition, other challenging discoveries have been found while investigating various 
aspects of the problem. The main contributions discussed in this thesis are summarized below:

1. The initial target of this study is to investigate the changes of the recent edition of the NBCC and recommend the best approach to maintain the same level of protection incorporated in the 2005 NBCC.

2. The calculated performance of a given gravity retaining wall based on $1995 \mathrm{NBCC}$ seismic design is close to a 1500 -year return period depending on the failure mechanism and the characteristics of the seismic hazard curve.

3. For design purposes, an overstrength factor equal to 1.55 represents the best estimate, and it is recommended to be applied directly to the PGA in the seismic design of the retaining walls. Higher values of the overstrength may be used, but not to exceed 1.95 to avoid a reduction of the design PGA below the PGA from the 1995 NBCC.

4. Because of the unique characteristics of the geotechnical design, the reserved overstrength in the design system might come from various factors which are only applicable to the geotechnical strength like those that will be discussed in Sections

\subsubsection{6 through 4.4.3.13.}

5. Based on the $1995 \mathrm{NBCC}$, the design performances are not uniform between different cities at the same tectonic region, but at different seismicity levels as will be discussed in Section 3.1.4 and illustrated in Figure 3-10.

6. It seems that the philosophy of seismic design has changed in the new building codes, American and Canadian, from designing a structure to resist 475-year event (1995 $\mathrm{NBCC}$ ) to designing a structure that will survive a 2500-year event (2005 NBCC). 


\section{Chapter 2 Literature Review and Background}

The first seismic provisions appeared after Santa Barbara earthquake in 1925. The seismic force is far more complicated than a static force. It is not even like a pulse force which carry certain amount of energy that should be observed in predetermined paths, but because of its cyclic nature and the nonlinearity existed in nature, a dynamic seismic force of acceleration up to $1 g$ (as recorded from some earthquake) may be resisted by less than a $0.1 m g$ (a practical value for base shear, $m=$ mass). These special characteristics of seismic force will require different rules to govern its design.

\subsection{Statement of the Problem}

In 2005, a new edition of the building code was introduced in Canada. Several new guidelines were introduced in the new code especially with respect to seismic provisions as discussed in Section 1.1. Designers of retaining walls were challenged to meet the new seismic requirements that resulted in significant increases in the seismic force. The big challenge is how to achieve a design consistent with the safety level of the structures designed in accordance with the new building code.

Therefore, this study has to investigate the historical developments of seismic provisions to estimate the rationale theme of the developments of seismic provisions. In addition, seismic thrust on retaining walls is investigated to evaluate the design approaches available in the literature. The similarities between structural design and retaining wall design will be beneficial in determination of the best approach to achieve the 2005 NBCC based seismic design of gravity retaining walls. 


\subsection{Developments of the Seismic Provisions of the NBCC}

Seismic provisions are the guidelines that control the seismic detailing arrangements. The historical developments of the seismic provisions will be classified as the following:

\subsubsection{Historical Development of Base Shear Equation}

The first mandatory seismic code was published in 1933 (Saatcioglu 2004) which was the birth of the first generation of the base shear equation $(V)$.

$$
V=C W
$$

$C$ is a constant that fluctuates around 0.02 depending on some conditions like the seismic activity of the site.

$W$, however, is the total dead loads and sometimes part of the live loads as well.

This equation was suggested without any analyses or experiments to support the introduced equation which is the forerunner of the base shear equation in the recent edition of NBCC. More factors were included later in that equation when the code was updated. Although some of these factors were introduced based on applied science principles, there were other factors assigned to the base shear equation based on engineering judgments. After 1933, other editions were introduced, but the associated safety level did not remarkably change.

In the National Building Code of Canada 1970 (1970 NBCC), more factors were incorporated in the base shear equation: 
$W$ is the total weight of the structure (similar to the previous code of 1933).

$I$ is the importance factor. This factor was suggested as 1.3 for post-disaster buildings, and 1.0 for all other buildings (Tso 1992).

$F$ is the foundation factor. It varies from 1.5 for highly compressible soils, and 1.0 for all other soils

$C$ is the seismicity coefficient.

$R$ is a factor that depends on the region. It varies from a maximum value of 4.0 to a minimum value of 0.0 in seismically inactive regions.

A huge change in the base shear equation was carried out by introducing new terms. The $F$ factor that is dependent on soil conditions, is an adjusting factor introduced on a rational basis. Researchers, who adopted that factor, relied on their experience to estimate these factors. The earthquake failure mechanism observed in the several past earthquakes, had proved that soil may amplify the seismic vibrations to a very high level, and the amplification factor may reach 2 to 4 depending on how soft the soil is, and how deep the bedrock is located. Thus, the factor of 1.3 that is suggested in 1970 NBCC, may underestimate the applied force.

In the national building code of Canada of 1980 (1980 NBCC), dynamic analysis was encouraged for special buildings like irregular buildings. However, the code regulations placed restrictions on the employment of natural frequencies from structural dynamic analyses directly in seismic design. The equivalent static load analysis was also 
improved using seismic response factor $S$ which has a probability 0.01 of exceedance equivalent to 100 years return period.

A new parameter was introduced in the 1985 edition of NBCC, i.e., Zonal velocity ratio; the reason for this factor is to incorporate the influence of the peak ground velocity. The other parameters had undergone no serious changes from $1980 \mathrm{NBCC}$ to 1985 NBCC. Heidebrecht and Tso (1985) and Tso (1992) have documented the various developments of the seismic provisions of the building codes of Canada.

In the $1995 \mathrm{NBCC}$, the seismic provisions were essentially the same as for the 1990 NBCC. A new reduction factor was applied to the base shear. This factor will incorporate the ductility effects on the structure lateral resistance.

$$
V=\frac{V_{e}}{R} U
$$

$V$ is the design seismic force used directly in Limit State Analysis (LSA) with the force factor equal to one.

$V_{e}$ is the elastic force given by:

$V_{e}=v S I F W: v$ is the zonal velocity ratio

All other factors appear to have the same value as previously stated in earlier editions of the code.

Another development has been introduced in the $1995 \mathrm{NBCC}$, which is related to the shape that the base shear distribution along the structure. An empirical equation was introduced to ensure that higher loads are assigned to the upper levels. On the other hand, 
a detailed dynamic analysis will reflect actual seismic forces, but their values and shapes are different from the $1995 \mathrm{NBCC}$ recommendations.

The recent edition of the Building Code (2005 NBCC) was published in 2005. The developments of the new code were remarkable. The base shear equation was rearranged, and other new factors were incorporated in the new code. Furthermore, the philosophy of the seismic design has changed in the new code. In Chapter 3, a comprehensive evaluation of the new developments of the $2005 \mathrm{NBCC}$ will be presented from several perspectives.

\subsubsection{Recent Developments of the NEHRP Recommended Provisions}

NEHRP is the National Earthquake Hazards Reduction Program of the U.S. Building Seismic Safety Council. NEHRP recommends provisions that control the seismic design of engineering systems.

Seismic Provisions in the United States have undergone significant developments in the recent editions of the NEHRP Recommended Provisions for Seismic Regulations. The following section highlights the main points of these developments.

\subsubsection{Development of the USGS Seismic Maps}

In earlier editions of the NEHRP Provisions, seismic hazard maps for United States were developed uniformly at 10 percent probability of exceedance in 50 years. Similarly, the seismic provisions of the 1995 NBCC were also developed with the same probability of exceedance. The NEHRP provisions provided a uniform likelihood that the design ground motion would not be exceeded throughout the U.S. 
The U.S. Geological Survey (USGS) in charge of developing seismic hazard maps indicated that the provisions are intended to provide uniform level of performance for structures nationwide.

In different zones of the United States, slopes of seismic hazard curves are not the same, especially in the range of $10 \%$ exceedance in 50 years. Therefore, designs in these zones performed at the same probability of exceedance, will achieve different performances. To reach consistent designs in different regions, the seismic hazard curves in different places were normalized at $2 \%$ in 50 years, as illustrated in Figure 2-1.

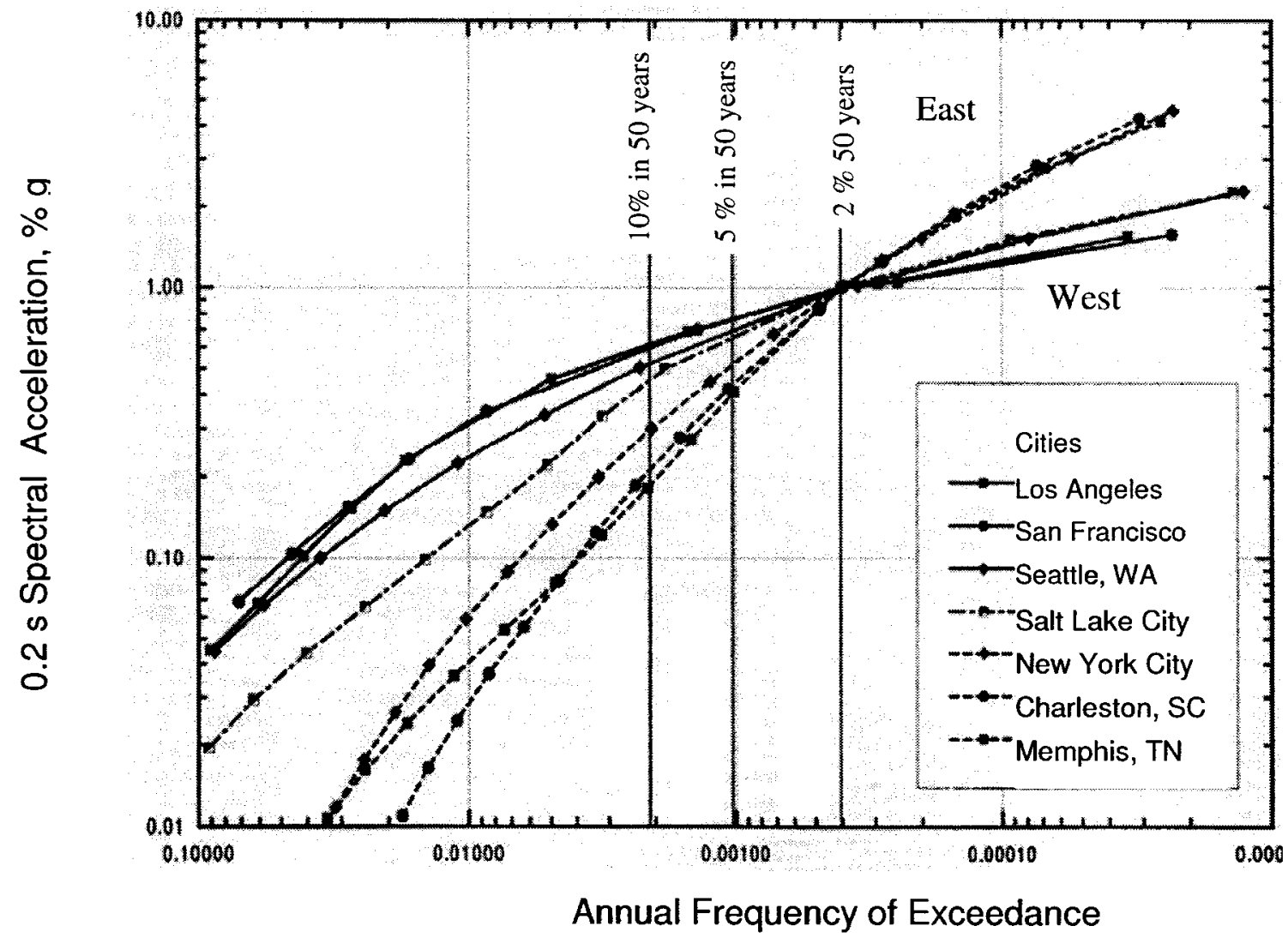

Figure 2-1: Seismic hazard curves (after NEHRP 2003 Commentary) 
In the above graph, two general slopes of the normalized seismic hazard curves could be easily identified between the East "Dashed curves" and the West "continuous curves" of the country (United States).

\subsubsection{The Design Ground Motion}

The design ground motion is the level of shaking that an engineering system should be designed for. In other words, in limit state design (LSD), the design ground motion represents the demand. To reach the design ground motion level from the performance ground motion, i.e., $2 \%$ probability of exceedance in 50 years, a lower bound was set at 66.6 percent (2/3) of the performance ground motion with 2500 years return period (NEHRP Commentary 1997).

In most locations across the United States, ground motions corresponding to the probability of $2 \%$ in 50 years are at least 1.5 times higher than those of the 10 percent probability of exceedance in 50 years. This means that the new approach of normalizing the ground motion will lead to a remarkable increase in safety level (Kennedy et al. 1994; Cornell 1994; Ellingwood 1994).

In summary to the historical developments of the seismic provisions of the NBCC, It is clear that the early structural developments of the seismic design provisions were not entirely based on precise knowledge of earthquake engineering analysis. In addition, the design philosophy in $1995 \mathrm{NBCC}$ is most likely to design structures that will resist a seismic level of 10 percent probability of exceedance in 50 years. 


\subsection{Seismic Thrust on Retaining Walls}

A pseudo-static method introduced by Okabe (1926) and Mononobe and Matsuo (1929) was the forerunner of the retaining wall seismic design. A steady improvement of the seismic design was gained as research continued to support the engineering profession with more knowledge on the behavior of soil during earthquake loading. However, recent studies of dynamic response of retaining walls have revealed several characteristics of the wall response. In the following section, a summary of some efforts to evaluate the wall response will be briefly presented:

\subsubsection{Degrees of Freedom}

Nadim and Whitman (1984) and Siddharthan et al. (1992) have reported that retaining walls may response by rotation and/or translation in lateral/vertical direction. One or more of these movements may become predominant for some walls. As illustrated in Figure 2-2, three independent earthquake-induced movements would potentially happen in retaining walls. These movements would also define three main degrees of freedom in the dynamic wall system. In addition, the stability analysis indicates that the vertical acceleration/displacement of retaining walls is not important for seismic design. 


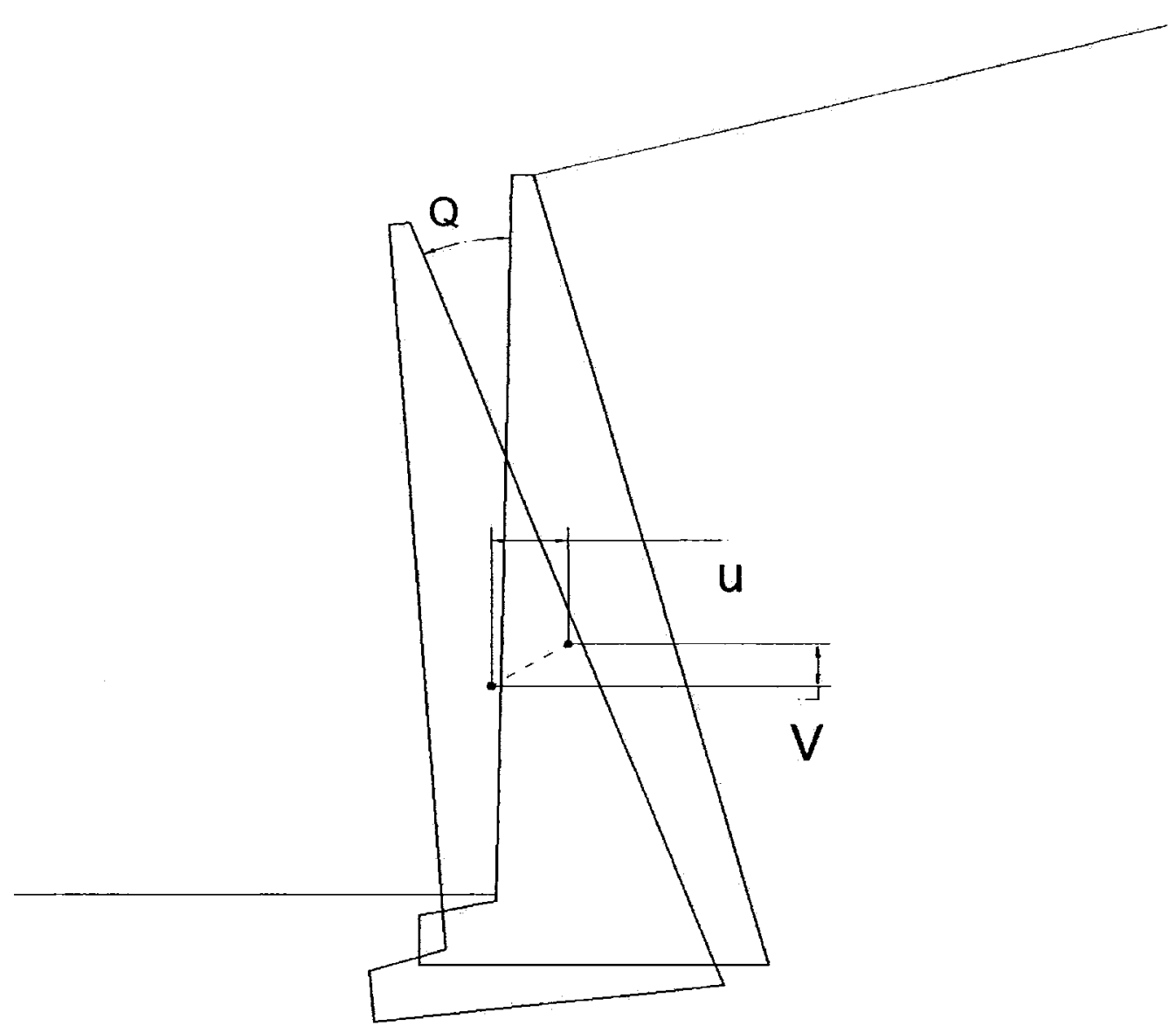

Figure 2-2: Three deformation modes and three degrees of freedom

The magnitude and the shape of seismic wall pressures are influenced by the mode of the wall movement, i.e., translation in a vertical or horizontal directions, rotation about the base, or rotation about the top. This is similar to the nature of the static pressure developed behind retaining structures (Sherif et al. 1982; Sherif and Fang 1984).

\subsubsection{Inertia forces}

The maximum soil thrust acting on a wall generally occurs when the wall translates or rotates toward the backfill, i.e., when the inertial force on the wall is directed towards the backfill. The minimum soil thrust occurs when the wall has translated or rotated away from the backfill (Kramer 1996). 
Step by step through time, the shape and amount of the thrust pressure on the back of the wall will change as the wall vibrates. The point of application of the soil thrust therefore moves up and down along the back of the wall. The position of the soil thrust is highest when the wall has moved towards the soil and lowest when the wall moves outwards.

In contrast to the previous proposition, inertia forces are not displacements dependent as it may be interpreted. Inertia forces are always dependent on the absolute accelerations in a certain object and always opposite the directions of these accelerations.

Figure 2-3 illustrates the inertia forces generated in a backfill and a wall where the $U^{\prime \prime}, V^{\prime \prime}$, and $\varphi^{\prime \prime}$ are the accelerations or second differential of the displacements with time. $M$ is the moment from inertia forces; $m$ is the mass; $I$ is the moment of inertia about the centre of the mass; $F_{x}$ and $F_{y}$ are the inertia forces in horizontal and vertical directions, respectively. 


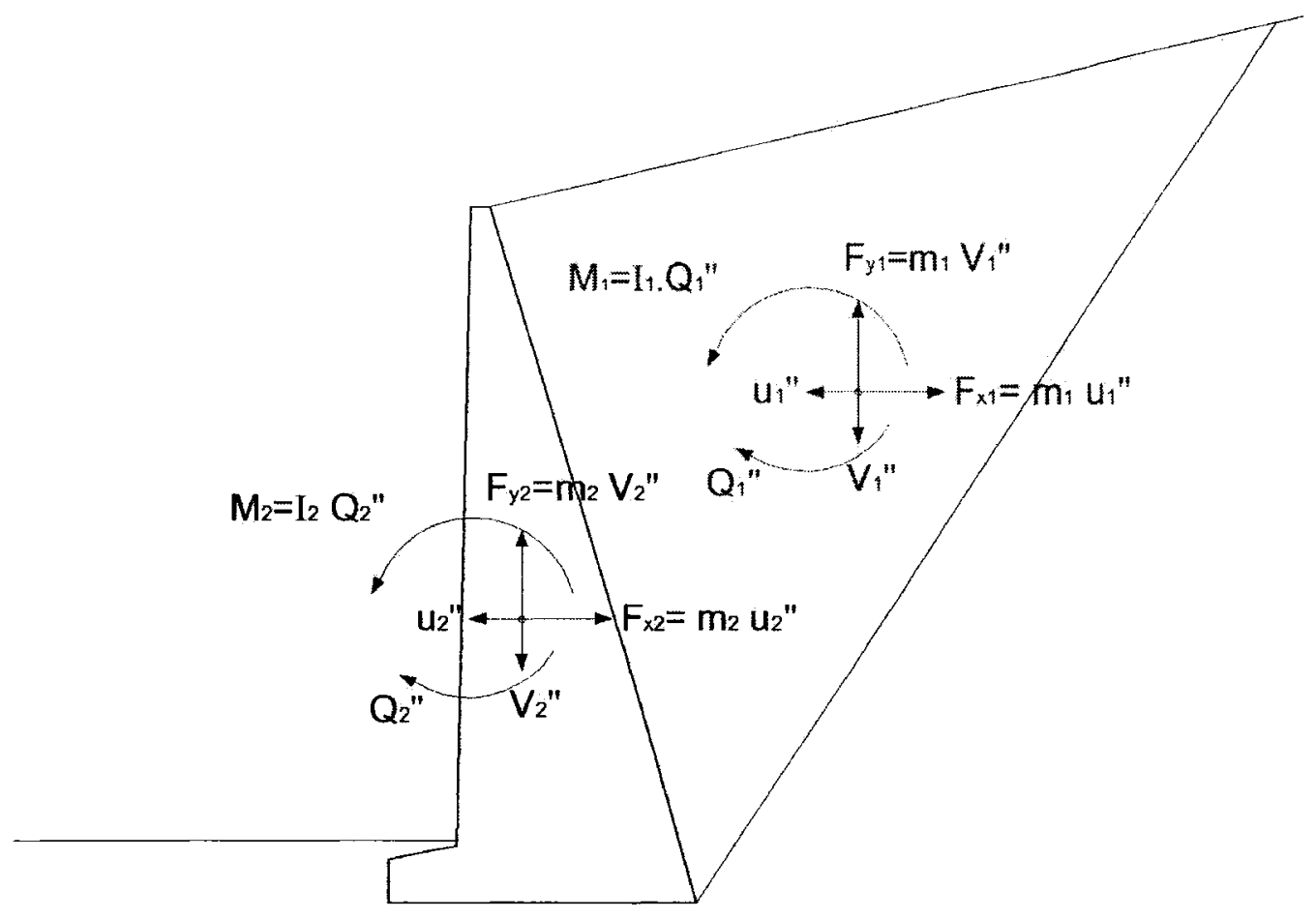

Figure 2-3: Inertia Forces

Finally, the soil thrust would depend on the relative accelerations between both the backfill and the wall, so the thrust might not be affected if both accelerations were identical through time.

\subsubsection{Pseudo-Static Methods}

The pseudo-static accelerations ( $a_{h}$ and $a_{v}$ for the horizontal and vertical components, respectively) used in Mononobe-Okabe (1926-1929) (M-O) method are functions of the peak ground accelerations (PGA). The inertia forces generated by ground motions would be dependent on the available ground acceleration. However, the direction of the inertia forces will be reversed as the ground moves to the other peak. Psarropoulos et al. (2005) have reported consistency with the M-O method after FE analysis. Veletsos and Younan (1997) have also achieved comparable results with M-O method using the limited displacement-based method. 


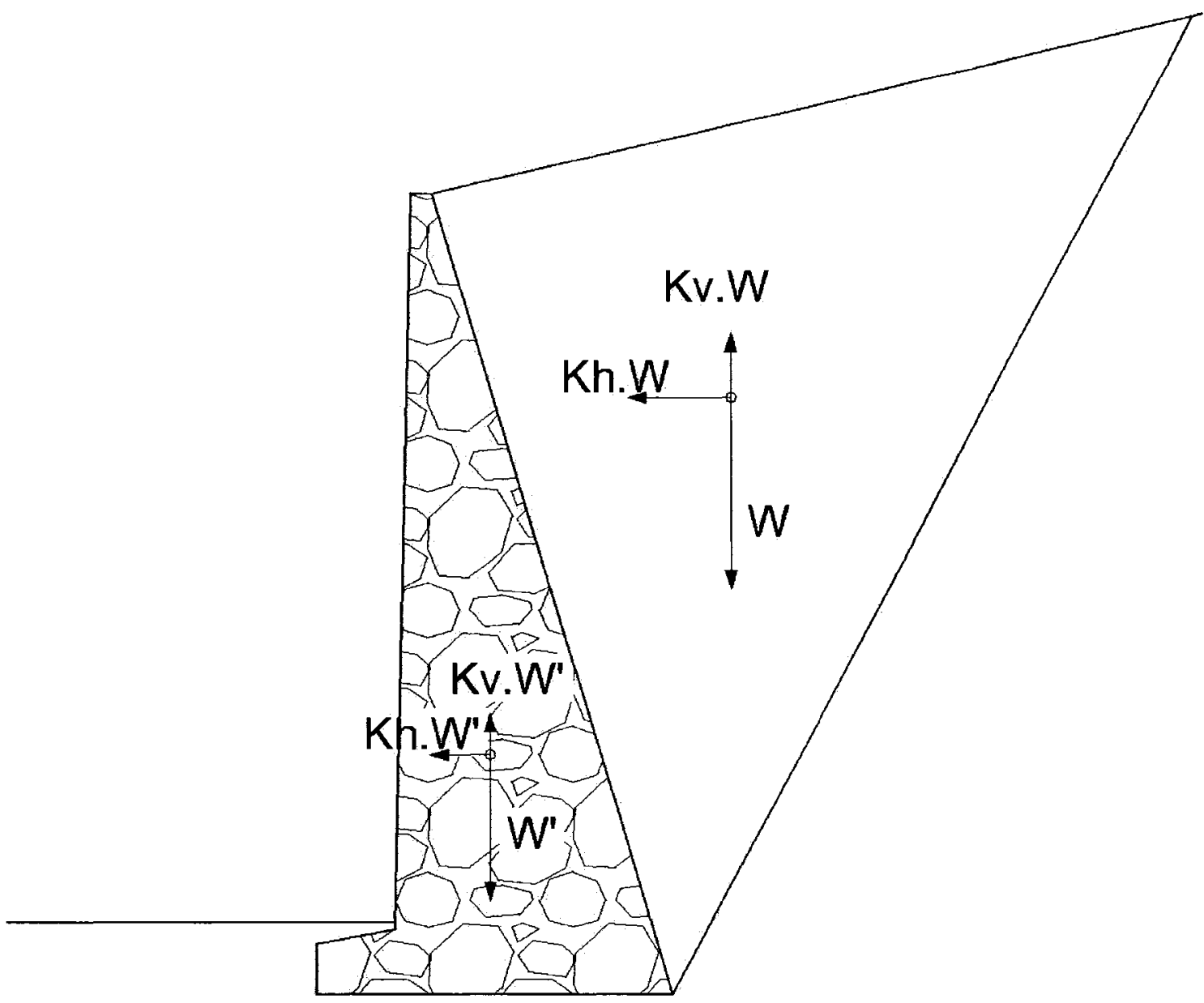

Monobe-Okabe forces

\section{Figure 2-4: Pseudo-static forces}

The maximum horizontal acceleration is also commonly referred to as the peak ground acceleration (Day 2002). However, other procedures like Richard and Elms (1979) do not use the PGA directly in design; but instead, they use a function of PGA, $\left(a_{V}\right)$. Richard and Elms (1979), proposed that the $a_{V}$ should be obtained from the allowable permanent block displacement as the following

$$
d_{p e r m}=0.087 \frac{v_{\max }^{2} \cdot a_{\max }^{3}}{a_{y}^{4}}
$$


where $v_{\max }$ and $a_{\max }$ are the peak ground velocity and peak ground acceleration, respectively.

On the other hand, it would be unreasonable to blindly estimate the resultant response by only simulating the inertia forces from the pseudo-static accelerations. In addition, some results by Veletsos and Younan (1997) have confirmed the approximate convergence between the $\mathrm{M}-\mathrm{O}$ and the elasticity-based solutions for rotationally flexible walls. At the same time, these results have identified a beneficial effect of soil heterogeneity and that the wave propagation in the underlying foundation layer may have an effect that cannot be simply quantified. Furthermore, Navarro and Samartín (1988) using FE program (FLUSH) have indicated that the horizontal component of the seismic earth thrust was much greater than that introduced in Mononobe-Okabe method.

\subsubsection{Resonance Effect}

Seismic loading on retaining walls will also be in agreement with dynamic principles. Thus, resonance effect will remarkably contribute to the seismic thrust on retaining walls. Steedman and Zeng (1990) have indicated that the dynamic wall pressure (seismic thrust) may increase significantly near the natural frequency of the wall-backfill system. Using FE method and elastic non-homogeneous materials, Wu and Finn (1999) have indicated a remarkable influence of both the wall-backfill natural frequency and the input frequencies on the seismic thrust. It was found that the controlling frequency that causes the maximum soil pressure is close to the natural frequency of the backfill (Ostadan 2005). 
The resonance will also increase the residual pressure and movement. If the dominant frequencies of the input motion are near to the natural frequency of the wallbackfill system, permanent movements of the wall will significantly increase (Nadim 1982).

\subsubsection{Residual Movements}

Soils will behave plastically rather than elastically. The elasticity assumption may underestimate the dynamic pressure under strong shaking (Wu and Finn 1999). Thus, after seismic loading, soils may possess remarkable amount of residual movements (Whiteman 1990). Crespellani at el. (1994) had indicated that there is a good correlation between the wall permanent (residual) movement and the ground motion parameters PGA and PGV after they had conducted analyses on dry backfill using horizontal components of 155 earthquake motions taken from around the world.

\subsubsection{Flexibility of the Walls}

The developing of the active pressure will be dependent on how flexible the wall is to permit adequate movement for the pressure to drop to the minimum active. Therefore, the flexibility should be an important factor in determination of seismic thrust. In the analysis of flexible retaining walls, it was found that at relatively low seismicity accelerations the induced pressures were in general agreement with those pressures predicted by Mononobe-Okabe method. However, at relatively mid-size accelerations similar to those expected in regions of moderate seismicity, the pressures were larger than those predicted by the Mononobe-Okabe method (Green et al. 2003). The reason for these differences might be related to the relative flexibility of the cantilever wall. 
Numerical analyses by Younan and Veletsos (2000) on flexible retaining walls are conducted. Magnitudes and distributions of the earthquake-induced displacements and pressures are sensitive to the wall flexibility. If the wall flexibility increases, the induced displacements and pressures developed in the wall-soil system would decrease. For realistic wall flexibilities, the total wall force or the base shear for cantilever walls may be less than half of that obtained for fixed-base and rigid wall. Furthermore, the reduction of the resultant base moments was even larger. Because of the large stiffness in topsupported walls like basement walls, the effect of the flexibility on thrust pressure reduction in these walls are significantly smaller than that in cantilever walls. By using the 1940 El Centro earthquake in analysis, the maximum wall displacement relatively to the base for a cantilever wall of realistic flexibility was found to be less than $0.1-0.4 \%$ of the height of the wall.

In elastic systems, the base shear generated by impacts could be much higher than the weight of the building, and the base shear would increase with the increase in the stiffness of the retaining walls (Malhotra 1997).

In addition, Siddharthan and Maragakis (1988) have indicated that the maximum bending moments given by current design procedures are non-conservative for stiffer walls. Deflections of flexible walls were of major concern, and flexible walls supporting sand of medium density yield the greatest deflection. A finite element model was proposed for studying the seismic response of a flexible retaining wall-soil system. The model accounted for nonlinear hysteretic soil behaviour, and also for the increase in lateral stresses and settlement related to grain slip caused by cyclic loads. The response 
computed by the proposed method was compared with responses recorded at the Cambridge centrifuge facility, and they were in reasonable agreement. The same model was then used to study other factors such as flexibility of the wall and the relative density of the backfill.

\subsubsection{Secondary Importance of Longitudinal Loading}

Chugh (2005) has conducted analysis using 2D and 3D FLAC models of a cantilever retaining wall. Figure 2-5 illustrates the wall geometry and the soil properties.
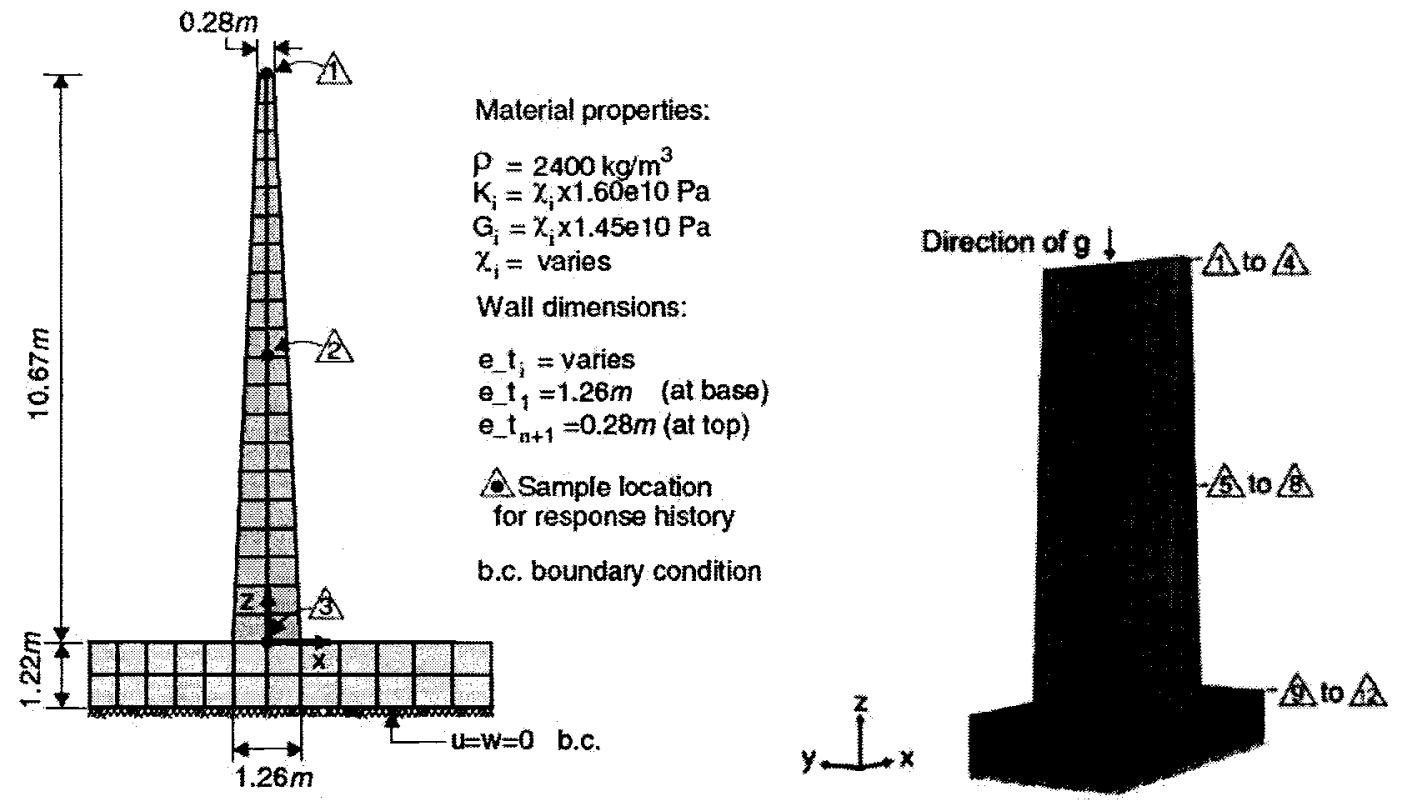

Figure 2-5: 2D and 3D models, Chugh (2005)

The dynamic properties of the two models are listed in Table 2-1. 
Table 2-1: Dynamic properties of the models, Chugh (2005)

\begin{tabular}{lccc}
\hline & & \multicolumn{2}{c}{$\begin{array}{c}\text { Natural frequency of } \\
\text { free vibrations: Hz }\end{array}$} \\
\cline { 3 - 4 } Wall type & Model & Axial & Transverse \\
\hline Prototype counterfort & $3-\mathrm{D}$ & 106 & 19 \\
Model cantilever & $3-\mathrm{D}$ & 108 & 23 \\
Model cantilever & 2-D & 108 & 24 \\
\hline
\end{tabular}

For seismic design purposes, this modelling may not have a significant contribution, but it proves that there is huge stiffness in the axial direction compared to the transverse direction.

\subsubsection{Experimental Testing and Earthquake Reports}

Lee (2005) conducted several dynamic centrifuge tests on caisson walls embedded in soils with various permeabilities. Based on these tests, some important conclusions were derived. Rotational and translational modes were found to be either in phase or out of phase. The test results indicated that the rotational mode makes the dominant contribution to the changes in both excess pore pressure and dynamic thrust at the deep layers of the backfill, but the translational mode however, makes the dominant contribution at the shallow layers.

Fang et al. (2003) investigated the failures of three gravity walls due to the 1999 Chi-Chi earthquake. The geometries of these walls were characterized and the damages were carefully recorded. The backfill materials behind the damaged walls were collected and tested. A map for the epicentre was provided, and the locations of the damaged walls were identified. The failure mechanisms of these walls were not identical; the first wall 
collapsed due to a construction joint sliding, and the second due to a bearing capacity failure, but the third was severely damaged because it was located on the Chi-Chi fault rupture.

Valuable results could be derived from the evaluation of the failure of these walls if there were more data available. The limitations of the provided data are the ground motion analysis, and the foundation soil characteristics of these three walls. The evaluation of the seismic thrust was missing, and could not be concluded from the available data.

The ground motion analysis includes evaluation of the time history of a resultant shaking and its angle at the site. Most likely the strong motion stations would have eastwest and north-south records at the seismic stations as illustrated in Figure 2-6 and Table 2-2. To be able to benefit from these records, they should be deaggregated at the sites where the walls are located then, in analysis, the component of ground shaking that is perpendicular to longitudinal line should be used in the analysis. Figure 2-6 illustrates the proposed importance of the ground motion site analysis. 


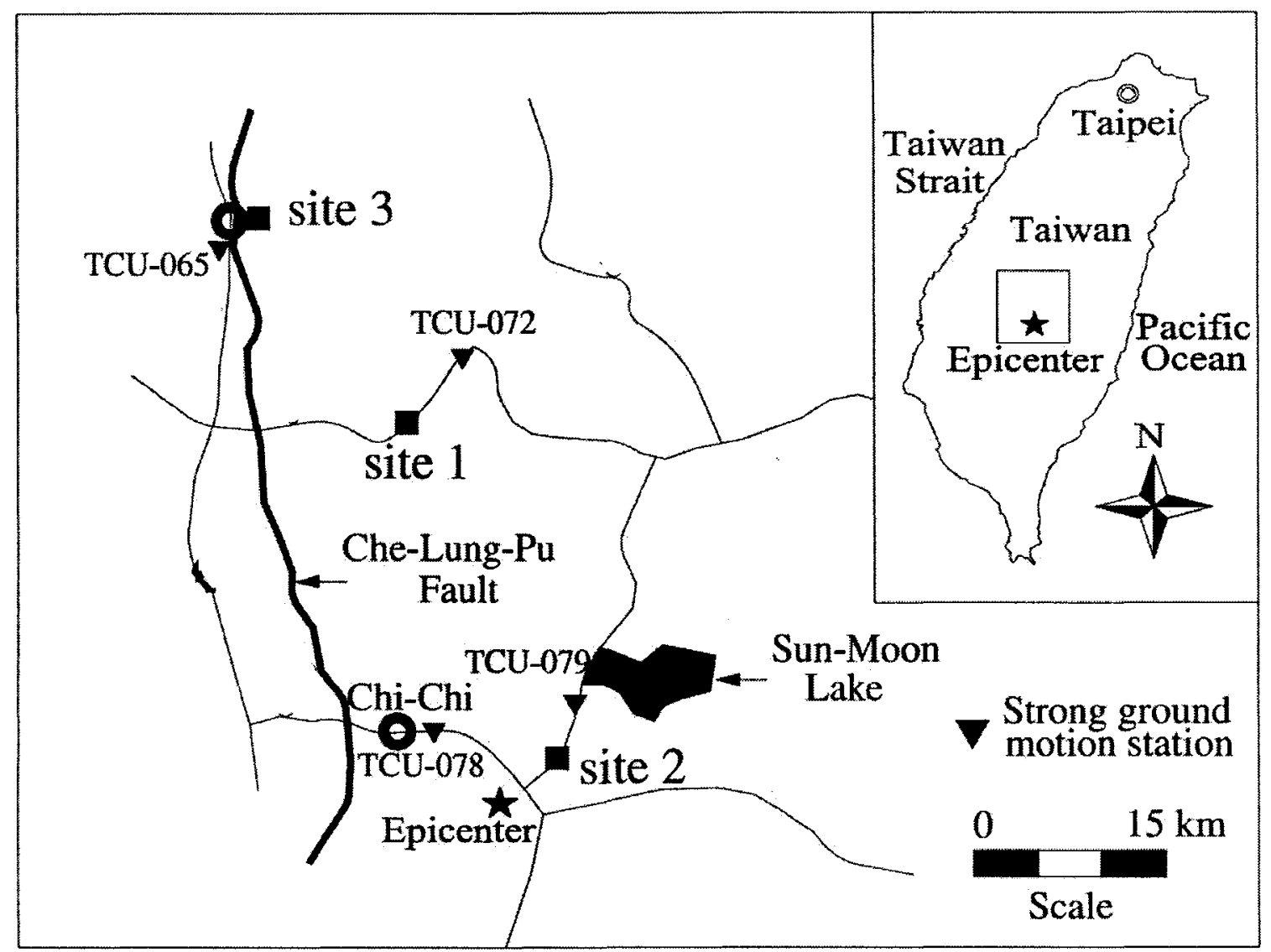

Figure 2-6: The locations of the walls and the strong ground motion stations (after Fang et al. 2003)

Table 2-2: PGAs $\left(\mathrm{cm} / \mathrm{s}^{2}\right)$ at three directions (after Fang et al. 2003)

\begin{tabular}{llll}
\hline & & \multicolumn{2}{l}{ Horizontal } \\
\cline { 3 - 4 } Station & Vertical & East-west & North-south \\
\hline TCU-065 & 258 & 563 & 774 \\
TCU-072 & 275 & 371 & 465 \\
TCU-078 & 171 & 302 & 440 \\
TCU-079 & 384 & 417 & 580 \\
\hline
\end{tabular}




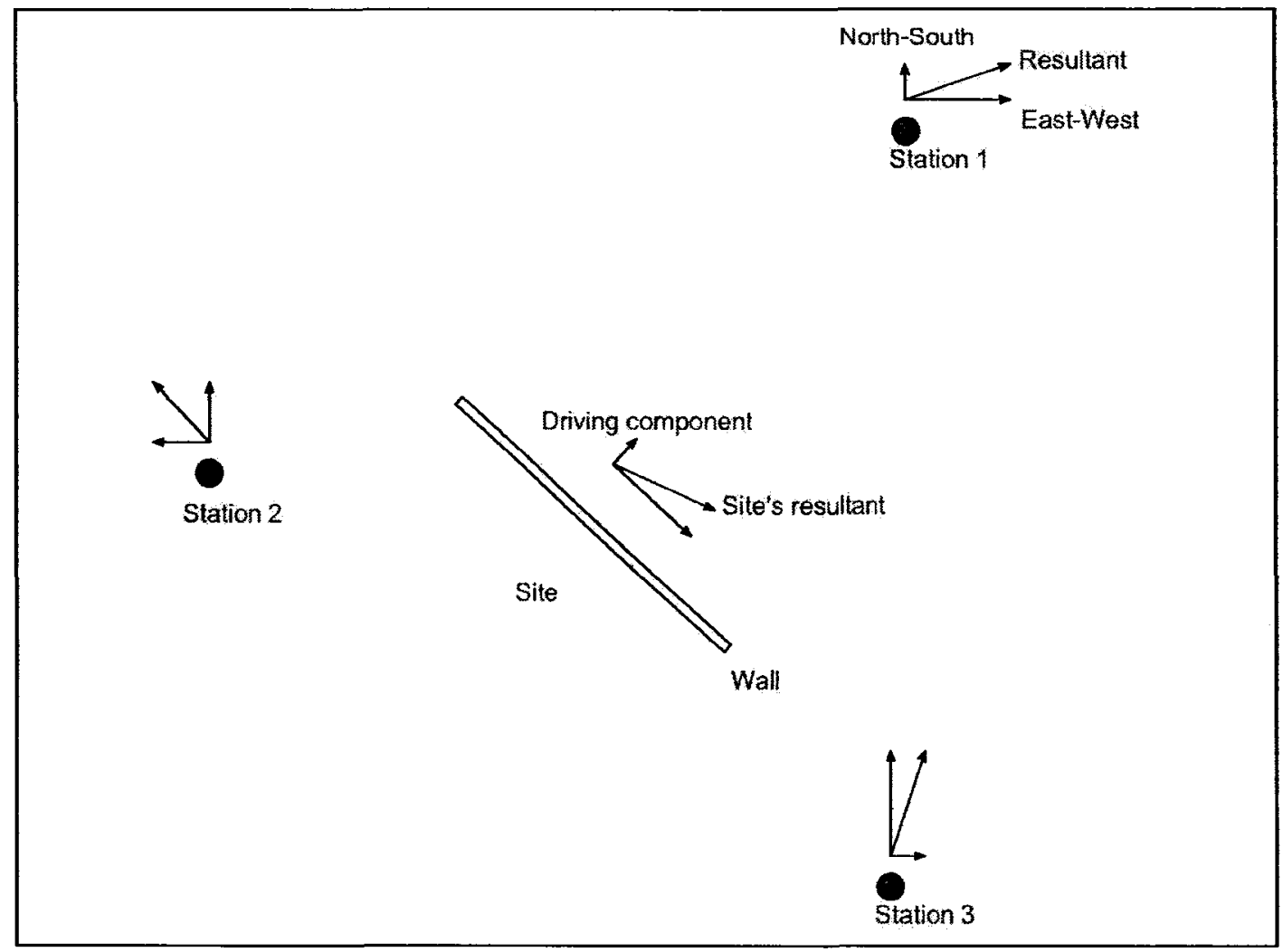

Figure 2-7: The difference between the driving component of the ground motion and the ground motion components in the surrounding stations

From Figure 2-7, the introduced driving component at the site is relatively small compared to the nearby excitations at the stations. Therefore, in order to have a precise evaluation of the seismic thrust, the driving components of the ground shakings at the sites of the walls have to be determined.

\subsubsection{Design Manuals}

Seismic design of retaining walls has undergone several developments in the past. The accumulated developments have formed the current form of design manuals. In the next section, some of the main design manuals will be studied: 
In the $3^{\text {rd }}$ edition of Canadian Foundation Engineering Manual (1992), the earthquake resistant design was comprehensively presented. The following section discusses some of the main features of the retaining wall seismic design that is covered by this manual:

- The seismic maps were presented on the basis of probability of exceedance of $10 \%$ in 50 years.

- Earthquake load factor for geotechnical design was set to 1.5 listed in Section 7.3 of the manual. This value was estimated based on deterministic approaches of general live loads, but the earthquake loads was estimated based on a probabilistic approach which means it is a factored load. This difference has resulted in double factoring of the earthquake load. Therefore, the earthquake load factor should be taken as 1.0 just like the structural design.

- The natural tendency for an earthfill is to slide downhill during an earthquake. This slide results in an increased pressure on retaining walls.

- Finally, this design manual did not cover all aspects of geotechnical seismic design; therefore, this leaves more room for experience and engineering judgment.

In Engineer Manual (1989), the earthquake loads on retaining walls were discussed in Section 3-26. A pseudo-static approach by Mononobe-Okabe was recommended. In addition, all other factors that were revealed by researches like those discussed earlier, were not incorporated in this manual. 


\subsection{Limitations of the Available Approaches}

It seems very clear that the early structural developments of the seismic design provisions were not entirely based on precise knowledge or earthquake engineering analysis. The reason is that the early editions of seismic provisions were determined mainly based on experience such as the base shear equation published in 1933

Despite the rich body of literature pertaining to seismic thrust on retaining walls, there are few guidelines and recommendations on design parameters in the design manuals. This matter was not only limited to retaining wall seismic design but also to several aspects of geotechnical applications. The geotechnical design manuals are lacking behind the research literature. Even the sophisticated methods that employed the state of the art computing capabilities have not found their way yet to the design manuals. For instance, the rigidity of the walls would significantly affect seismic thrust pressures, but yet the design manuals did not adopt a mechanism to accommodate such influence.

Several characteristics about the seismic thrust have been found, but only few of them have been precisely determined. For example, dynamic wall pressures may increase significantly near the natural frequency of the wall-backfill system (Steedman and Zeng 1990), but how much the exact increase was not determined. In addition, some studies like FE analysis carried out by Wu and Finn (1999) and other experimental analyses have identified a remarkable influence of both backfill natural frequency and input natural frequency on seismic thrust, but this effect called resonance is not incorporated yet in the design manuals. 
The conventional approach to solve the new seismic requirements on retaining wall design is to employ the accelerations from the 2005 NBCC directly in the existing formulae. The main limitation of this application is the high cost associated with it. For instance, the application of the new peak ground accelerations directly in retaining wall design may double the wall section size causing a big increase in construction costs.

\subsection{The Significance of the Current Study}

Economic benefits and safety are the motivation and the goals of most applied sciences. The new design challenges associated by the new seismic provisions will have a huge financial impact on national construction costs. Any contribution that could be gained from research in this field in order to solve this matter may be significantly valuable in lowering the estimated financial costs. 


\section{Chapter 3 Developments of the 2005 NBCC Seismic Provisions}

The seismic design requirements for retaining walls have changed through time as the building code has evolved. To be able to describe and measure the new seismic requirements for the retaining walls, a large-scale investigation should be conducted to trace, understand, describe, and quantify various aspects of the new developments of the National Building Code of Canada 2005 (2005 NBCC).

As a result from the research in applied sciences, the national building code of Canada is continuously developing not only to benefit from the ongoing research in Canada and the world but also to accommodate the new serviceability challenges. These challenges that have faced the design professionals, have eventually led to secure, safe, and economic structures. Several developments have been incorporated in the 2005 NBCC as a result of the accumulated research for the last ten years. In the 2005 NBCC, seismic provisions had undergone serious changes. Even the design philosophy of the seismic provisions has changed in the new code, as will be discussed in the following chapters.

For better understanding of the new changes, the new developments will be classified into three main applied sciences involved in the seismic response. The main scope of the seismic design is to provide adequate resistance against any earthquake motion that might be triggered in a specific site. An earthquake is a release of energy in the form of vibrations at the source. These vibrations travel through a conducting 
medium, i.e., from rock to the site. Depending on the soil profile at each particular site, the waves will propagate through the soil up to the existing structures. Thus, the response of engineering structures will depend on the combination of all the elements in this natural phenomenon. Different sciences including statistics are also involved in the understanding and quantifying the structural response that is expected by this phenomenon. From the source to the site, not only the seismologists will be responsible for the evaluation and estimation of the received seismic waves but also statistical expertise is also needed to simulate and quantify the associated hazards and the complicated uncertainties associated with this process. From the bedrock to the foundation, a possible magnification to the ground motion could be generated. The dynamic properties of the foundation soil evaluated by geotechnical engineers will determine the magnification amplitude. The last component of the response will be determined based on the dynamic properties of the structures. Based on principles of structural dynamics, the overall response of the structures will be evaluated, analyzed, and quantified.

\subsection{Seismological Developments}

In the new National Building Code of Canada, the Geological Survey of Canada has introduced several updates to the former seismic maps. The main updates from the Geological Survey of Canada (GSC) are summarized in the following four categories: 


\subsubsection{New Model to Simulate the Wave Propagation and the Sources}

Two decades have passed since the last seismic hazard maps were generated. Additional data from the recent earthquakes had helped to clearly describe the seismic sources in the country. Furthermore, the knowledge about the local earthquakes and the unexpected events have not only improved the recurrence models but also revealed previously unaccounted for risks that will eventually increase the seismicity level for certain areas as will be mentioned later when discussing the differences in the peak ground accelerations for different regions between 1995 NBCC and 2005 NBCC.

\subsubsection{Base Earthquake Data}

The 1995 NBCC was built based on the seismic hazard maps published in early 1980 's. The 1995 NBCC was originally developed based on the earthquake data recorded up to 1977. As discussed in Section 3.1.1, the characteristics of the sources and the seismic models will be determined based on the historical data collected from the past earthquakes. Therefore, these data are an important part of the seismic analysis process. The seismic hazard maps incorporated in the 2005 NBCC use the earthquake data recorded up to 1990 for the eastern part of the country, and up to 1991 for the west (Adams and Atkinson 2003). As the data have increased through the years, the design confidence should also increase. In other words, the accumulated data from the seismic activities will eventually decrease the uncertainty that existed in the determination of the seismic hazards which in turn should decrease the design constrains. The peak ground values used in design should also be decreased as a result of the rise of confidence level 
gained from the extra data obtained with time. However, it was not the case in the 2005 $\mathrm{NBCC}$ because there are other reasons involved that will be explained later in this thesis.

\subsubsection{Uniform Hazard Spectra (UHS)}

The estimation of the response of structural dynamic of any building is a complex procedure. Structural engineers have developed a simplified method to simulate building response. First, the building model will be divided into a series of single degree of freedom systems; second, the responses of these systems will be determined using response spectrum; third, these responses will be combined to obtain the response of the building. Each mode response will be identified using the design spectrum which accommodates all periods. The use of the response spectra technique will incorporate the possible influence of a resonance for the combination of both the structure natural frequencies and the earthquake dominant frequency. The spectral values will also be dependent on the damping level in the system. For simplicity, the viscous damping is assigned to be equivalent to the estimated total damping in the structural system. Figure 3-1 illustrates an example of $2 \%$ damping acceleration response spectra. 
Response Spectrum for $2 \%$ damping ACCELERATION

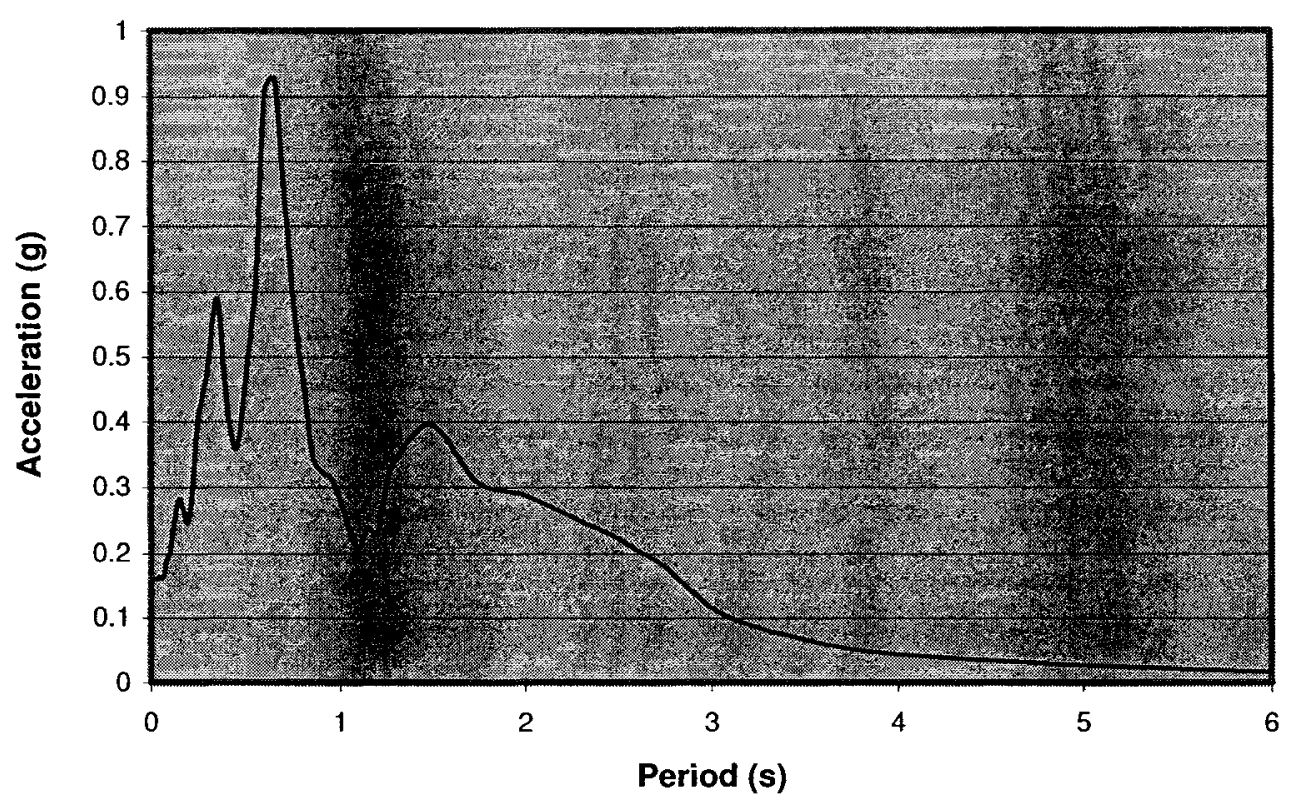

Figure 3-1: Acceleration Response Spectrum of 2\% Damping, Treasure Island Record, Loma Prieta earthquake

The artificial design spectrum curve in design codes is different from a real spectrum curve. The irregularity of the real curve illustrated in Figure $3-1$ is eliminated in the design spectral curve. This is because the design spectrum will cover all expected earthquakes with their different dominant frequencies, durations, and magnitudes. 


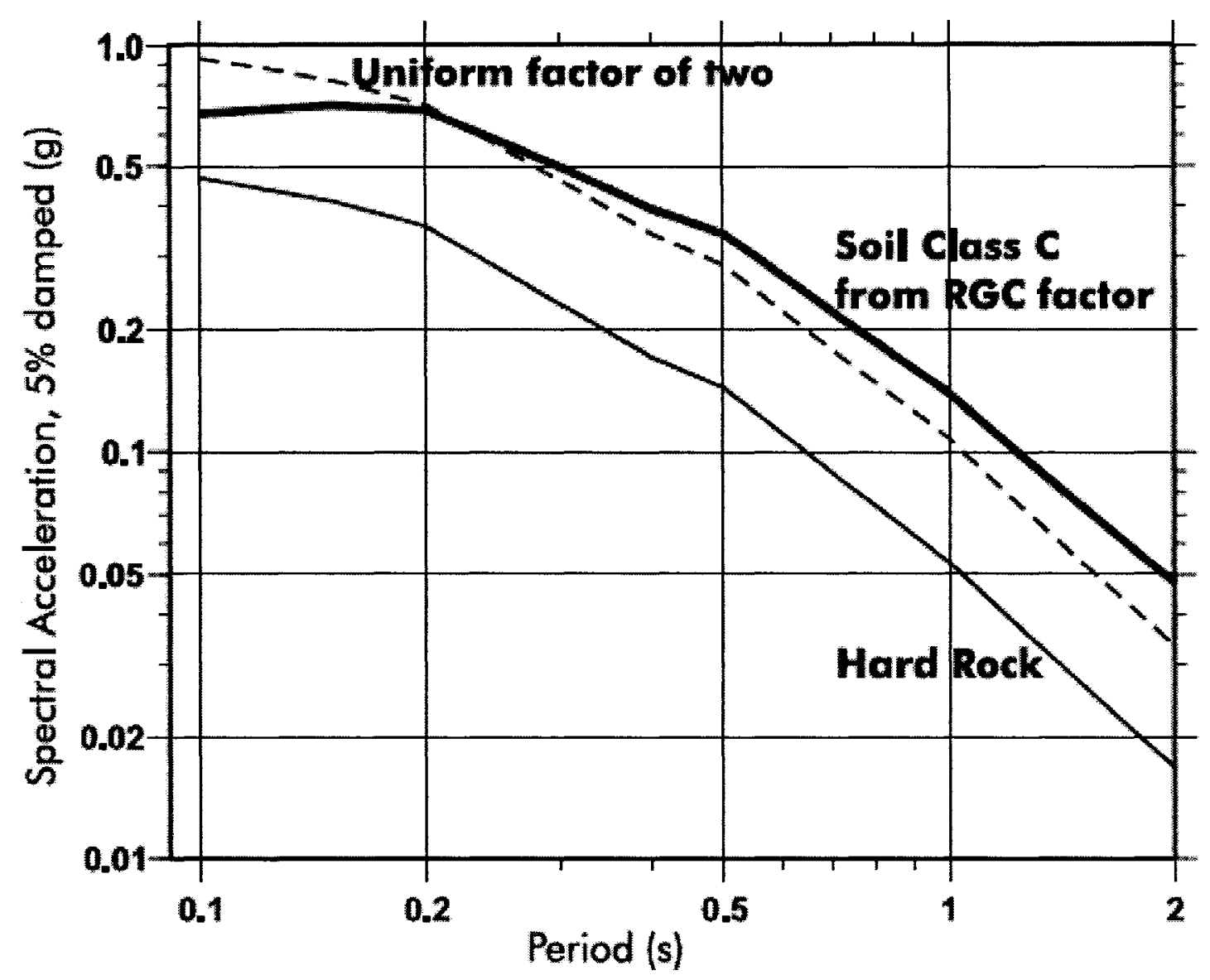

Figure 3-2: Uniform design hazard spectrum for Montréal (after Adams and Atkinson 2003)

The third development of the seismic provisions is that the new probabilistic models were developed to directly correlate the probability level, i.e., $2 \%$ in 50 years to the spectral values of the four main periods, i.e., $0.2,0.5,1.0$, and 2.0s. In the previous code, the probabilistic models were developed to correlate the probability level, i.e., $10 \%$ in 50 years with the peak ground acceleration and peak ground velocity, then estimate the spectral values from these two peaks.

In the new seismological approach, six ground motion parameters for each city have been developed. These parameters are the previous two peaks (PGA and PGV) and the four acceleration spectral values at $0.2,0.5,1.0$, and $2.0 \mathrm{~s}$. In the previous approach, 
only two ground motion parameters were developed: the PGA and the PGV. In Table 3-1, part of the hazard values that were developed for the new code is introduced. The letter next to each number at Table 3-1 identifies the type of the seismological model. For instance, $\mathrm{H}$ is the historical model; $\mathrm{R}$ is the regional model.

Table 3-1: 2005 NBCC design values (median values) for selected Canadian cities after Adams and Atkinson (2003)

\begin{tabular}{|c|c|c|c|c|c|}
\hline City & $\mathrm{Sa}(0.2)$ & $\mathrm{Sa}(0.5)$ & $\mathrm{Sa}(1.0)$ & $\mathrm{Sa}(2.0)$ & $\mathrm{PGA}$ \\
\hline St. John's & $0.18 \mathrm{R}$ & $0.11 \mathrm{R}$ & $0.060 \mathrm{R}$ & $0.016 \mathrm{R}$ & $0.090 \mathrm{R}$ \\
\hline Halifax & $0.23 \mathrm{R}$ & $0.13 \mathrm{R}$ & $0.070 \mathrm{R}$ & $0.019 \mathrm{R}$ & $0.12 \mathrm{R}$ \\
\hline Moncton & $0.30 \mathrm{H}$ & $0.16 \mathrm{H}$ & $0.068 \mathrm{H}$ & $0.021 \mathrm{H}$ & $0.21 \mathrm{H}$ \\
\hline Fredericton & $0.39 \mathrm{R}$ & $0.20 \mathrm{R}$ & $0.086 \mathrm{H}$ & $0.027 \mathrm{H}$ & $0.27 \mathrm{R}$ \\
\hline La Malbaie & $2.3 \mathrm{H}$ & $1.2 \mathrm{H}$ & $0.60 \mathrm{H}$ & $0.19 \mathrm{H}$ & $1.1 \mathrm{H}$ \\
\hline Québec & $0.59 \mathrm{R}$ & $0.29 \mathrm{H}$ & $0.14 \mathrm{H}$ & $0.048 \mathrm{H}$ & $0.37 \mathrm{R}$ \\
\hline Trois-Rivières & $0.64 \mathrm{R}$ & $0.31 \mathrm{R}$ & $0.12 \mathrm{R}$ & $0.043 \mathrm{R}$ & $0.40 \mathrm{R}$ \\
\hline Montréal & $0.69 \mathrm{R}$ & $0.34 \mathrm{R}$ & $0.14 \mathrm{R}$ & $0.048 \mathrm{R}$ & $0.43 \mathrm{R}$ \\
\hline Ottawa & $0.67 \mathrm{R}$ & $0.32 \mathrm{R}$ & $0.14 \mathrm{R}$ & $0.045 \mathrm{R}$ & $0.42 \mathrm{R}$ \\
\hline Niagara Falls & $0.41 \mathrm{H}$ & $0.20 \mathrm{H}$ & $0.073 \mathrm{H}$ & $0.021 \mathrm{H}$ & $0.30 \mathrm{H}$ \\
\hline Toronto & $0.28 \mathrm{H}$ & $0.14 \mathrm{H}$ & $0.055 \mathrm{R}$ & $0.016 \mathrm{H}$ & $0.20 \mathrm{H}$ \\
\hline Windsor & $0.18 \mathrm{R}$ & $0.087 \mathrm{R}$ & $0.040 \mathrm{R}$ & $0.011 \mathrm{R}$ & $0.12 \mathrm{R}$ \\
\hline Winnipeg & $0.12 \mathrm{~F}$ & $0.056 \mathrm{~F}$ & $0.023 \mathrm{~F}$ & $0.006 \mathrm{~F}$ & $0.059 \mathrm{~F}$ \\
\hline Calgary & $0.15 \mathrm{H}$ & $0.084 \mathrm{H}$ & $0.041 \mathrm{H}$ & $0.023 \mathrm{H}$ & $0.088 \mathrm{H}$ \\
\hline Kelowna & $0.28 \mathrm{H}$ & $0.17 \mathrm{H}$ & $0.089 \mathrm{R}$ & $0.053 \mathrm{R}$ & $0.14 \mathrm{H}$ \\
\hline Kamloops & $0.28 \mathrm{H}$ & $0.17 \mathrm{H}$ & $0.10 \mathrm{R}$ & $0.060 \mathrm{R}$ & $0.14 \mathrm{H}$ \\
\hline Prince George & $0.13 \mathrm{H}$ & $0.080 \mathrm{H}$ & $0.041 \mathrm{R}$ & $0.026 \mathrm{R}$ & $0.071 \mathrm{H}$ \\
\hline Vancouver & $0.96 \mathrm{H}$ & $0.66 \mathrm{R}$ & $0.34 \mathrm{R}$ & $0.18 \mathrm{R}$ & $0.48 \mathrm{H}$ \\
\hline Victoria & $1.2 \mathrm{H}$ & $0.83 \mathrm{H}$ & $0.38 \mathrm{H}$ & $0.19 \mathrm{R}$ & $0.62 \mathrm{H}$ \\
\hline Tofino & $1.2 \mathrm{C}$ & $0.93 \mathrm{C}$ & $0.47 \mathrm{C}$ & $0.21 \mathrm{C}$ & $0.52 \mathrm{C}$ \\
\hline Prince Rupert & $0.38 \mathrm{R}$ & $0.25 \mathrm{R}$ & $0.17 \mathrm{R}$ & $0.096 \mathrm{R}$ & $0.18 \mathrm{R}$ \\
\hline Queen & $0.66 \mathrm{R}$ & $0.63 \mathrm{R}$ & $0.50 \mathrm{R}$ & $0.26 \mathrm{R}$ & $0.36 \mathrm{R}$ \\
Charlotte City & & & & & \\
\hline Inuvik & $0.12 \mathrm{~F}$ & $0.067 \mathrm{H}$ & $0.039 \mathrm{R}$ & $0.025 \mathrm{R}$ & $0.060 \mathrm{H}$ \\
\hline
\end{tabular}

From mathematical viewpoint, in any simulation of a natural variable such as the seismic hazard, whenever the number of simulating variables increases such as the design values presented in Table 3-1, the complexity increases and the uncertainty should decrease. To illustrate this mathematical viewpoint in the hazard simulation, Figure 3-3 is 
prepared. Assuming a spectral acceleration curve of a certain design range has the shape as shown in Figure 3-3-a. This curve has an irregular shape. To simplify the irregular shape, it will be fitted with a mathematical representation. Figure 3-3-b shows one simple representation curve, i.e., a two-point based line similar to the two ground peaks in the $1995 \mathrm{NBCC}$. The shaded area between the natural curve and the fitting line represents the resultant error from the simulation process. Other fitting solution is illustrated in Figure 3-3-c. In this fitting solution (six points or five lines), a complex and more representative curve is achieved. The associated error (uncertainty) however is reduced in this tilted curve.

The design spectral acceleration hazard curve may not look like the curve introduced in Figure 3-3, but to some extend, there are similarities. As a result of the use of the spectral values, design confidence level should increase. This in turn, theoretically, should lead to a reduction in the design restrictions because the total uncertainty is reduced. Figure 3-4 illustrates the gain from the reduction of the uncertainty of the spectral values, i.e., the seismic design forces. Thus, it should be possible to reduce the seismic design force and maintain the same probability of exceedance. In the following example, $5 \%$ was used as a design probability of exceedance. For the same $5 \%$, the curve of the less uncertainty in the Figure 3-4-b has led to a significant reduction in design force. This conclusion was under an assumption that the force average value (50\%) has not changed as illustrated in Figure 3-4. 

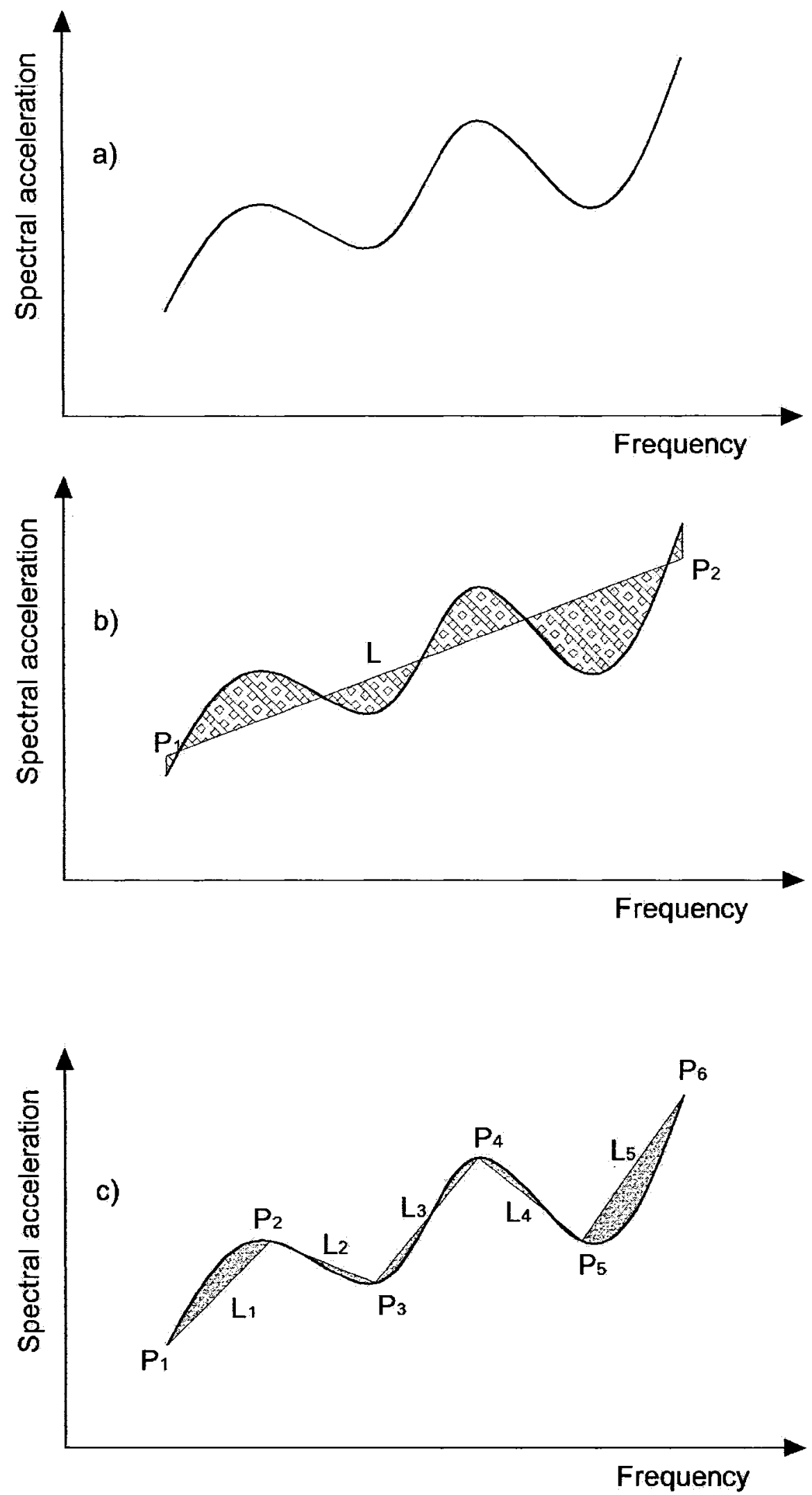

Figure 3-3: Arbitrary Spectral Acceleration Curve with two Fitting Curves 


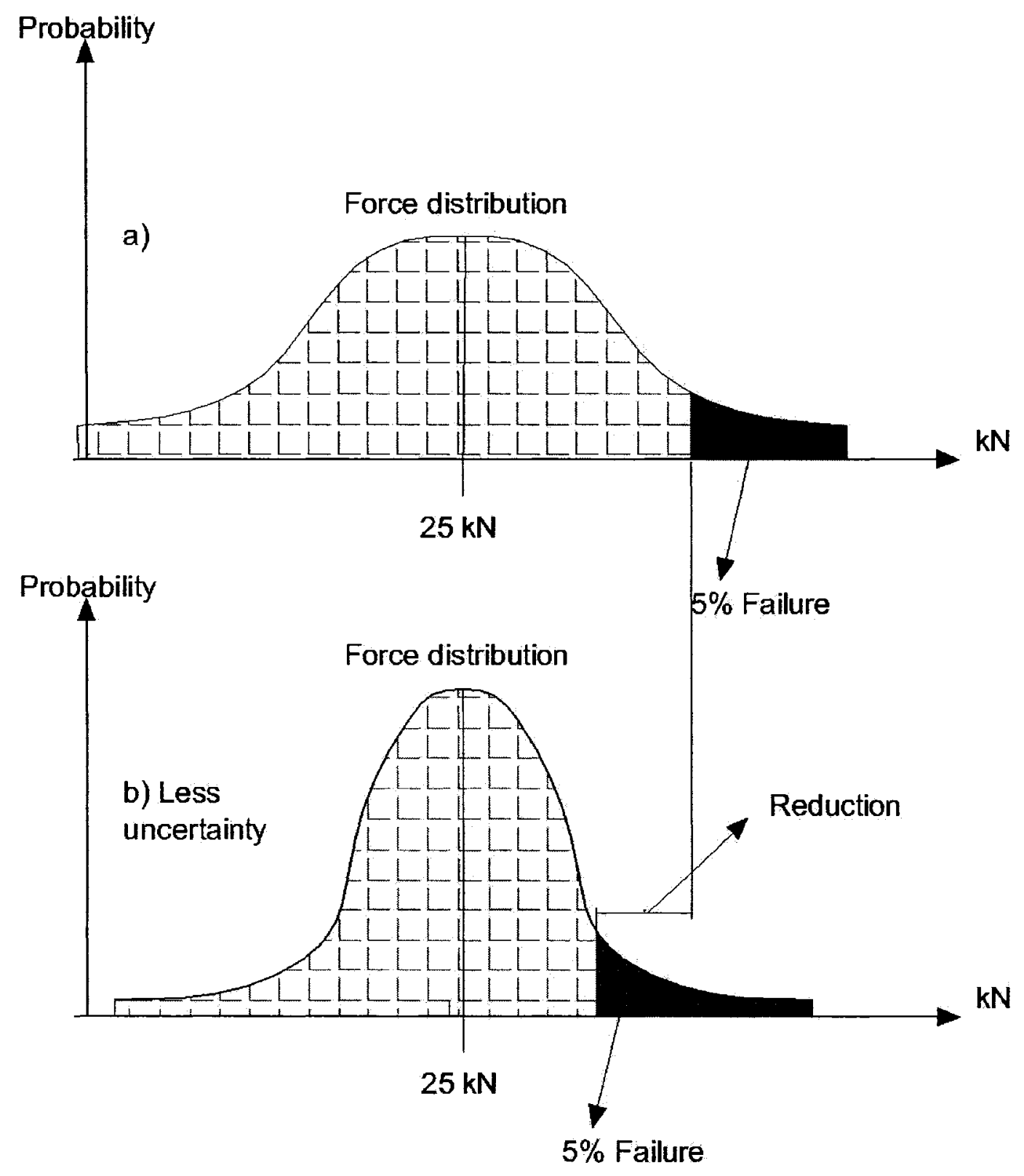

Figure 3-4: Different failure values from two uncertainties

\subsubsection{The Probability of $2 \%$ in 50 years}

The nature of the earthquake source in Canada is not the same from one region to another. Three different regions were identified: the west coast, the east coast, and across North American plate shown in Figures 3-5. The theories of continental drift and plate 
tectonics discussed earlier divide the earth surface into different seismic regions. Each region has certain hazard level. Beside the historical data recorded from the worldwide network of seismographs, these clear satellite images also help to identify the seismic region boundaries. Figures 3-5 thru 3-7 are satellite pictures taken from Google-Earth and Google Maps services. In Figure 3-5, 3D real image was presented for the North American plate. The tectonic boundaries of the plate's shape are easily identified at the east coast.

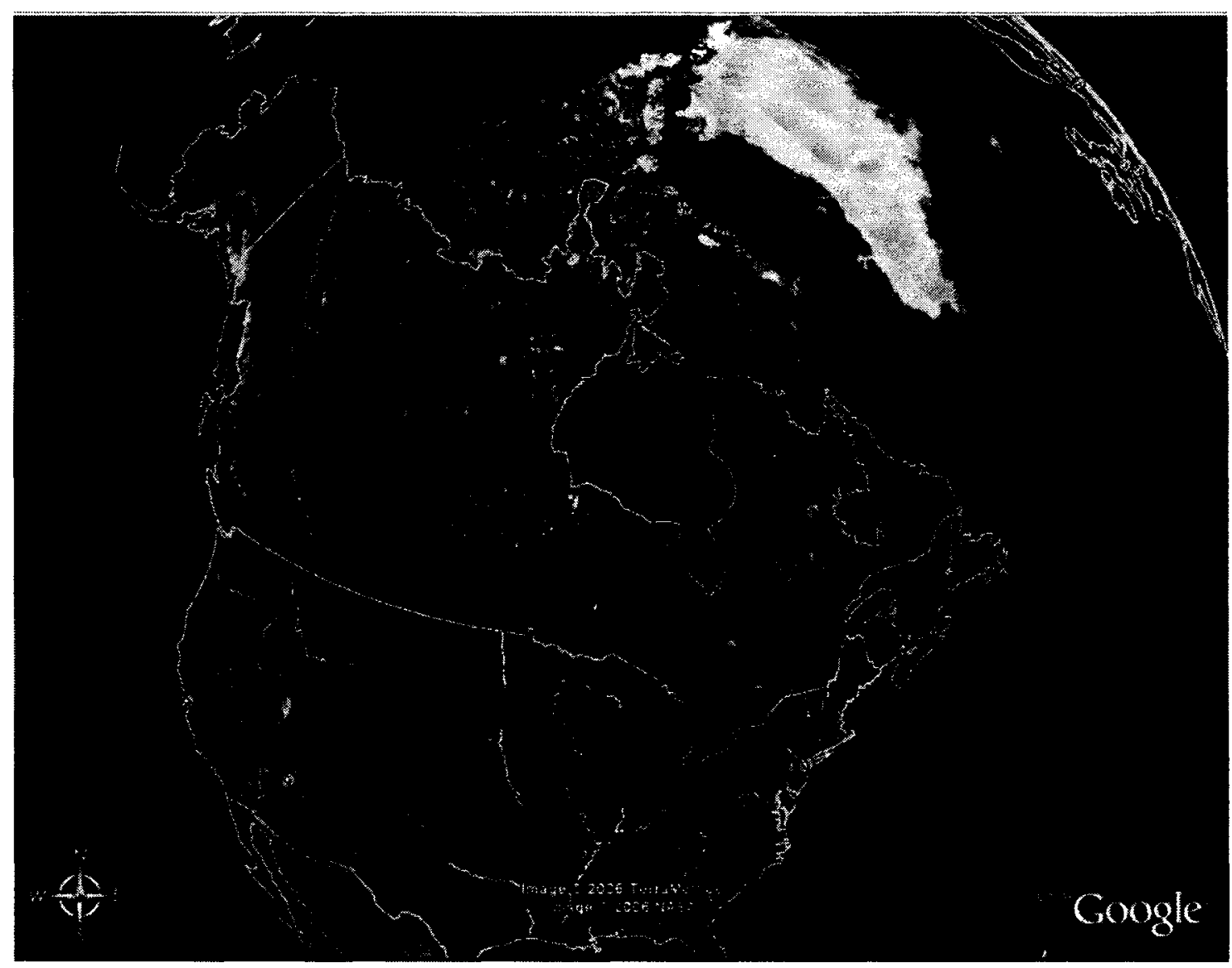

Figure 3-5: Boundary of North American Plate

In Figure 3-6, 3D Canadian east coast image was presented, and out of this image, the spreading continent edge shadow is precisely identified just east of the eastern shores. 
The broken continent edge may be easily seen deep in the ocean just offshore the east coast. Because of the unique tectonic history of the east coast, i.e., a Spreading Edge, the nature of the earthquakes at the east coast is expected to be different from the rest of the country.

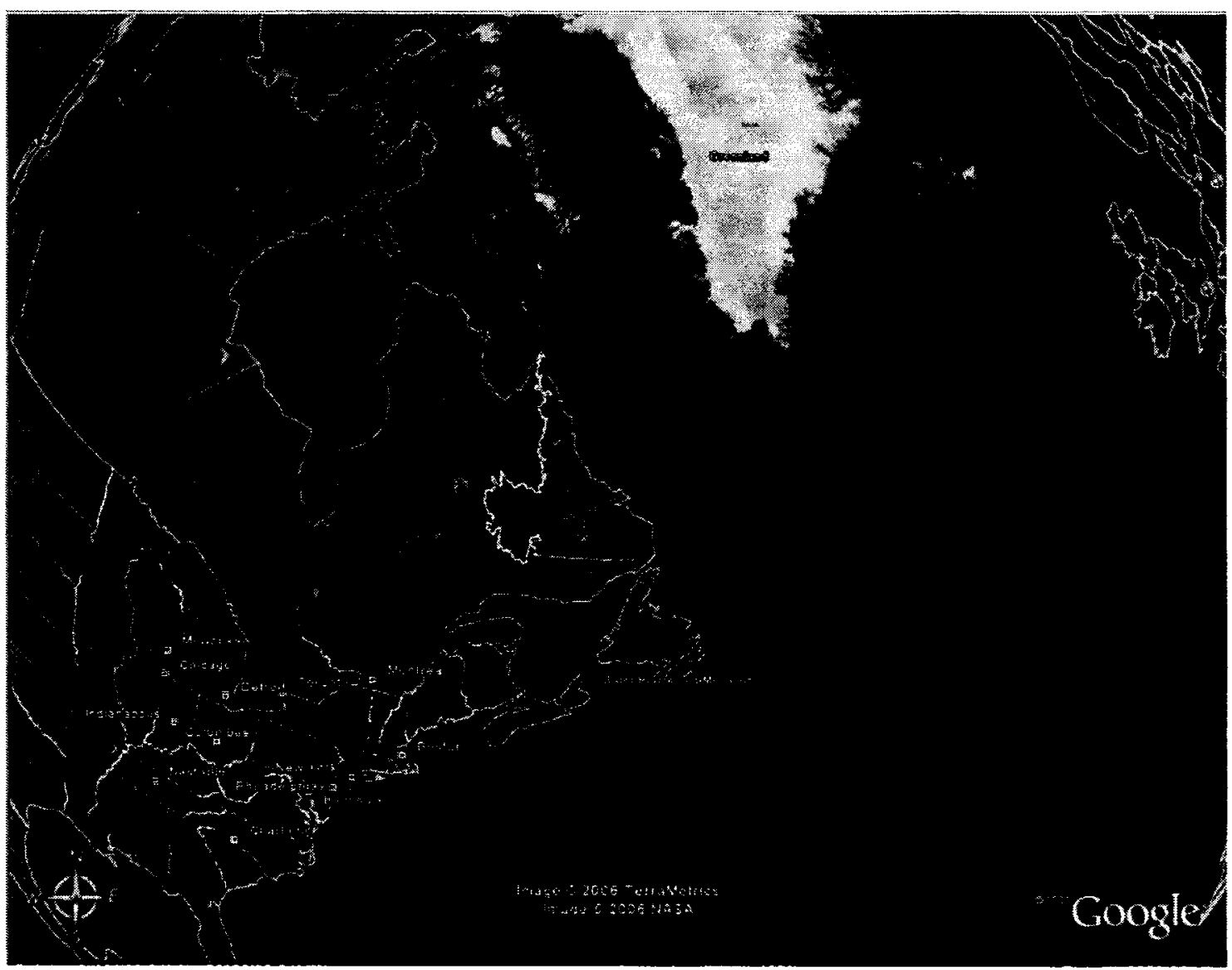

\section{Figure 3-6: 3D Canadian East Coast}

The west coast is the other unique region of the country. In Figure 3-7, a 2D image of the west coast is presented. Unlike the east coast where there is a spreading ridge, the west coast is a natural edge of the earth main plate called Pangaea as it was 200 million years ago according to Wegener (1915) quoted by Kramer (1996). Although part 
of the west coast is a subduction zone edge, the nature of the majority of the Canadian west coast is not resulted from a tectonic movement.

The middle of the country is the third seismic region. Mid-plate or stable Canada as suggested by Geological Survey of Canada (GSC) is the last region to be considered in the Canadian code. The historical data recorded from the seismograph network, and the recurrence models adopted for the country also support these satellite images previously introduced.

The different source natures of earthquakes in different regions and the different models used to estimate the probabilistic exceedance are responsible for the difference in the seismic hazard curves. In Figure 3-8, the spectral hazard curves have been plotted for two major cities: one in the east (Montréal) and the other in the west (Vancouver). 


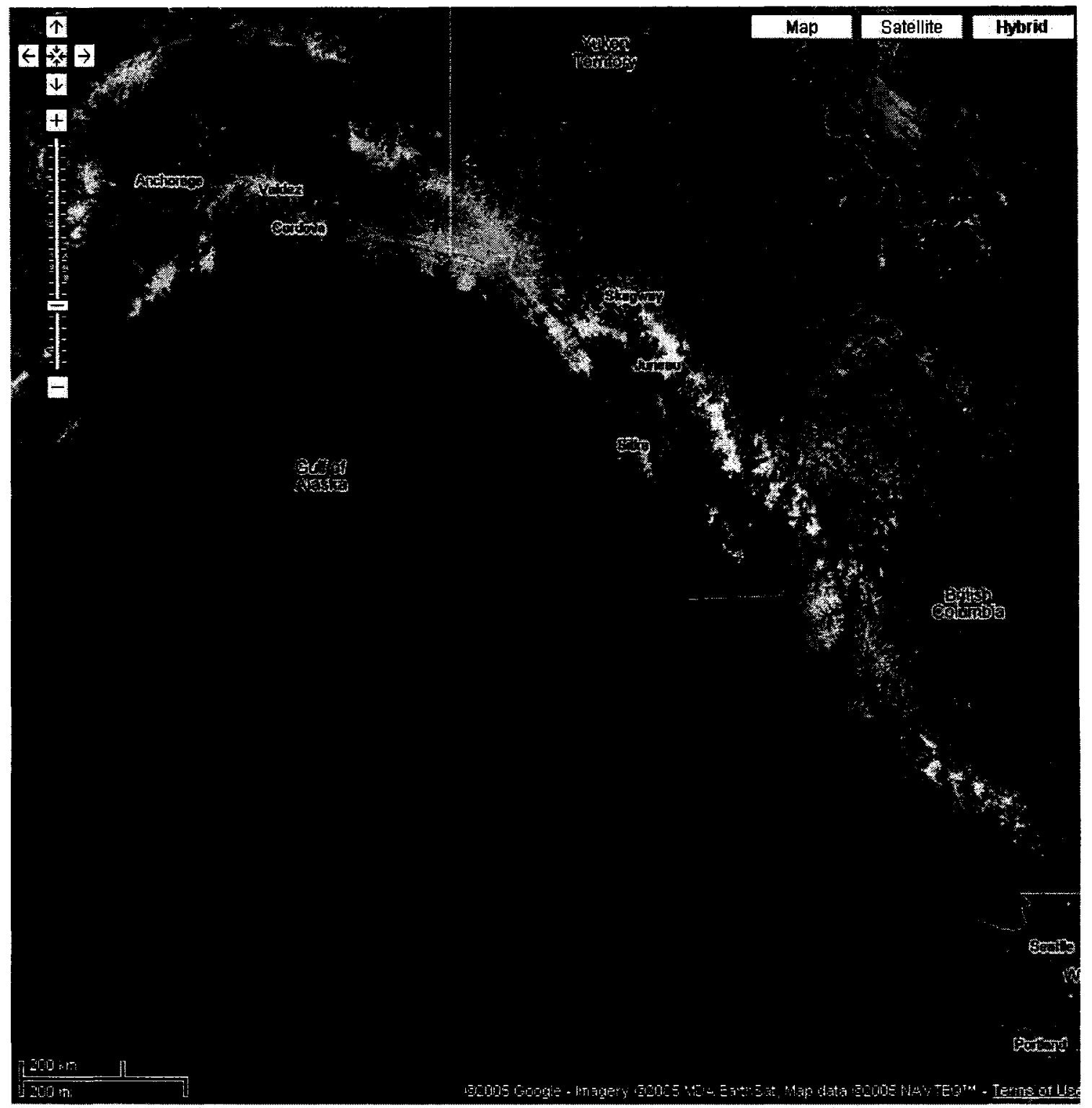

Figure 3-7: 2D Canadian West coast 


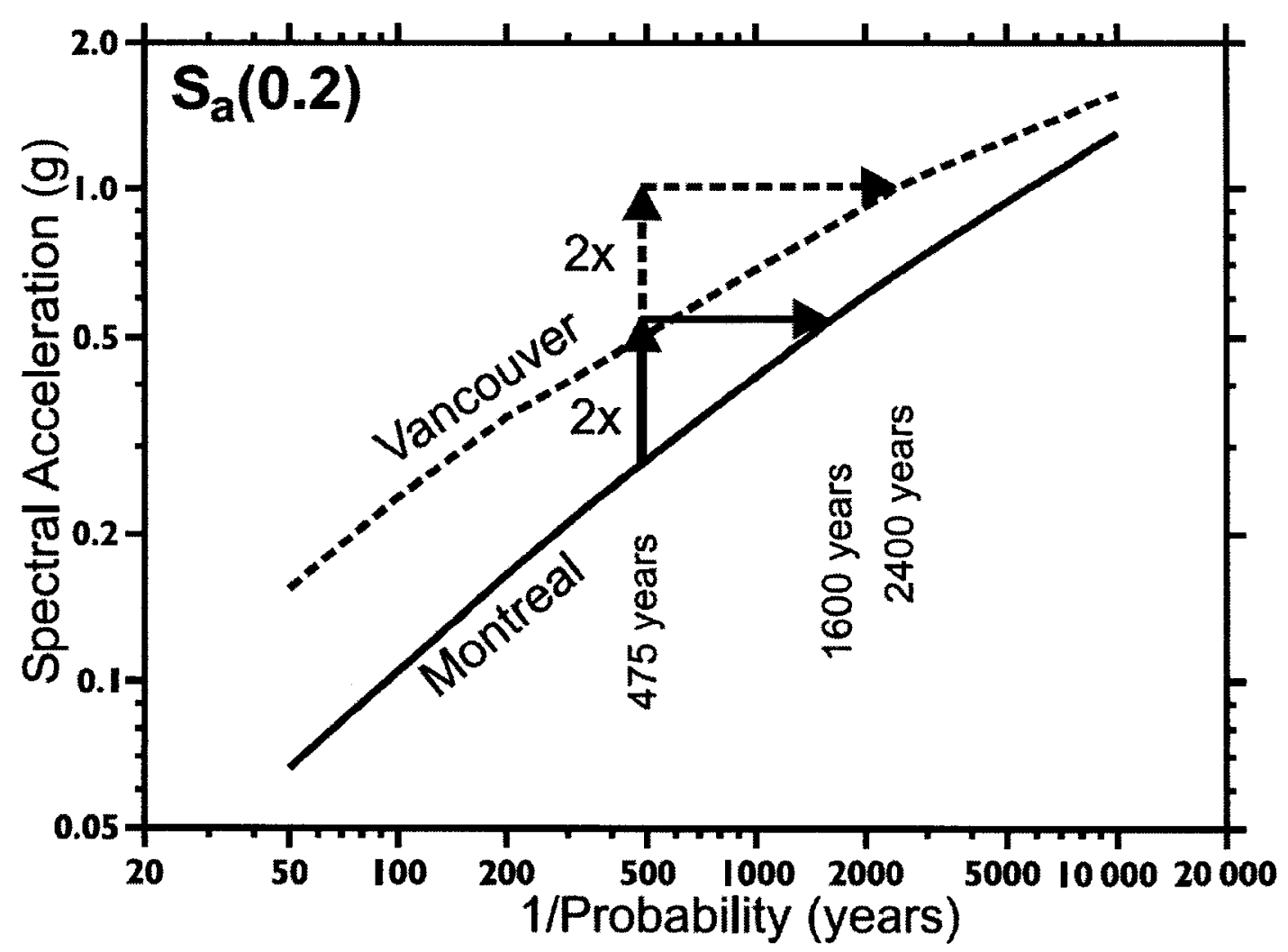

Figure 3-8: Seismic hazard curves of Montréal and Vancouver (after Adams and Atkinson 2003)

The rationale behind the famous Figure 3-8 has probably initiated the recent changes in the $2005 \mathrm{NBCC}$. The different performances between different regions are the major reasons for the recent developments of seismic provisions (Adams 2006). This graph delivered the same idea incorporated in Figure 2-1 introduced in the NEHRP Commentary (2003). The first feature of the two seismic hazard curves is that they have different slopes in the range of structural performance. The gentle slope curve in the west of the country (Vancouver) will have higher performance for the same safety margin. To illustrate the importance of the slope difference, a simple plot is presented in Figure 3-9. 


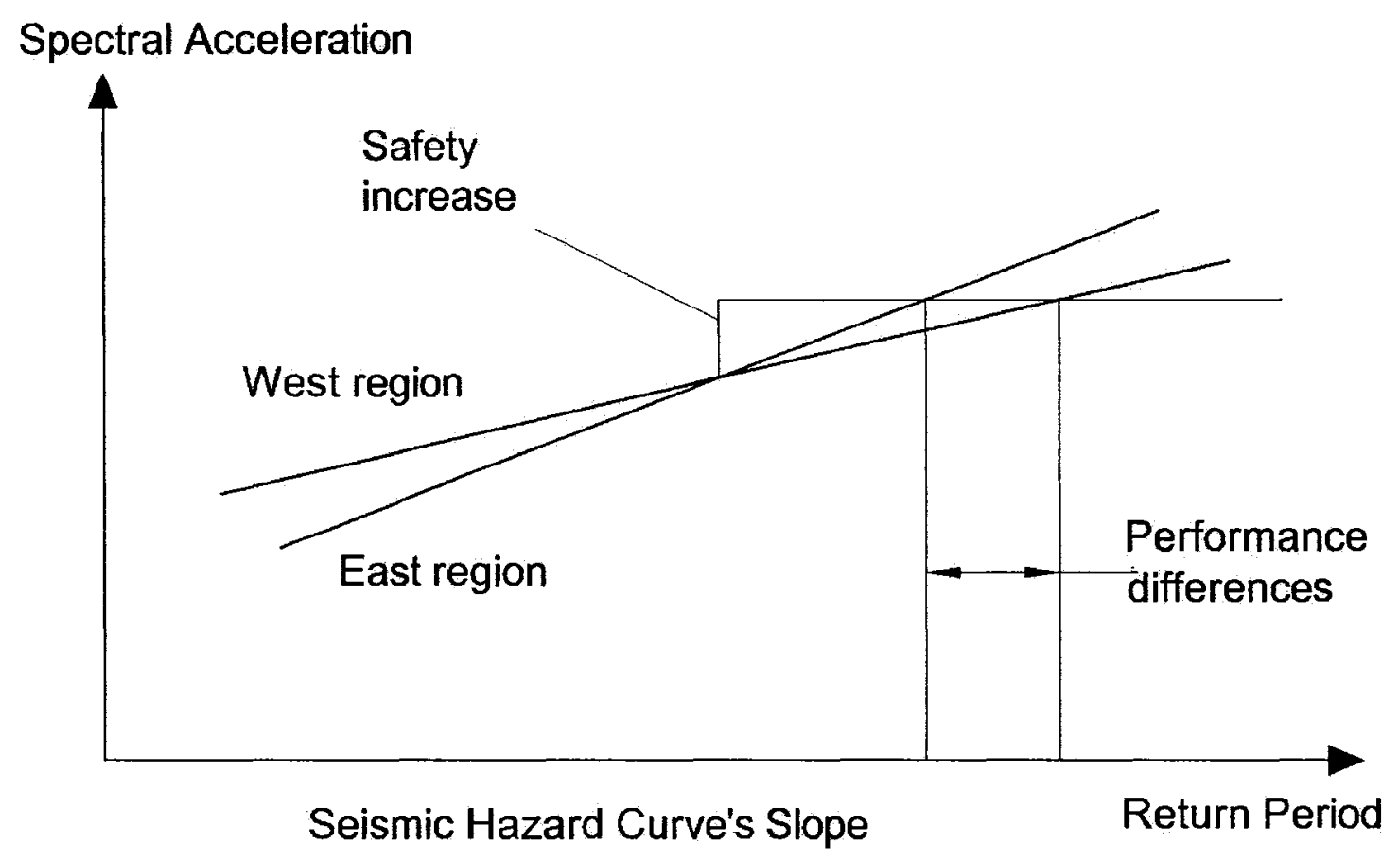

Figure 3-9: Two performances for two seismic hazard curves of different slopes

A remarkable difference in the performance levels will be achieved for the same safety margin in two identical systems; one from the West and the other from the East. The seismic hazard curve of the gentle slope at a Western city will reveal a higher performance level for the same design hazard level and safety factor.

Another important feature of the seismic hazard curves is that they would reflect different performance levels, not only between the east and the west of the country but also within the same tectonic region. This feature of the seismic hazard is simply because of the different hazard levels across any tectonic region. In Figure 3-10, the difference in seismic hazard levels of two different places at the same seismic region, i.e., the same seismic source characteristics has revealed different performances at an identical safety factor $F s=2$. 
Spectral Acceleration

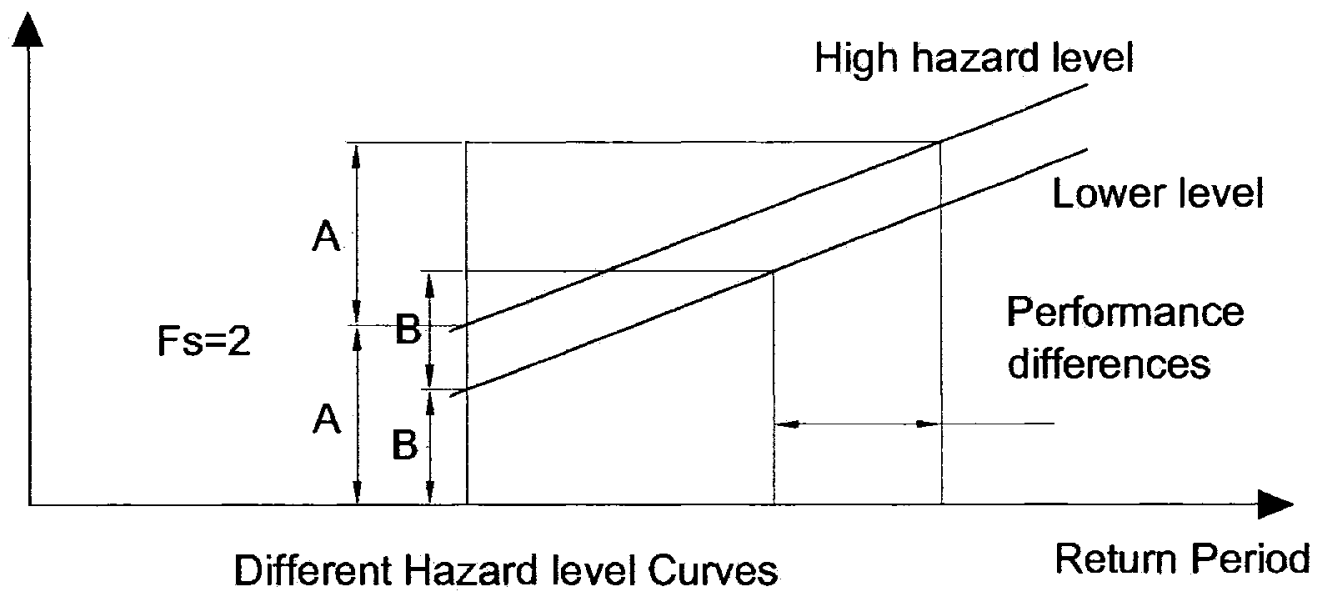

Figure 3-10: Different performances at different hazard levels within the same seismic region

The new seismic design approach is to specify one target performance level, and then reduce it back to find the design level using a uniform safety factor. Figure 3-11 illustrates the new design approach that is incorporated in the $2005 \mathrm{NBCC}$ using a safety factor that equals $1 / 0.75=1.333$.

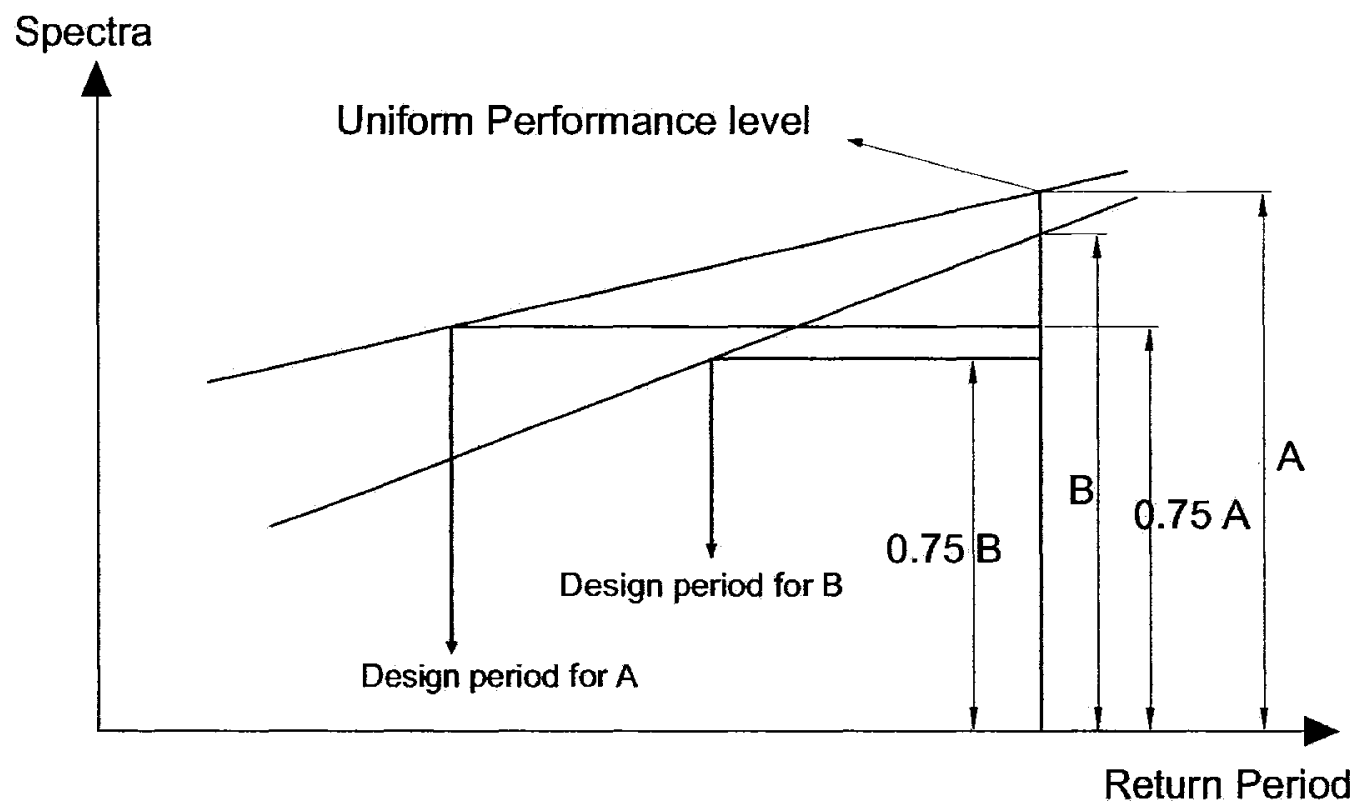

Figure 3-11: Uniform performance but different design levels similar to $2005 \mathrm{NBCC}$ 
Finally, four distinct seismological developments have been incorporated in the new National Building Code of Canada (2005 NBCC). To evaluate the overall change in the peak ground acceleration, Table 3-2 has listed the new and the previous acceleration at two seismicity levels. A remarkable increase in PGA between the $10 \%$ in 50 years event used in $1995 \mathrm{NBCC}$ and the $2 \%$ in 50 years event used in 2005 NBCC. However, this increase is not the same from city to city, e.g., $110 \%$ increase for Ottawa, and $257 \%$ increase for Toronto. The other difference is that within the same probability level, i.e., $10 \%$ there are differences in the accelerations. A moderate increase or decrease of PGA was noticed between 1995 and 2005 at $10 \%$ in 50 years. This change is most likely a consequence of the first three seismological developments discussed in Section 3.1.

Table 3-2: Peak ground accelerations (Open File 4459 GSC, 2003)

\begin{tabular}{|c|c|c|c|}
\hline PGA(g) & $\begin{array}{c}2 \% / 50 y r s ~ 2005 \\
\text { NBCC }\end{array}$ & $\begin{array}{c}10 \% / 50 y r s ~ 1995 \\
\text { NBCC }\end{array}$ & NBCC \\
\hline Québec & 0.37 & 0.19 & 0.16 \\
\hline Toronto & 0.20 & 0.056 & 0.080 \\
\hline Vancouver & 0.48 & 0.21 & 0.26 \\
\hline Calgary & 0.088 & 0.019 & 0.040 \\
\hline Ottawa & 0.42 & 0.20 & 0.20 \\
\hline Montréal & 0.43 & 0.18 & 0.20 \\
\hline
\end{tabular}

Unlike what it was expected to result, the new seismic models, the accumulated seismographic data, and the other research developments most likely did not lower the hazard values (PGA) that existed in the system. Instead, there was a moderate increase in seismic hazard values like spectral accelerations or PGAs. For instance, there was an 
increase of over $100 \%$ in PGA for the City of Calgary $(0.019 \mathrm{~g}$ to $0.04 \mathrm{~g})$. This increase may be due to in part to the multiple uncertainties inherent in the system, so any rearrangement of the models that are involved would more likely shift the reference of the probability level.

\subsection{Geotechnical Developments}

Unlike the Seismological developments, the seismic provisions of 2005 NBCC have undergone minor geotechnical developments. The influence of soil dynamic properties on the amplification of the structural response has been incorporated in the new code. The main geotechnical developments will be discussed in the following section.

\subsubsection{The Uniform Hazard Spectra UHS was developed for Site Class C}

Civil engineering structures are usually built where their foundations are accommodated (installed) within the top ten meters from the soil surface, so it is rather convenient to update the response spectra to the soil profile that would be expected to occupy the top ten meters of the soil. In Canada and in most countries, the majority of the foundation soils are more likely to be classified near to Site Class C, i.e., dense sand or soft rock. Outcrop rock foundation would be an exceptional case. It is much more practical to develop the UHS for soil class $C$ rather than $A$; and then amplify it or deamplify it for other soil profiles. However, in the $1995 \mathrm{NBCC}$, only four nominal numbers were defined for soil foundation factors, and the design spectrum was 
normalized to subclass A. In Figure 3-12, an arbitrary shape of foundation factor is introduced.

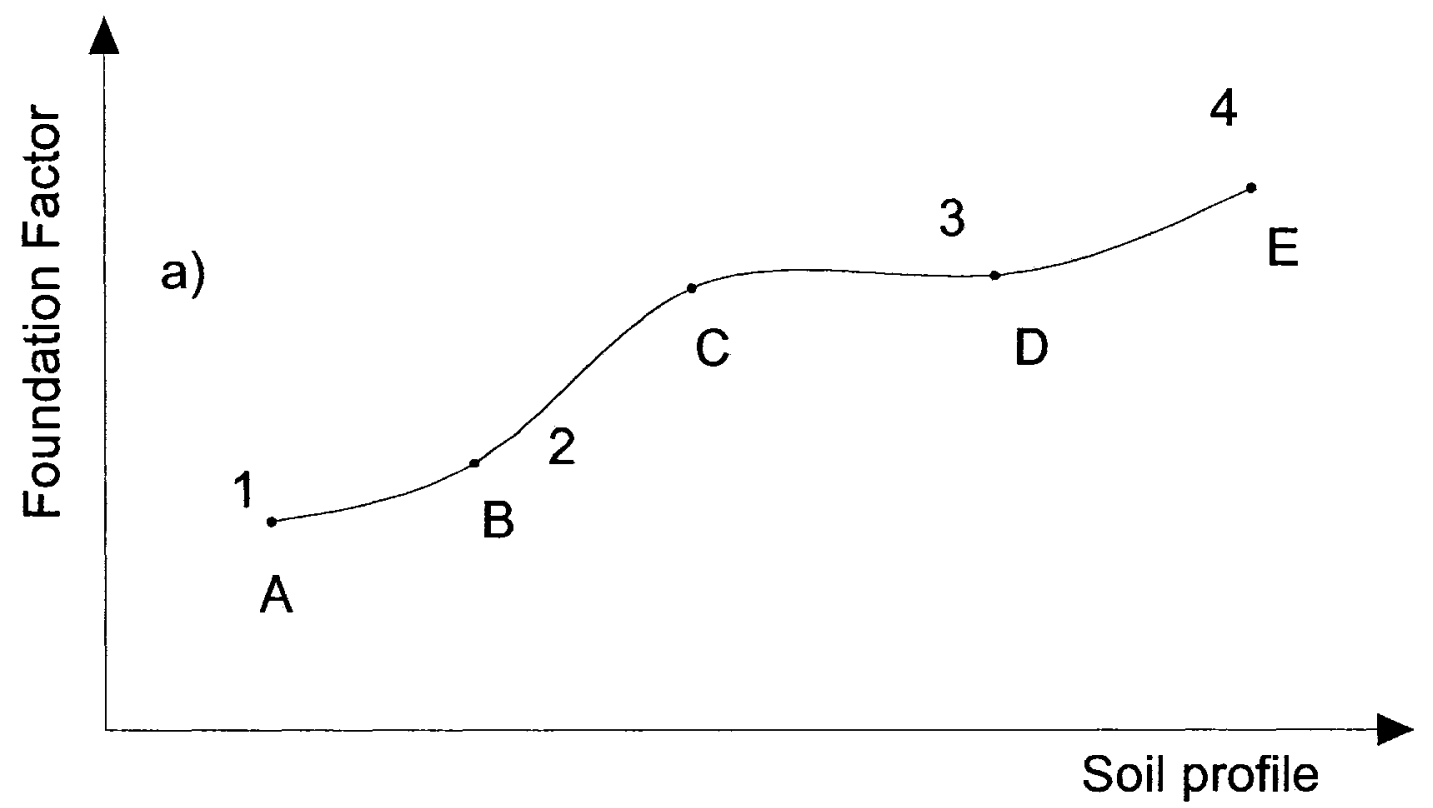

Figure 3-12: Natural variation of a foundation factor

To illustrate the influence of interpolation reference based on soil class $\mathrm{C}$, Figure 3-13- $a$ was introduced where the reference used is a subclass A, and then in Figure 3-13b, the soil profile reference was set to a $C$ subclass. The overall error in the second case is readily seen to be lower than the first case. Although the illustration in Figures 3-12 and 3-13 may not be quite similar to the foundation factor, it possesses the same rationale. Furthermore, from a probabilistic point of view, the soil categories 1 and 4 specified in 1995 NBCC, which represent rock or very dense coarse-grained soil and very soft or soft fine-grained soil will practically represent fewer design cases than the other categories, i.e., 2 and 3. As a result, the errors will decrease much more than the illustrated amount in Figure 3-13 because the exposed error cases have been relatively lowered. 

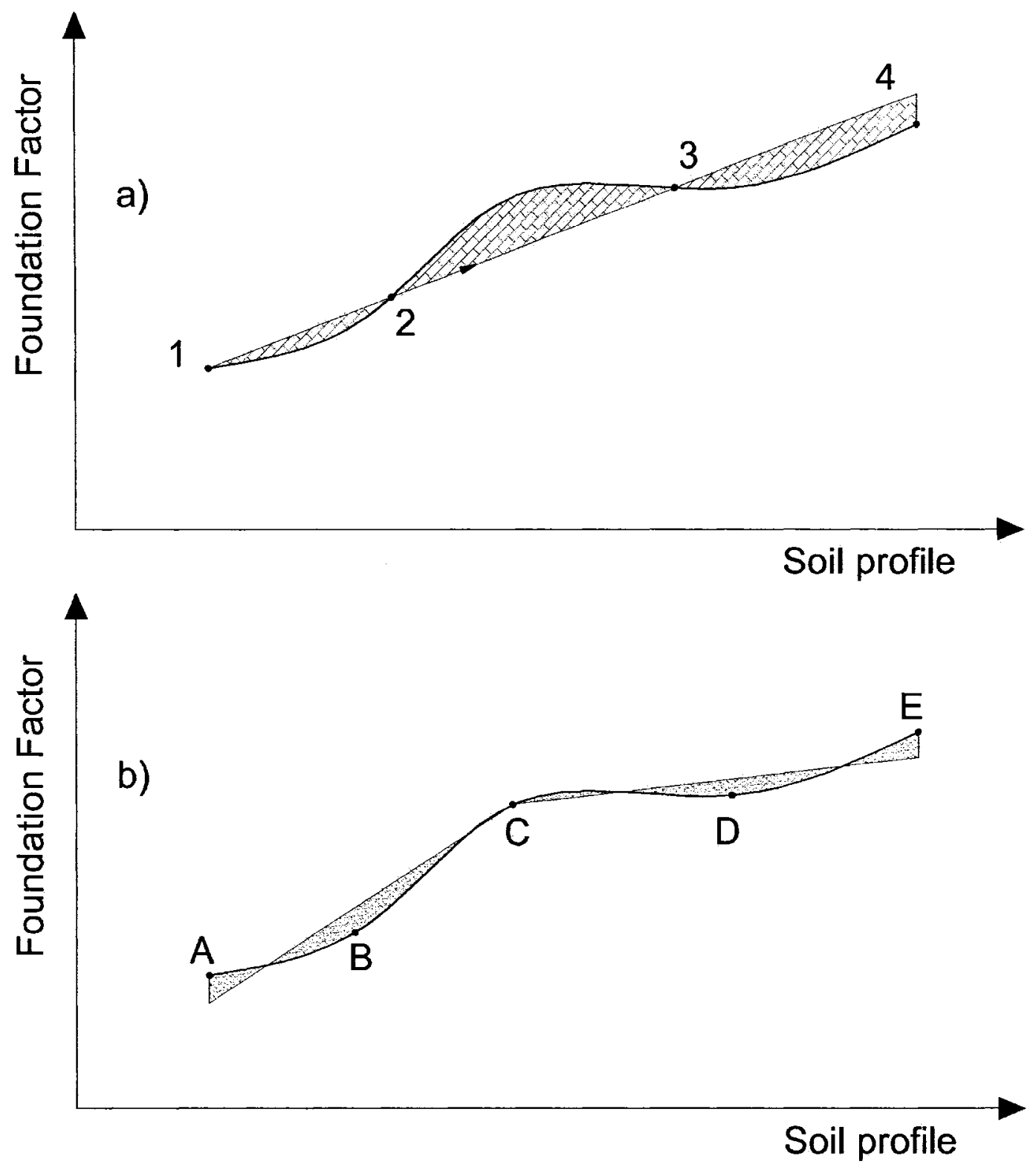

Figure 3-13: Errors from simulating the foundation factor; b) similar to 1995 NBCC approach and c) similar to $2005 \mathrm{NBCC}$

\subsubsection{Soil Effects Based on Natural Frequency}

Another major change of the foundation factor is its dependency on the soil natural frequency. Another development has been achieved by incorporating the natural frequency of the soil with that of the structure. The resonance phenomenon that 
historically was responsible for several earthquake disasters is an important factor of seismic response. In September 1985, the 8.1 magnitude earthquake in Mexico City that caused only moderate damages in the range of the epicenter caused severe selective destruction in some buildings in Mexico City, $350 \mathrm{~km}$ away from the epicenter. The thick layer of soft clay, i.e., up to $40 \mathrm{~m}$ thick and $75 \mathrm{~m} / \mathrm{s}$ s-wave velocity $(V s)$ had not only magnified the ground motion but also shifted its dominant frequency toward the natural frequency of the clay layer, i.e., $T s=4 H / V s \sim 2.1 s$. As illustrated in Figure $3-14$, the structural response, however, was selective to the natural frequency of the buildings. The damages were severe in buildings of stories from 5 to 20 having periods from 0.5 to $2.0 \mathrm{~s}$. The site period that was shifted close to the natural period of the clay layer had resonance effect with the thick clay, so both the tall buildings over 30 stories and the short building less than 5 stories were off the resonance range.

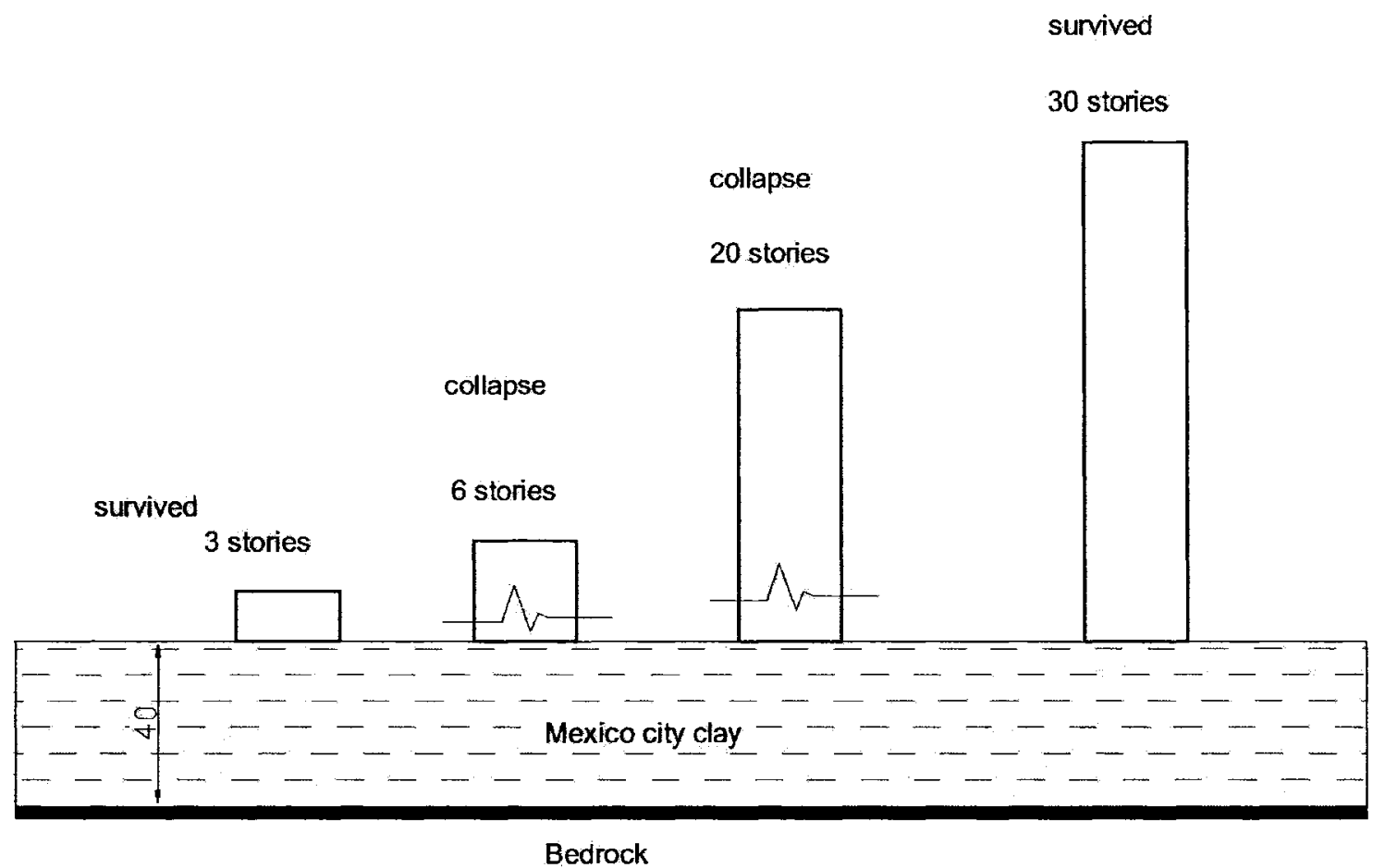

Figure 3-14: Selective damages in Mexico City earthquake of 1985 
Finally, the values of site coefficients $\left(F_{v}\right.$ and $\left.F_{a}\right)$ in the 2005 NBCC have been updated to account for possible resonance between the buildings $(S(T))$, and the soil layer, i.e., Site Class, as discussed in sentence 4.1.8.4 of 2005 NBCC. Chapter 8 of Geotechnical Earthquake Engineering book by Kramer (1996) is remarkable reference investigating the effect of the local site conditions on seismic response.

In addition, the foundation factor has undergone not only a change in becoming frequency dependent as discussed above but also an increase in its range as illustrated in Figure 3-15. The shaded areas in Figure 3-15 are the extra amounts of the foundation factor values used in design (Code values), but not required by natural conditions of soils. Furthermore, the maximum to the minimum ratio of the foundation factor range values has also changed from 2, i.e., (2/1) in the 1995 NBCC to 4.2 , i.e., $(2.1 / 0.5)$ in the 2005 NBCC. This new ratio indicates the important contribution of soil characteristics in seismic design because the new base shear would vary 4 times based on the soil conditions. 


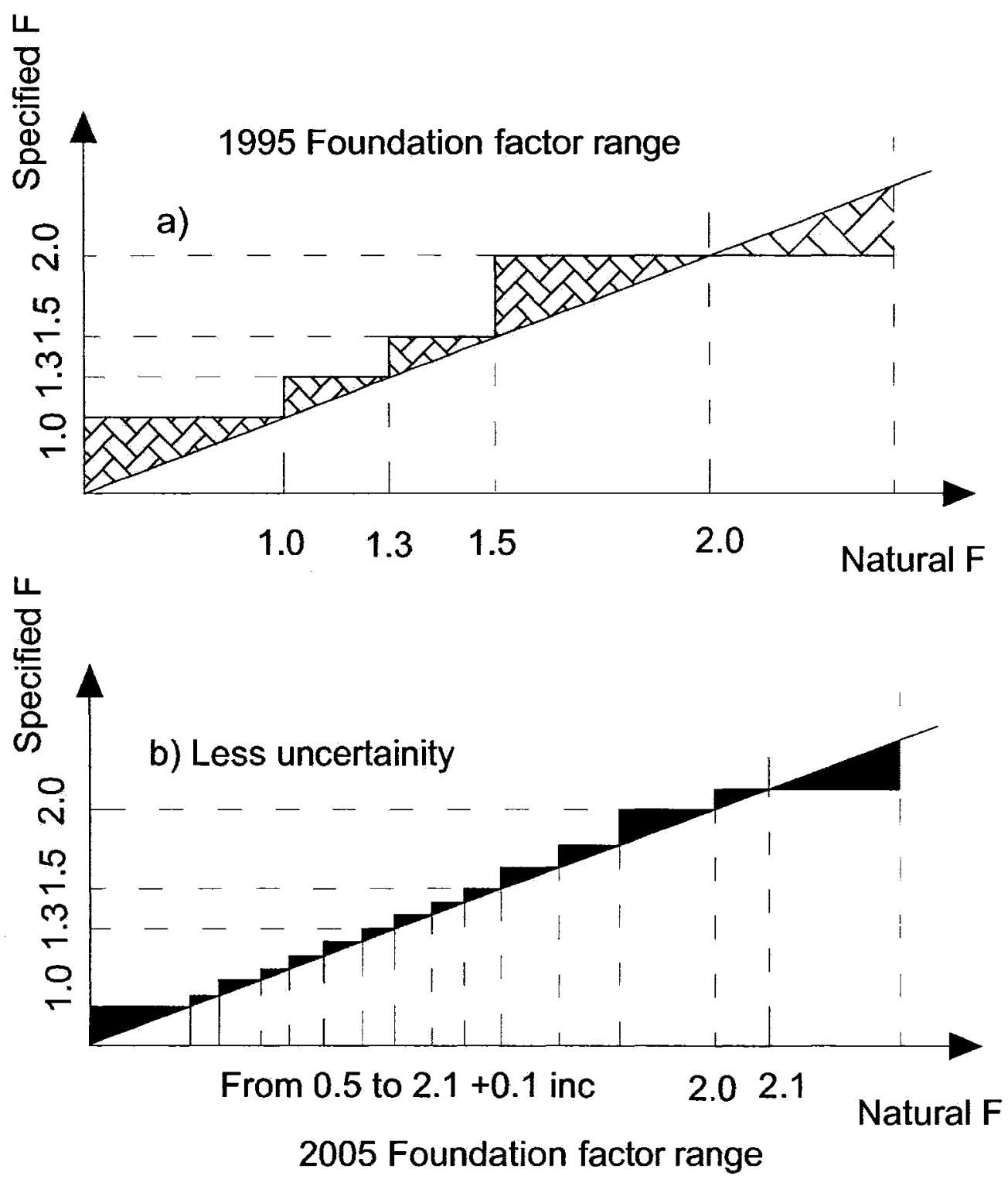

Figure 3-15: The differences between the natural and specified values of the foundation factors

The benefits from ongoing research have led to the changes in the foundation factor values, and this change may eventually lead to a lower risk associated with design. The change will also maintain the same design costs although the design risk was lowered. This type of development is so efficient in lowering the risk and maintaining the design costs almost constant, and it was the dominant type of most developments of seismic provisions as discussed earlier. Figure 3-16 shows a comprehensive 
representation of the benefits of specifying new factors to update the seismic base shear or any multi-factors design force.

Figures 3-16-a and 3-16-b are identical, and they represent a foundation factor versus a number of buildings nationwide. For simplicity, these distribution curves are assumed to be represented by a normal distribution rather than a lognormal one. The design costs illustrated in Figures 3-16-c and 3-16-d are related to: first, in 3-16-c, where no value was assigned to the foundation factor; second, in 3-16-d, where four values were used. The unit cost of the seismic cost is approximately proportional to the foundation factor. Although, the unit cost shapes of the two cases are different, the total costs (illustrated in Figures 3-16-e and 3-16-f) of nationwide designs (the national economy will pay) should be the same. However, the risk of failure (illustrated in Figures 3-16-i and 3-16-g) of all the structures on all soil conditions has significantly dropped in the multiple values case as oppose to the no factor used case. 

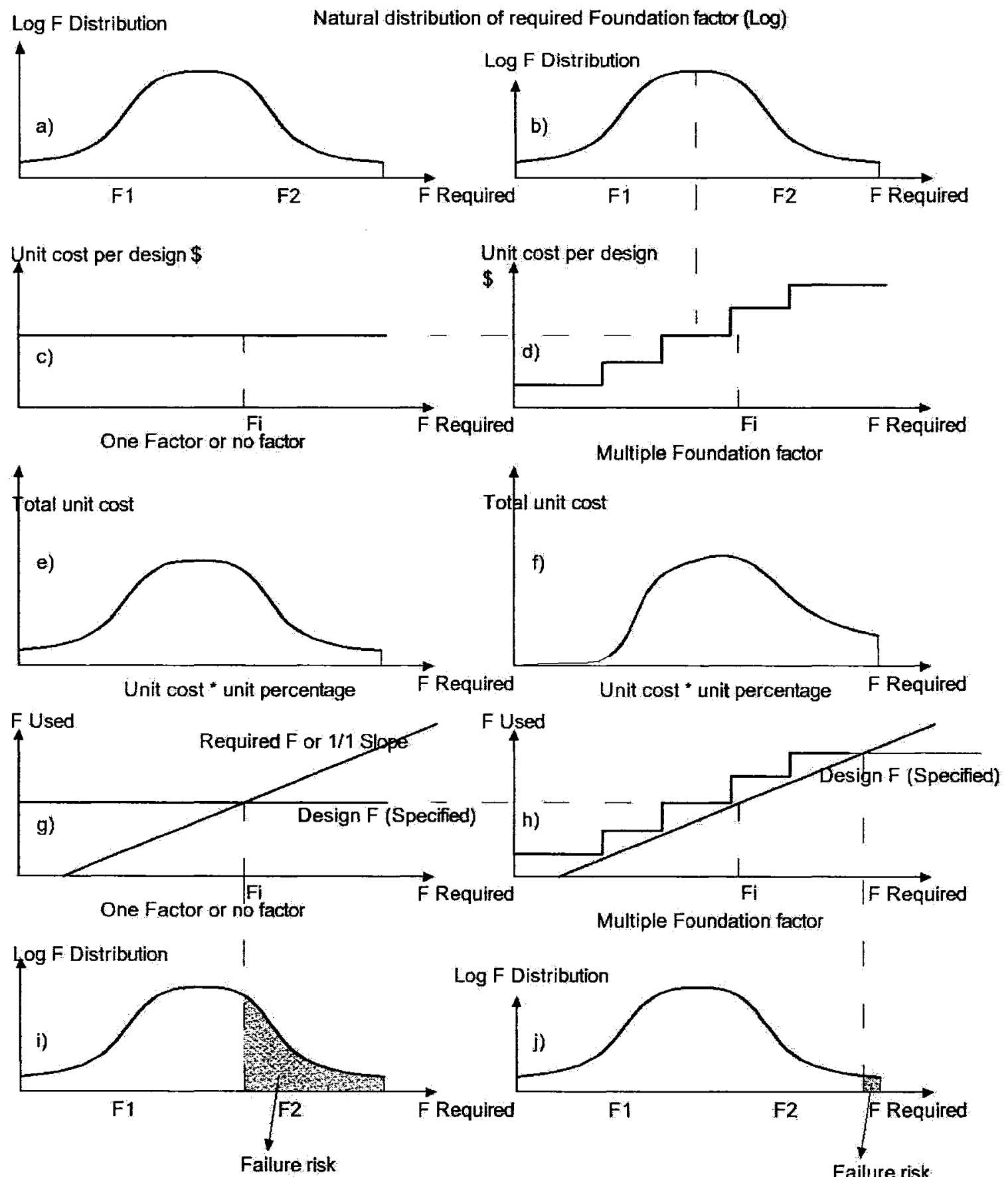

Multiple Foundation factor

Failure risk

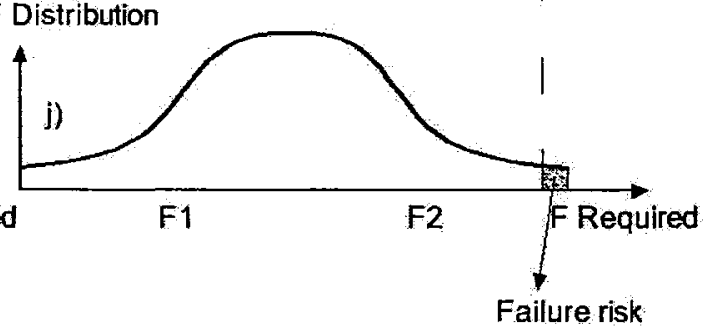

Figure 3-16: The impact from the use of foundation factor in design on the nationwide costs and the nationwide failure risks 
The failure criteria that are assumed in the Figures 3-16-g and 3-16-h are based on a deterministic assumption that a failure occurs when the design $F$ is less than the required $F$.

\subsection{Structural Developments}

Several changes and developments were applied to the structural section of the seismic provisions of the 2005 NBCC. These changes were not only to incorporate the huge gains of the ongoing researches in earthquake engineering but also to accommodate other related changes especially those coming from recent seismological developments.

The base shear is the main equation to evaluate the seismic design forces. In Section 2.3, the historical developments of the base shear equation were presented. From the $1995 \mathrm{NBCC}$ to the $2005 \mathrm{NBCC}$ the base shear equation has been rewritten.

1995 NBCC

$\underline{2005 \mathrm{NBCC}}$

$$
\begin{aligned}
& V_{e}=V \cdot S \cdot I \cdot F \cdot W \\
& V=\frac{V_{e}}{R} \cdot U
\end{aligned}
$$

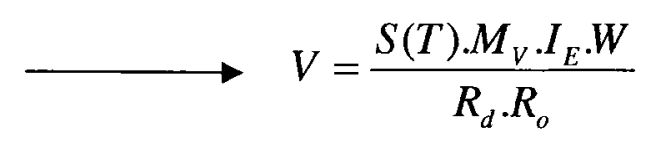

The factors used in the 1995 NBCC form are defined as follows:

$V_{e}:$ The elastic base shear

$v$ : The zonal velocity ratio

$S:$ Unit seismic response value

I: Importance factor 


\section{$F:$ Foundation factor}

$W$ : Dead loads plus $25 \%$ of snow loads plus $60 \%$ of storage loads and full tanks

$V$ : A minimum lateral seismic force at the base of the structure with a load factor $\left(\alpha_{E}\right)=1.0$ (for ultimate design approach)

$U:$ Calibration factor $(=0.6)$

$R:$ Force modification factor that accounts for the capability of the inelastic strain (Ductility).

The factors in the 2005 NBCC are:

$S(T):$ the design spectral acceleration

$M_{v}$ : the higher mode effect

$I_{E}$ : Importance factor (a new fourth value $(0.8)$ has been introduced to the low importance category)

W: a dead load plus the applicable portions of other loads (similar to the 1995 NBCC)

$R_{d}$ : Ductility related force modification factor (New high value (5.0) was introduced in the new ductility factor)

$R_{O}$ : the overstrength force modification factor

$V$ : Lateral earthquake design force at the base of the structure that is simply known as the base shear.

The structural developments and their impact on the safety level improvements are the main parts of the developments of the seismic provisions. $W$ and $V$ that existed in both codes have undergone almost no change in their definitions and functions. In the following sections, the structural developments will be discussed and evaluated. 


\subsubsection{Combining the Spectral Acceleration and the Foundation Factor}

$v, S$, and $F$ that were in the 1995 NBCC, are replaced by the spectral value $S(T)$ where $S(T)=F_{a / v} S_{a}(T)$ ( $F_{a / v}$ is foundation factor and $S_{a}(T)$ is spectral acceleration), so the spectral value has not undergone any conceptual change. In the new value, the same factors were just rearranged, and more details from the recent research were incorporated in these factors.

\subsubsection{Higher Mode Effect $M_{V}$}

Higher Mode Effect $\left(M_{V}\right)$ is a factor to incorporate the effect of the high modes responses on the base shear $M_{V}$ ranging from 1.0 (in a case where there is no higher mode effect) to 2.5 in few other cases. As the risk reduction resulting from this factor is exactly the same as that illustrated in Figure 3-16, so more nationwide risk reduction is expected while the national costs remain unchanged.

\subsubsection{Ductility Modification Factor (R)}

The ductility modification factor $(R)$ has not conceptually changed. However, the values of this factor have been updated benefiting from the ductility-related research. In Table 3-3, 23 cases of lateral resisting systems are presented. The corresponding $\mathrm{R}$ values, called force modification factor in the $1995 \mathrm{NBCC}$, range from 1.0 to 4.0 . In the 2005 NBCC, more details have been identified. In Tables 3-4 and 3-5, both ductility and overstrength factors are listed based on structural resisting systems. In the new code, not 
only the range has been extended (1.0-5.0) but also the specified number of cases has been increased by almost eleven more categories.

Table 3-3: Force Modification Factor (1995 NBCC)

\begin{tabular}{|c|c|c|}
\hline Case & Type of Lateral-Force-Resisting System & $R$ \\
\hline 1 & $\begin{array}{l}\text { Steel Structures Designed and Detailed According to CAN/CSA-S16.1-M } \\
\text { ductile moment-resisting frame }\end{array}$ & 4.0 \\
\hline 2 & ductile eccentrically braced trame & 4.0 \\
\hline 3 & ductile steel plate shear wall & 4.0 \\
\hline 4 & ductile braced frame & 3.0 \\
\hline 5 & moment-resisting frame with nominal ductility & 3.0 \\
\hline 6 & nominally ductile steel plate shear wall & 3.0 \\
\hline 7 & braced trame with nominal ductility & 2.0 \\
\hline 8 & ordinary steel plate shear wall & 2.0 \\
\hline 9 & other lateral-force-resisting systems not defined in Cases 1 to 8 & 1.5 \\
\hline & Reintorced Concrete Structures Designed and Detailed According to CSA A23.3 & \\
\hline 10 & ductile moment-resisting frame & 4.0 \\
\hline 11 & ductile coupled wall & 4.0 \\
\hline 12 & other ductile wall systems & 3.5 \\
\hline 13 & moment-resisting frame with nominal ductility & 2.0 \\
\hline 14 & wall with nominal ductility & 2.0 \\
\hline 15 & $\begin{array}{l}\text { other lateral-force-resisting systems not defined in Cases } 10 \text { lo } 14 \\
\text { Timber Structures Designed and Detailed According to CSA O86.1 }\end{array}$ & 1.5 \\
\hline 16 & nailed shear panel with plywood, waterboard or OSB & 3.0 \\
\hline 17 & concentrically braced heavy limber frame with ductile connections & 2.0 \\
\hline 18 & moment-resisting wood frame with ductile connections & 2.0 \\
\hline 19 & other systems not included in Cases 16 to 18 & 1.5 \\
\hline 20 & $\begin{array}{l}\text { Masonry Structures Designed and Detailed According to CSA S304.1 } \\
\text { reintorced masonry wall with nominal ductility }\end{array}$ & 20 \\
\hline 21 & reintorced masonry & 1.5 \\
\hline 22 & unreinforced masonny & 1.0 \\
\hline 23 & Other Lateral-force-resisting Systems not Defined in Cases 1 lo 22 & 1.0 \\
\hline
\end{tabular}


Table 3-4: Ductility Modification Factor, $\mathbf{R}_{\mathbf{d}}$, and Overstrength Factor, $\mathbf{R}_{0}$, (2005 NBCC)

\begin{tabular}{|c|c|c|c|c|c|c|c|}
\hline \multirow{3}{*}{ Type of SFRS } & \multirow{3}{*}{$\mathbf{R}_{\mathbf{d}}$} & \multirow{3}{*}{$R_{0}$} & \multicolumn{5}{|c|}{ Restrictions(2) } \\
\hline & & & \multicolumn{4}{|c|}{ Cases Where $\mathrm{I}_{\mathrm{E}} \mathrm{F}_{\mathrm{a}} \mathrm{S}_{\mathrm{b}}(0.2)$} & \multirow{2}{*}{$\begin{array}{c}\begin{array}{c}\text { Cases } \\
\text { Where }\end{array} \\
I_{E} F_{V} S_{a}(1.0) \\
>0.3\end{array}$} \\
\hline & & & $<0.2$ & $\begin{array}{l}\geq 0.260 \\
<0.35\end{array}$ & $\begin{array}{c}\geq 0.35 \text { to } \\
\leq 0.75\end{array}$ & $>0.75$ & \\
\hline \multicolumn{8}{|c|}{ Steel Structures Designed and Detailed According to CANKCSA-S16 } \\
\hline Ductile moment-resisting trames & 5.0 & 1.5 & NL & $\mathrm{N}$ & $\mathrm{NL}$ & NL & $\mathrm{NL}$ \\
\hline $\begin{array}{l}\text { Moderalely ductile moment-resisting } \\
\text { frames }\end{array}$ & 3.5 & 1.5 & NL & NL & NL. & $N L$ & $\mathrm{NL}$ \\
\hline $\begin{array}{l}\text { Limited ducti泣y moment-resisting } \\
\text { trames }\end{array}$ & 20 & 1.3 & NL & NL & 60 & $30 \quad \because$ & 30 \\
\hline \multicolumn{8}{|l|}{$\begin{array}{l}\text { Moderately ductile concentrically } \\
\text { braced frames }\end{array}$} \\
\hline Non-chevion braces . & 3.0 & 1.3 & NL & M & 40 & 40 & 40 \\
\hline Chevron braces & 3.0 & 1.3 & NL & M & 40 & 40 & 40 \\
\hline Tension only braces & 3.0 & 1.3 & NL & ML & 20 & 20 & 20 \\
\hline \multicolumn{8}{|l|}{$\begin{array}{l}\text { Limited ductility concentrically braced } \\
\text { frames }\end{array}$} \\
\hline Non-chevron braces & 2.0 & 1.3 & NL & NL & 60 & 60 & 60 \\
\hline Cherron braces & 2.0 & 1.3 & NL & NL & 60 & 60 & 60 \\
\hline Tension only braces & 2.0 & 1.3 & $\mathbf{N L}$ & NL. & 40 & 40 & 40 \\
\hline Ductile eccentricaly braced frames & 4.0 & 1.5 & NL & NL & NL & NL & $\mathbf{N L}$ \\
\hline Ductile trame plate shear walls & 5.0 & 1.6 & NL & NL & NL & NL & $\mathrm{NL}$ \\
\hline Moderately ductile plate shear walls & 2.0 & 1.5 & $\mathbf{M L}$ & $\mathbf{M}$. & 60 & 60 & 60 \\
\hline $\begin{array}{l}\text { Conventional construction of moment } \\
\text { frames, braced frames or shear walls }\end{array}$ & 1.5 & 1.3 & $\mathbf{N L}$ & $\mathbf{N} \mathbf{L}$ & 15 & 15 & 15 \\
\hline $\begin{array}{l}\text { Other steel SFRS(s) not defined } \\
\text { above }\end{array}$ & 1.0 & 1.0 & 15 & 15 & NP & NP & NP \\
\hline \multicolumn{8}{|c|}{ Concrete Structures Designed and Detalled According to CSA A23.3 } \\
\hline Ductile moment-resisting frames & 4.0 & 1.7 & $\mathbf{M L}$ & NL & $\mathbf{N L}$ & NL & NL \\
\hline $\begin{array}{l}\text { Moderately ductile moment-resisting } \\
\text { frames. }\end{array}$ & 2.5 & 1.4 & NL & ML & 60 & 40 & 40 \\
\hline Ductile coupled walls & 4.0 & 1.7 & NL & NL. & NL & NL & NL \\
\hline Ductile partially coupled wals & 3.5 & 1.7 & N & ML & NL & NL & NL \\
\hline Ductile shear walls & 3.5 & 1.6 & NL & NL & ML & NL & $\mathrm{NL}$ \\
\hline Moderately ductile shear walls & 2.0 & 1.4 & NL & NL & NL & 60 & 60 \\
\hline Conventional construction & & & & & & & \\
\hline Moment-resisting frames & 1.5 & 1.3 & $\mathbf{N}$ & NL & 15 & $\mathbf{N P}$ & NP \\
\hline
\end{tabular}


Table 3-5: Ductility Modification Factor, $R_{d}$, and Overstrength Factor, $R_{0}$, (2005 NBCC)

\begin{tabular}{|c|c|c|c|c|c|c|c|}
\hline \multirow{3}{*}{ Type of SFRS } & \multirow{3}{*}{$\mathbf{R}_{\mathbf{d}}$} & \multirow{3}{*}{$\mathbf{R}_{0}$} & \multicolumn{5}{|c|}{ Restrictions(2) } \\
\hline & & & \multicolumn{4}{|c|}{ Cases Where $\mathrm{EF}_{\mathrm{g}} \mathrm{S}_{\mathrm{I}}(0.2)$} & \multirow{2}{*}{ 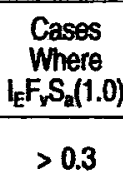 } \\
\hline & & & $<0.2$ & $\begin{array}{l}\geq 0.2 \text { to } \\
<0.35\end{array}$ & $\begin{array}{l}\geq 0.35 \text { to } \\
\leq 0.75\end{array}$ & $>0.75$ & \\
\hline Shear walls & 1.5 & 1.3 & ML & NL & 40 & 30 & 30 \\
\hline $\begin{array}{l}\text { Other concrete SFRS(s) not listed } \\
\text { above }\end{array}$ & 1.0 & 1.0 & 15 & 15 & NP & NP & NP \\
\hline \multicolumn{8}{|c|}{ Timber Structures Designed and Detalied According to CANCSA-086 } \\
\hline \multicolumn{8}{|l|}{ Shear walls } \\
\hline $\begin{array}{l}\text { Nailed shear walls: wood based } \\
\text { panel }\end{array}$ & 3.0 & 1.7 & NL & NL & 30 & 20 & 20 \\
\hline $\begin{array}{l}\text { Shear walls: woodbased and } \\
\text { gypsum panels in combination }\end{array}$ & 2.0 & 1.7 & NL & NL & 20 & 20 . & 20 \\
\hline \multicolumn{8}{|l|}{$\begin{array}{l}\text { Braced or moment-resisting frames } \\
\text { with ductile connections }\end{array}$} \\
\hline Moderately ductile & 2.0 & 1.5 & NL & NL & 20 & 20 & 20 \\
\hline Limited ductitity & 1.5 & 1.5 & NL & NL & 15 & 15 & 15 \\
\hline $\begin{array}{l}\text { Other wood- or gypsum-based } \\
\text { SFRS(s) not listed above }\end{array}$ & 1.0 & 1.0 & 15 & 15 & $\mathbf{N P}$ & NP & NP \\
\hline \multicolumn{8}{|c|}{ Masonry Structures Designed and Detaled Acconding to CSA S304.1 } \\
\hline Moderately ductile shear walls & 2.0 & 1.5 & NL & NL & 60 & 40 & 40 \\
\hline Limited ductility shear walls & 1.5 & 1.5 & NL. & NL & 40 & 30 & 30 \\
\hline \multicolumn{8}{|l|}{ Conventional construction } \\
\hline Shear walls & 1.5 & 1.5 & ML & 60 & 30 & 15 & 15 \\
\hline Moment-resisting frames & 1.5 & 1.5 & NL & 30 & NP & NP & NP \\
\hline Unreinforced masonry & 1.0 & 1.0 & 30 & 15 & NP & NP & NP \\
\hline $\begin{array}{l}\text { Other masonry SFRS(s) not listed } \\
\text { above }\end{array}$ & 1.0 & 1.0 & 15 & NP & NP & NP & NP \\
\hline
\end{tabular}

\subsubsection{Calibration Factor $\mathbf{U}$}

The Calibration factor first introduced in the 1995 NBCC was not included in the 2005 NBCC provisions. Unlike other factors in the 1995 NBCC seismic provisions, calibration factor value (0.6) was set based mainly on experience. 


\subsubsection{Overstrength Factor $\mathbf{R}_{\mathbf{O}}$}

The overstrength factor accounts for the tendency of structures designed according to specific standards like CSA S304.I to reserve strength beyond the design strength. This factor is totally new, and was introduced to match other changes in the seismic provisions. The overstrength factor is most likely the only factor from the new base shear equation that is developed to match the seismological developments especially the concept of $2 \%$ in 50 years. The $2 \%$ in 50 years event which is a rare event of ultimate performance or near-collapse event will be achieved under extreme load effects (Mitchell et al. 2003). The following explains the rationale for the need of this factor.

In the working stress design approach (WSDA), all types of uncertainties are covered by a single safety factor Fs defined as the ratio of the resistance to the design force. What would happen if the applied force exceeds the design force? The answer is nothing for as long as the applied force does not exceed the resistance. When the applied force is somewhere between the design force and resistance, the system is still stable, and this is understood as the overstrength being operative.

Within a country, the design of an engineering system will follow the same standard specifications like CSA for Wood in Canada, so the resistance distribution function which depends on analysis methods, environmental factors, construction techniques, and material properties, will be identical nationwide. Seismic forces, however, will not have the same distribution function nationwide as illustrated earlier in Figures 3-9, 3-10, and 3-11. The new concept of performance level from the 2005 NBCC seismic provisions suggests a uniform performance throughout the country. An example 
is described in Figure 3-17 to illustrate the idea that the change of the seismic force reference from 475-year return period to 2500 -year return period has kept the failure probability largely unchanged.

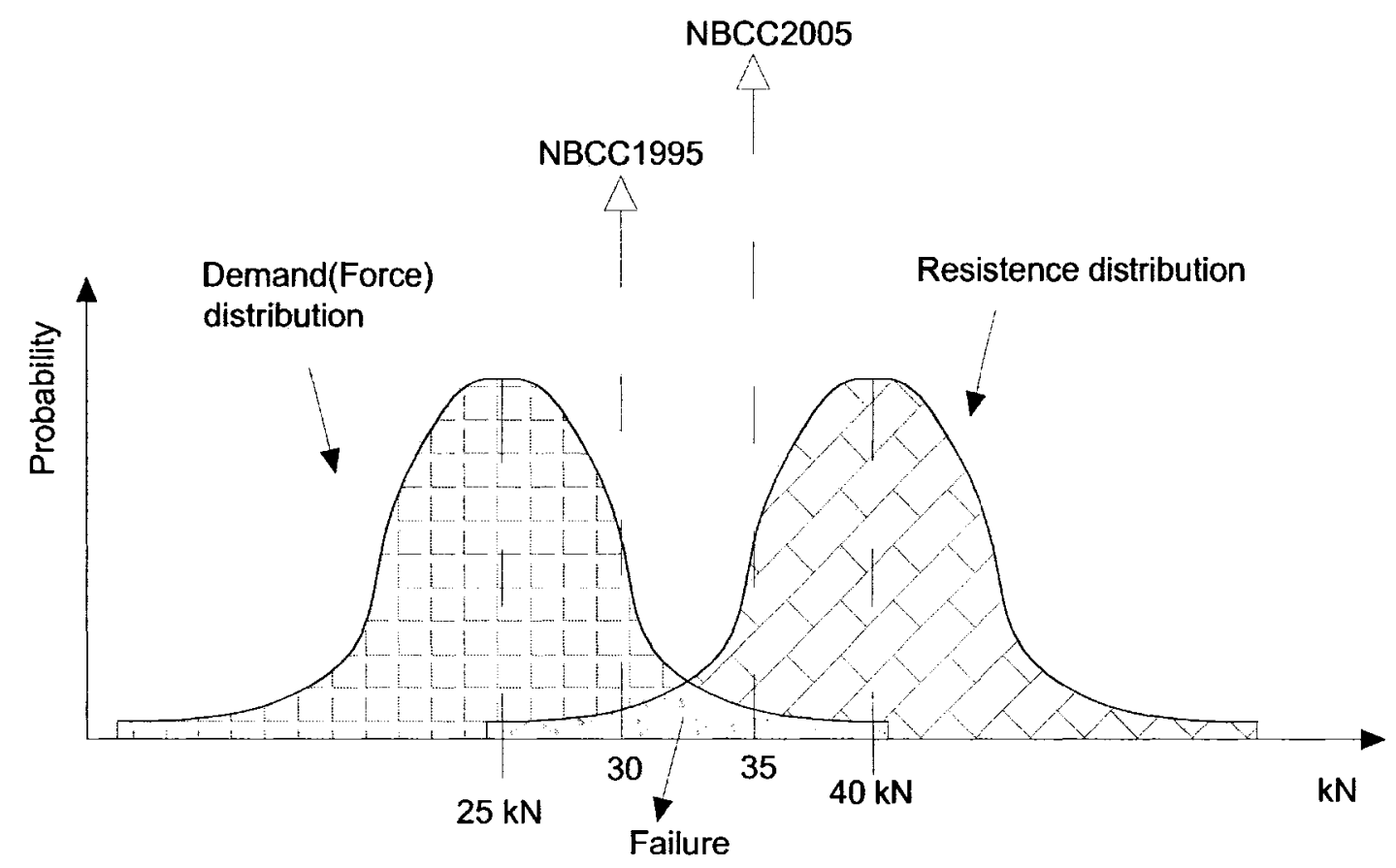

Figure 3-17: "Two reference levels but the same failure probabilities in the two codes"

The design procedure of the $1995 \mathrm{NBCC}$ is first to obtain the seismic force (demand) at $10 \%$ in 50 year level (say, $30 \mathrm{kN}$ in Figure 3-17), and second to design the section or the column to take that force based on an appropriate design standard. This design will require a factored resistance equal to $30 \mathrm{kN}$ (which is translated to a mean resistance of $40 \mathrm{kN}$ ). On other hand, the new procedure of the $2005 \mathrm{NBCC}$ is to obtain the seismic force (performance force) at $2 \%$ in 50 years level (say, $35 \mathrm{kN}$ ), then to lower it back to the design level (about $30 \mathrm{kN}$ ) by a factor called overstrength factor. Finally the section or the column is designed based on the same design standard. Hence, we are 
designing for more or less the same force in the new code (2005 NBCC) as in the old code (1995 NBCC). Thus, the probability of failure remains largely unchanged. This new procedure may have no effect on a particular system, but it will uniformly match the performances to a $2 \%$ in 50 years probability of exceedance. In Chapter 6 , the overstrength factor will be discussed and numerically incorporated it in the retaining walls seismic design.

\subsubsection{Dynamic Analysis Enforcement}

The new code encourages more dependency on structural dynamics analyses rather than equivalent static approach (base shear). It may appear that the code makers are finally satisfied with the sciences behind Dynamic Analysis Procedures. This seemed to be another benefit from the ongoing research around the world.

\subsection{Safety Level Summary and Conclusion}

Indeed, it is almost impossible to explicitly estimate the safety level associated with seismic design because of its complex nature and the uncertainty involved. However, for certain degree of credibility, it might be possible to estimate the change in safety level, but not the total safety level. This nature of variable is common in physics and applied sciences like thermodynamics where it is very hard to measure an energy stored in a thermodynamic system, but it is relatively easier to measure the change in that energy.

In the $2005 \mathrm{NBCC}$, several improvements have been added to the safety level. Most of these improvements have not involved increases in the nationwide design costs, 
but they however, redistributed the resistance between the design categories so the nationwide cost remains relatively unchanged.

There are two types of safety gains: a unit gain for an individual category and an average safety gain which uniformly increases or decreases the safety level for all categories. Unit safety gain will increase safety level of a category like Site Class B that possesses the minimum safety unit or the high risk. On the other hand, the average safety gain is related to all units for one particular factor like the benefits from introducing the overstrength factor. This factor will uniformly decrease the nationwide safety level. Furthermore, any increase of average safety level will most likely be associated with an increase of the nationwide design costs.

\subsubsection{Unit Safety Gains}

Unit safety gain will shift the resistance from one category to another, while keeping the average resistances (sum of nationwide costs) unchanged. The benefit of this shift is to reduce the risk associated in the lower safety level unit, and to increase the risk of the conservative unit; the nationwide costs will not change significantly. These improvements will be achieved mainly based on both research and practical experience. Some of the previous seismological, geotechnical, and structural developments might be classified in unit type of safety improvements as follows:

1. The effects of structure frequency on foundation factor as discussed in Section 3.2.2 have rearranged the safety level to have more uniform shape distribution. 2. Higher mode effect Mv. 
3. Importance factor I.

4. Ductility $R_{d}$

Table 3-6 outlines most of the identified improvements, their impacts on nationwide cost, and the expected main cause of the improvement.

\subsubsection{Average Safety Gain Improvements}

These improvements will simply uniformly increase or decrease the safety level for all sub units or classes. The nationwide costs may increase or decrease as these factors change.

1. The new seismological models discussed in Section 3.1.1 will greatly increase the safety level for all structures in all regions. This can be attributed to research in seismological sciences.

2. Similarly, the earthquake data incorporated in the new seismological models.

3. The use of uniform hazard spectra UHS as a reference but not two ground motion peaks (velocity and acceleration).

4. The change of probability of exceedance from $10 \%$ in 50 years to $2 \%$ in 50 years has significantly increased the safety level and the nationwide costs by at least 2 times.

5. The change of site class reference from soil type $\mathrm{A}$ to $\mathrm{C}$ has most likely dropped the safety level and the nationwide costs by a moderate level. 
6. Although the initial value of calibration factor at $1995 \mathrm{NBCC}$, i.e., 0.6 is set based on experience, the ignorance of this factor in $2005 \mathrm{NBCC}$ may unnecessarily raise the safety level and the nationwide costs.

7. Overstrength factor set to match the change in probability of exceedance level should theoretically decrease semi-uniformly the costs and safety level.

Table 3-6 addresses the improvements discussed in Section 3.4, and their impact on nationwide cost, and also suggests the main cause of those improvements.

Table 3-6: Unit and Average safety gains and their initiatives

\begin{tabular}{|c|c|c|c|c|}
\hline & Average Safety & $\begin{array}{l}\text { Minimum } \\
\text { safety unit }\end{array}$ & $\begin{array}{c}\text { Nationwide } \\
\text { cost }\end{array}$ & Source \\
\hline New Seismicity model & Increase & & $\begin{array}{c}\text { About the } \\
\text { same }\end{array}$ & Research \\
\hline More E.Q. Data & Increase & & $"$ & Research \\
\hline UHS & Increase & & $"$ & Research \\
\hline $2 \%$ not $10 \% / 50$ years & Increase & Increase & $\approx 2$ times $\uparrow$ & Non-research \\
\hline Site class $\mathrm{C}$ & Decrease & Decrease & Slightly low $\downarrow$ & Non-research \\
\hline $\begin{array}{l}\text { Frequency based } \\
\text { Foundation Factor }\end{array}$ & Non & Increase & $\begin{array}{c}\text { About the } \\
\text { same }\end{array}$ & Research \\
\hline Higher mode Mv & Little increase & Increase & " & Research \\
\hline Importance factor I & Little decrease & Non & $"$ & Research \\
\hline Ductility & Little decrease & Non & $"$ & Research \\
\hline Calibration factor & Increase & Increase & $"$ & Non-research \\
\hline Overstrength factor & Decrease & Decrease & $\approx 0.5$ times & Non-research \\
\hline
\end{tabular}




\subsubsection{The Result of the Safety Level Change}

First of all, the nationwide costs associated with research-based changes have not practically changed, but the non-research-based changes have led to first, an increase in nationwide costs ( $2 \% / 50$ years), second, a decrease due to the overstrength factor, and third, an increase due to calibration factor, i.e., not explicitly discussed anywhere in the literature. The outcome of the $1^{\text {st }}$ and $2^{\text {nd }}$ changes would theoretically cancel each other out. On the other hand, the introduction of the new factor and new ground motions do bring some changes from some cases as noted by Heidebrecht (2003) on the base shear coefficient which will be illustrated in the next chapter. 


\section{Chapter 4 Seismic Design of Retaining Walls in Accordance with 2005 NBCC}

A gravity retaining wall (Figure 4-1) relies on its own weight for stability. It is commonly constructed of plain concrete or stone masonry. The design of retaining wall is covered in text books and manuals such as the Canadian Foundation Engineering Manual as discussed earlier in Section 2.3.9.

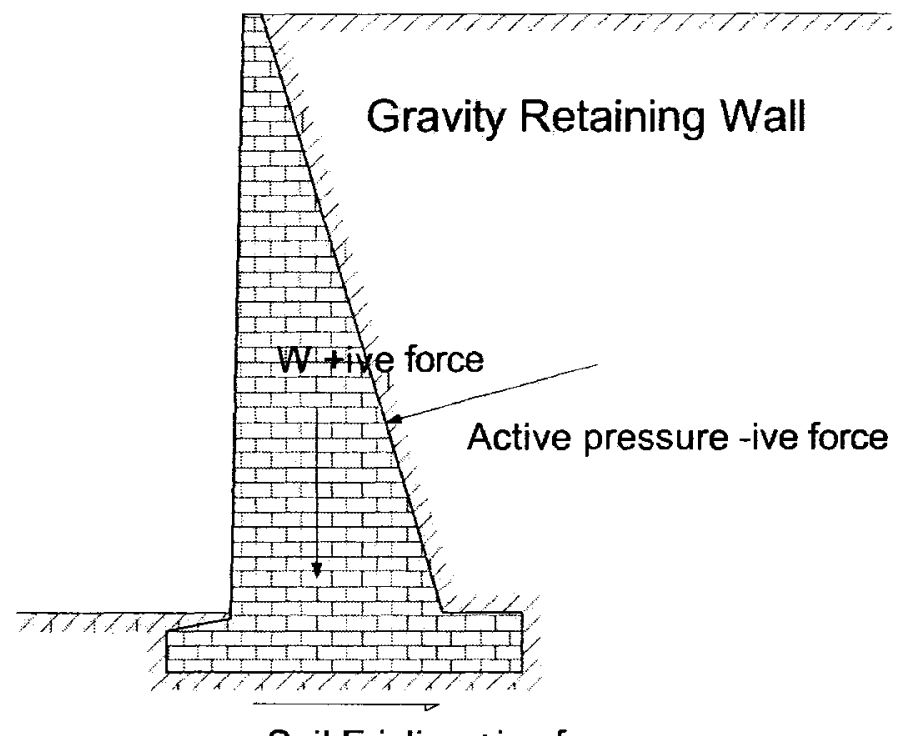

Soil Friction +ive force

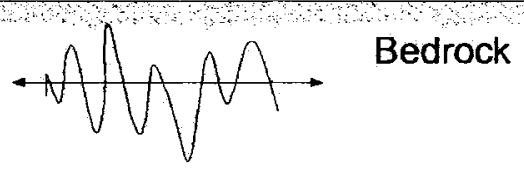

Figure 4-1: Simple shape of a gravity wall

\subsection{Seismic Design Parameters}

Several design methods are available in the literature for the design of retaining walls under seismic condition; some of these methods were discussed in Chapter 2. The 
yielding walls, which by design, permit movements to develop active or passive pressures, and have been studied by Mononobe and Okabe (1920's), Richards and Elms (1979), Whitman and Liao (1985), and Steedman and Zeng (1990). The non-yielding walls (Wood 1973) have different design approaches. Both methods employ almost similar parameters to estimate the seismic portion of the soil thrust. The main seismic design parameters are discussed in the following sections:

\subsubsection{Peak Ground Acceleration}

The early seismic design methods relate the seismic force to the peak ground acceleration (PGA) and/or peak ground velocity (PGV). The pseudo-static acceleration coefficients ( $a_{h}$ and $a_{v}$ for horizontal and vertical components, respectively) used in Mononobe and Okabe (M-O) method are functions of PGA. This method differs from the real situation in which the instantaneous inertia forces generated by the ground shaking is related to the instantaneous ground acceleration, but the direction of the inertia forces would quickly reverse as the ground motion changes its direction. Thus, the M-O method suffers from some problems in estimating the resultant response by only simulating the inertia forces. Lessons from post-earthquake analyses on surviving structures should be very useful for seismic design.

The maximum horizontal acceleration is also commonly referred to as the peak ground acceleration in the pseudo-static method. However, other design procedures do not include the direct use of PGA, instead, a function of it (like one third of the PGA according to Marcuson 1981). Richard and Elms (1979) method quoted by Kramer 
(1996), proposed that $a_{y}$ should be obtained from the allowable permanent block displacement $\left(d_{p e r m}\right)$ as follows:

$$
d_{\text {perm }}=0.087 \frac{v_{\max }^{2} \cdot a_{\max }^{3}}{a_{y}^{4}}
$$

where $v_{\max }$ and $a_{\max }$ are the PGV and PGA, respectively.

Furthermore, liquefaction occurrence, i.e., one of the main challenges in the geotechnical seismic design, is also dependent on the PGA. For instance, the stress method for analyzing liquefaction potential uses the Cyclic Stress Ratio (CSR) which is a function of PGA.

\subsubsection{Peak Ground Velocity}

Similarly, the PGV has been used as one of the main parameters to evaluate the seismic forces especially for long-period structures. In soil, however, PGV has relatively less effect on seismic thrust level compared to PGA. Design approaches have hardly adopted the PGV as a parameter for design.

\subsubsection{Tolerable Displacement}

During an earthquake, a retaining wall may slide away from the supported fill if the excitation exceeds a certain level. Depending on the wall location, the tolerable displacement may play a key role in the wall design. The higher the accepted tolerable displacement, the lower is the design force. 


\subsection{Limitation of the PGA to Quantify Ground Motions}

PGA is a poor parameter to quantify a ground motion (Adams 2006). Away from the highest peak, several other characteristics could also affect the wall's response during earthquakes. Analyses discussed in Chapter 2 indicate that other factors will also affect the dynamic response. The damping mechanism which represents the amount and type of energy loss during vibration, would limit the vibration response from infinite oscillations. The characteristics of other peaks in the time history would also affect the overall response. Figure 4.2 illustrates a typical time history record. The PGA recorded at $12^{\text {th }}$ second as shown in the time history is $(-0.18 \mathrm{~g})$. For retaining wall stability, this peak could generate inertial force with the direction of the positive force, but the other peak $(+0.13 \mathrm{~g})$ is the one in the negative direction of stability. There will be $38 \%$ increase of design requirements if the PGA (.18g) is used in this design.

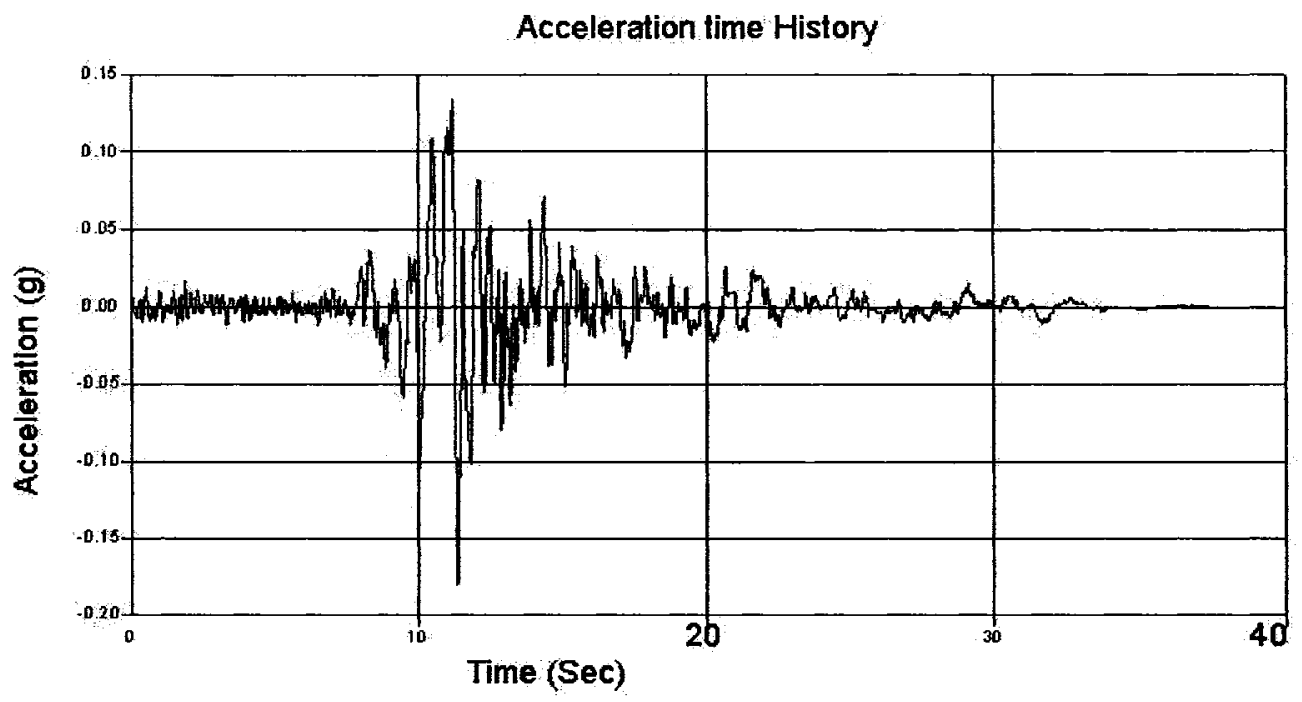

Figure 4-2: An acceleration time history $(\mathrm{PHA}=\mathbf{- 0 . 1 8 g})$ 
In Chapter 5, a new factor will be introduced to quantify the earthquake time history in one simple parameter. This factor is called average peak ground acceleration (APGA). A complete set of study is carried out to estimate the quality of the new parameter. The first part of the study is to quantify the uncertainty of the seismic nonlinear responses of a given soil profile using PGA to normalize several ground motion time histories. In the other part of the study, the parameter APGA was used to quantify the time histories. The selection of the criterion for this new parameter is very simple: first filter out the low peaks that fall within a certain threshold range as illustrated in Figure 4-3 and second, consider the top percentiles (like top 10\%) of the remaining peaks.

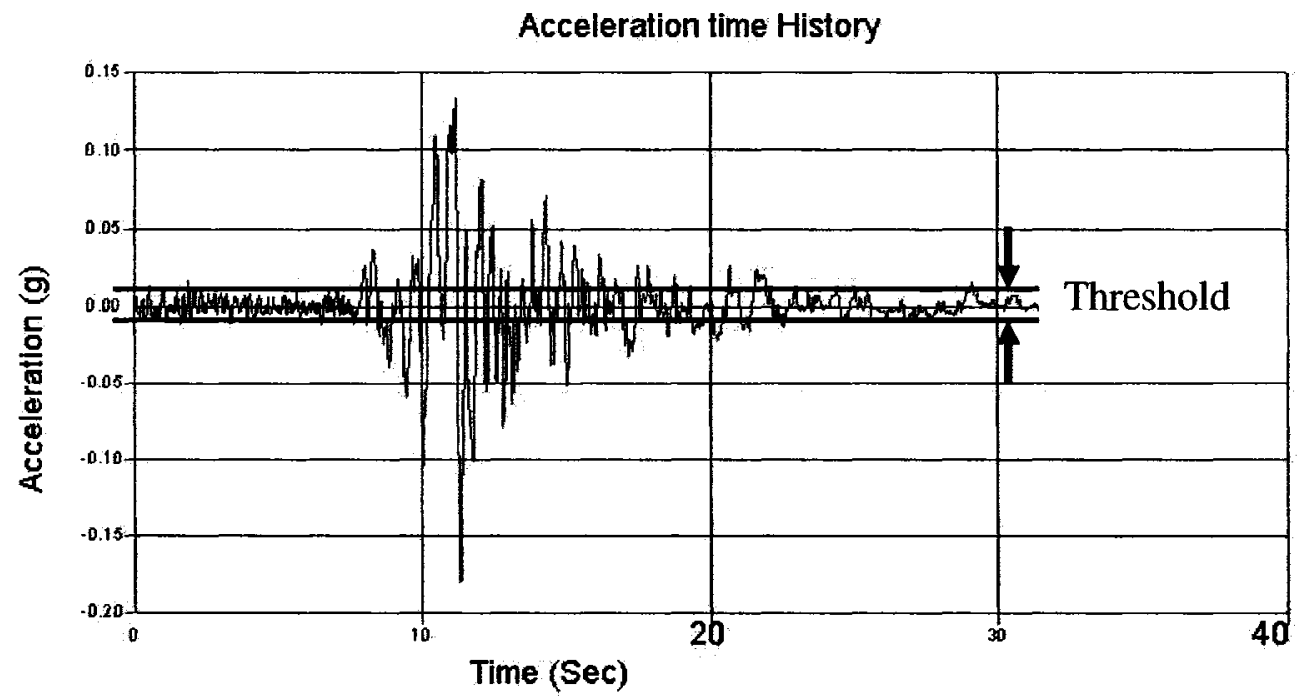

Figure 4-3: Filtering Technique

A comprehensive explanation of this technique is discussed in Chapter 5. EduShake (2002) was used for this analysis and six different ground motions were used for comparison. Finally, the new parameter (APGA) is shown a potential advantage over 
PGA in quantifying the ground motion time history as a single parameter. The consistency in the resultant nonlinear-responses has changed by $25 \%$.

\subsection{The Expected New Seismic Developments of Geotechnical Designs}

Geotechnical design is an essential part of engineering design and forms the base platform of most projects. For this reason, geotechnical design has to be consistent with other designs. In addition, the safety factors associated with geotechnical design should match those of other designs. As previously discussed, it is difficult to estimate the safety levels of geotechnical projects. However, it is relatively easy to estimate the safety level changes. The recent changes of seismic provisions in structural design will have an impact not only on geotechnical design but also on the design philosophy as well. The two main interrelated changes are both the rise of return period from 475 years to 2500 years and the overstrength reduction factor to reduce the extra unnecessary strength created in the design system. The main changes that may affect the geotechnical design are as given in the following:

\subsubsection{The Reduction of Hazard Level to $2 \%$ in 50 years}

The peak ground acceleration is one of the seismic hazard parameters. The lower the design hazard, the higher is the expected PGA. In seismic design of retaining walls, PGA is the key design parameters. Based on Table 3-2, there is a drastic increase of PGA for different Canadian cities in the new design procedure. Therefore, the cost of retaining wall increases due to the PGA increase. 


\subsubsection{Seismological Developments}

Some of the new developments, i.e., new seismicity model and more ground motion data incorporated in the seismic provisions of $2005 \mathrm{NBCC}$, will have the same contribution to the safety level of geotechnical designs as that for structural designs.

\subsubsection{Overstrength}

The overstrength factor is a rational consequence of the new change of hazard level. This factor is dependent on the expected performance of a system. The resistance system of a retaining wall may have many overstrength factors inherent in the materials, the design models, and the correlation equation. Because these factors are very important to evaluate the changes in the new code, they will be discussed in greater detail in the following sections.

Table 4-1 outlines the developments that have been incorporated in the 2005 NBCC seismic provisions and are applicable to the design of retaining wall.

Table 4-1: Applicable new developments on retaining wall design

\begin{tabular}{|c|c|c|c|c|}
\hline Development & Average Safety & Safety unit & Nationwide cost & $\begin{array}{c}\text { Development } \\
\text { Source }\end{array}$ \\
\hline New seismicity model & Increase & & About the same & Research \\
\hline More earthquake data & Increase & & About the same & Research \\
\hline Hazard Spectrum & Increase & & About the same & Research \\
\hline $2 \%$ not $10 \% / 50$ years & Increase & Increase & $\sim 2$ times & Non-research \\
\hline Overstrength factor & Decrease & Decrease & $\sim 0.5$ times & Non-research \\
\hline
\end{tabular}


Table 4-1 demonstrates similarities associated in the design between buildings and retaining walls. There are, however, two main interrelated developments that would influence the design of retaining walls. First, there is a decrease in probability level. Second, there is the overstrength factor. In the next section, the possible overstrength in the design system of retaining walls will be discussed.

\subsection{Overstrength}

The reason for the overstrength in seismic designs is that the design of a seismic resistant system is conducted at seismicity level lower than the performance level, i.e., uniform nationwide in the structural design. Therefore, the overstrength factor associated with PGA should be reflected by the average of all nationwide increases in the PGA.

\subsubsection{Overstrength in Structural Systems}

Just like all resistant systems, for various reasons, the structural design controlled by specific standards like CSA-S16-01 will have an amount of overstrength in its elements. The Canadian National Committee on Earthquake Engineering (CANCEE) has introduced the following factors that will cause overstrength in structural systems:

$$
R_{o}=R_{\text {size }} R_{\phi} R_{\text {gield }} R_{\text {sh }} R_{\text {rech }}
$$

Each one of these factor will contribute a portion to the overstrength. In the following section, these factors and the rationales behind them will be discussed. 


\subsubsection{Rsize (Size effect)}

The actual sizes of the all structural elements are more likely to be larger than the calculated sizes (the sections will be thicker, and the spans will be shorter). This provides the resisting system with extra strength which will not be used under design loads. To account for this component of overstrength, it needs a wide statistical study on how construction is taking place for seismic resisting systems. Typically, structural sections will be selected next to the higher standard product available from the manufacturer. For typical structural shapes (columns), a survey indicated a value of 1.05 is applicable, and for plate walls, a value of 1.1 has been chosen (Mitchell et al. 2003).

\subsubsection{2. $\mathrm{R}_{\varphi}$ (Nominal vs factored)}

$R_{\varphi}$ is the ratio between the nominal and factored resistances. Generally, the nominal strength is larger than the factored strength. A resistance reduction factor represents this difference. Because the new criterion in the code is to assign $2 \%$ exceedance in 50 years to the near collapse condition, we are more likely to use the nominal resistance rather than the factored resistance. Thus, $R_{\varphi}$ is simply taken as $1 / \varphi$ which equals to $1 / 0.9=1.10$ for steel and 1.18 for concrete (Mitchell et al. 2003).

\subsubsection{3. $\mathrm{R}_{\text {yield }}$ (Yield effect)}

This factor accounts for the fact that the minimum specified strength controlled by the material specifications is evaluated below the actual strength achieved by manufacturers (Mitchell et al. 2003). A value of 1.10 for steel has been assigned for $R_{\text {yield }}$ in W shapes steel sections as determined by Schmidt and Bartlett (2002). 


\subsubsection{4. $\mathrm{R}_{\mathrm{sh}}$ (Strength reserved in hardening process)}

$\mathrm{R}_{\mathrm{sh}}$ is from the strain hardening effects. The strain hardening is a phenomenon that happens when the strength continues to increase beyond yielding. For extreme seismic event leading to failure, strain hardening will increase the reserved strength. Figure 4-4 illustrates the relationships between strength and strain in both hardening and softening mechanisms.

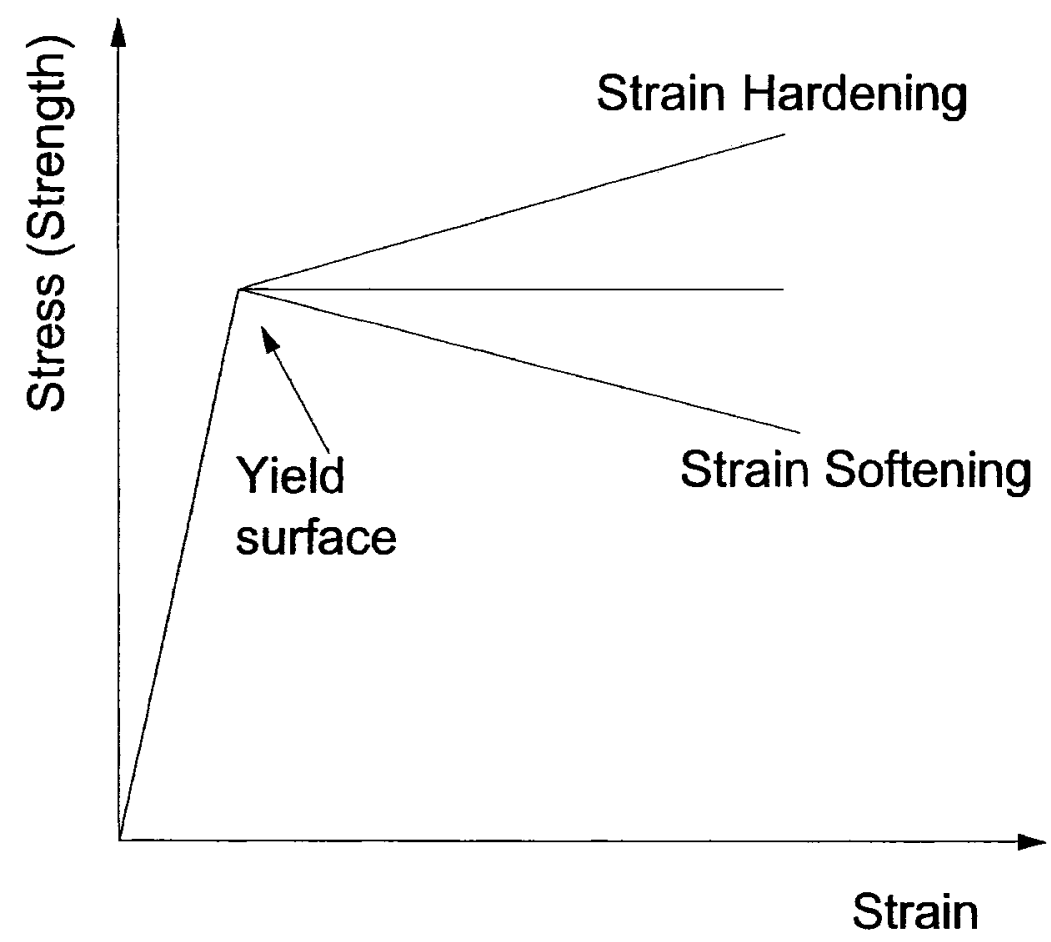

Figure 4-4: $1 D$ Yield surface and post yield strength

In structural resistant systems, $R_{\mathrm{sh}}$ ranges from 1.3 for eccentrically braced frames to 1.05 in frames with limited ductility. 


\subsubsection{5. $\mathrm{R}_{\text {mech }}$ (Failure Mechanism)}

In structural systems, the failure will occur only if sufficient plastic hinges have developed so that the system loses its stability. The failure will occur on a sequence basis; one plastic hinge occurs after the other until the structure collapses. Therefore, the $R_{\text {mech }}$ factor is introduced to account for the sequence failure mechanisms in structural systems (Mitchell et al. 2003).

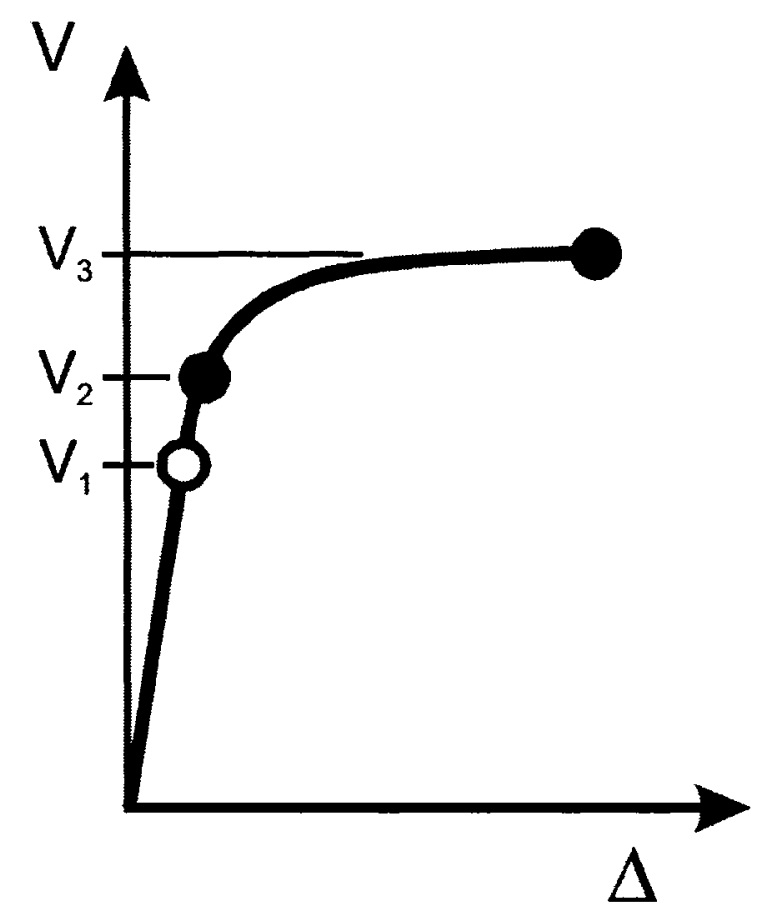

Figure 4-5: Strength levels (from Mitchell et al. 2003)

In Figure 4-5, $V_{l}$ represents the factored resistance, $V_{2}$ represents the specified yield resistance, and finally $V_{3}$ is the collapse resistance. This figure illustrates the rationale for introducing the overstrength factors. 
Although the values of the overstrength factors have been precisely determined in the code, their values have been based on judgment and experience.

\subsubsection{Overstrength in Geotechnical Design}

Similar to structural resistant systems, geotechnical design systems will possess an extra strength reserved in their design approaches. The safety factors in geotechnical designs are generally higher than that in structural designs because of the large uncertainties about the strength in soil. Other factors like correlation equations will contribute also to the overstrength, and these factors are not applicable in the structural resistant systems.

\subsubsection{Overstrength in Gravity Retaining Wall Design}

Because the main scope of this study is the gravity wall design in accordance with the 2005 NBCC provisions, the overstrength in gravity retaining walls resistant systems will be comprehensively evaluated. Design of gravity retaining walls has some similarity with the structural design because of their structural body. In the following, the main sources of overstrength in retaining walls are discussed.

\subsubsection{1. $\mathrm{R}_{\text {Size }}$}

Actual dimensions of a retaining wall are more likely to be larger than the calculated dimensions (the sections will be thicker) due to the tolerable allowances in construction. This provides the resisting system with more strength which forms more 
reserve strength, but because the gravity walls are thicker than the columns, the impact on the strength will be lower than that for columns.

On the other hand, this allowance will depend on the unit system. The practical rounding off the dimension section unit is one inch in the American system and $5 \mathrm{~cm}$ in the Canadian system (Metric, SI), so larger sizes may be used for using the SI system. Sometimes, the design is performed in metric tolerable allowances, and then an extra allowance may be added during construction if the contractor calibrates the units to inches.

Another factor which will increase the size effect is the design procedure. Most procedures will follow a standard shape of gravity walls with normalized geometries, and then check the various failure criteria. Figure 4-6 illustrates a standard shape for gravity walls which will arbitrarily increase the geometries. 


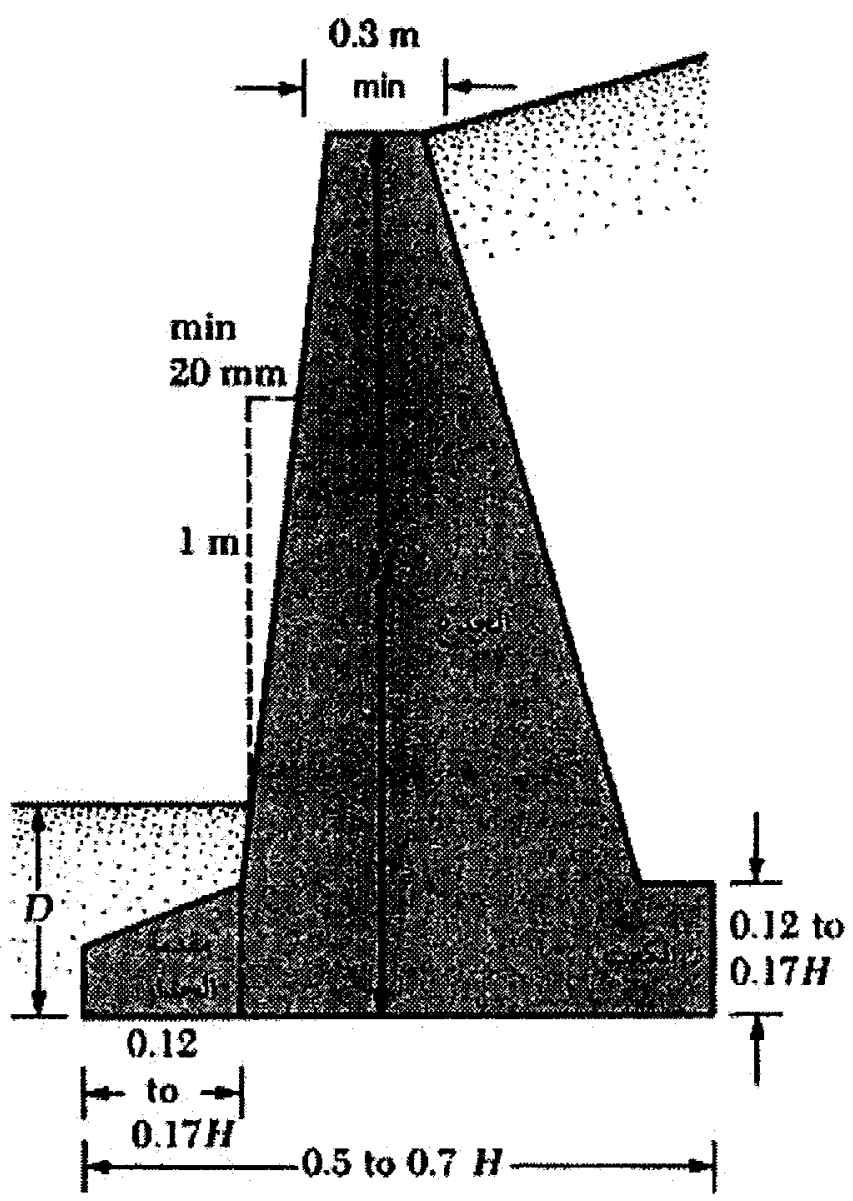

Figure 4-6: Standard geometries of a retaining wall (after Kaadan 2001)

In addition, the flexural resistance of a structural section will be proportional to the square of the effective depth $d\left(d^{2}\right)$, but the shear strength will be proportional to $d$. Thickness in gravity walls will linearly increase the weight of the walls. Thus, the friction resistance force under the wall will be proportional to the thickness, but the overturning resistance moment will be proportional to the square of the thickness. Similarly, the flexural resistance in structural design is also proportional to the square of the thickness (d) as follows:

Capacity moment (resistance) equals to $C *(d-a / 2)$ where $C$ is defined in Figure 4-7. 
Figure 4-7 illustrates the flexural resistance diagram:

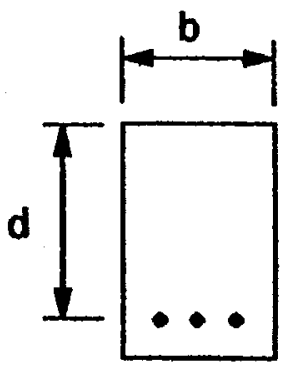

(a) Cross Section

0.0035

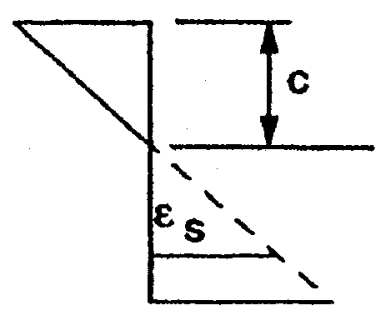

(c) Strains

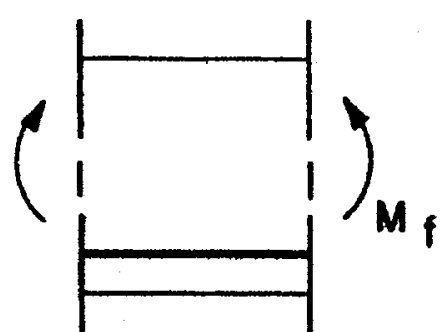

(b) Elevation View

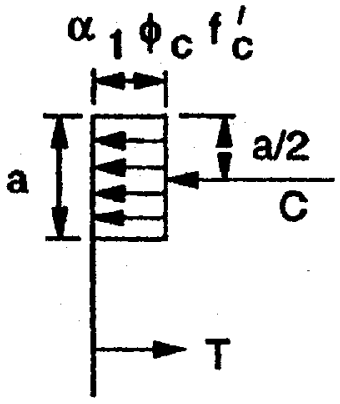

(e) Equivalent

Stresses

$$
\begin{aligned}
& a=\beta_{1} c \\
& T=\phi_{s} A_{s} f_{y} \\
& c=\alpha_{1} \phi_{c} f_{c}^{\prime} a b
\end{aligned}
$$

Figure 4-7: Flexure Resistance, Concrete Design CSA Standard A23.3 (1994)

These facts will contribute further to the size factor. To count precisely for this factor, it needs a wide statistical study on how construction is taking place for gravity retaining walls. For initial considerations, $R_{\text {Size }}$ may take a reasonable value of 1.05 for gravity walls and 1.09 for cantilever retaining walls. Therefore, it is important to indicate this component of the overstrength is a best estimate. 


\subsubsection{2. $\mathrm{R}_{\varphi}$}

$R_{\varphi}$ is used essentially to account for the uncertainty in soil strength parameters, friction angle and cohesion. The uncertainty arises from environmental and seismological factors controlling the formation of the soil. The uncertainty is displayed in the heterogeneous nature of the soil and the presences of fissures and planes of weakness.

In conventional geotechnical approach (Working Stress Design, WSD), the uncertainty is taken care of by means of a safety factor. However, there is an increasing trend utilizing the limit state design (LSD) such as described in the Canadian Foundation Engineering Manual and in the EuroCode, or by researchers such as Becker (1996). Table 4-2 lists the resistance and the load factors from some design manuals around the world.

Table 4-2: "Resistance and load factors" (Taken from Canadian Foundation Manual 1993; Allen 1975; Becker 1996; Meyerhof 1993, 1995; Brinch Hansen 1953, 1956)

\begin{tabular}{|c|c|c|c|}
\hline Strength and Load & $\begin{array}{c}\text { Canadian } \\
\text { Foundation Manual }\end{array}$ & $\begin{array}{c}\text { Eurocode 7 } \\
(\text { CEN 1992) }\end{array}$ & $\begin{array}{c}\text { Denmark } \\
1965)\end{array}$ \\
\hline $\begin{array}{c}\text { Cohesion (earth pressure) } \\
\mathrm{f}_{\mathrm{c}}\end{array}$ & $1.54(=1 / 0.65)$ & $1.4-1.6$ & 1.5 \\
\hline Friction $(\tan \varphi) \mathrm{f}_{\varphi}$ & $1.25(=1 / 0.8)$ & 1.25 & 1.25 \\
\hline \hline Dead load & 1.25 & $1.1(0.9)$ & 1.0 \\
\hline Live load & 1.5 & $1.5(0)$ & 1.5 \\
\hline Water pressure & 1.25 & $1.0(0)$ & 1.0 \\
\hline
\end{tabular}

On the other hand, the WSD approach incorporates the overall safety factors of earth retaining structures in a single safety factor. Terzaghi (1948) and Peck (1967) suggested safety factor from 1.5 to 2.0 to be used in retaining wall design. These values are also recommended by the Canadian Foundation Manual where 1.5 is set for the 
maximum loading and worst environmental conditions (earthquake). Figure 4-8 illustrates the differences between the geotechnical and the structural nominal values of the resistances.

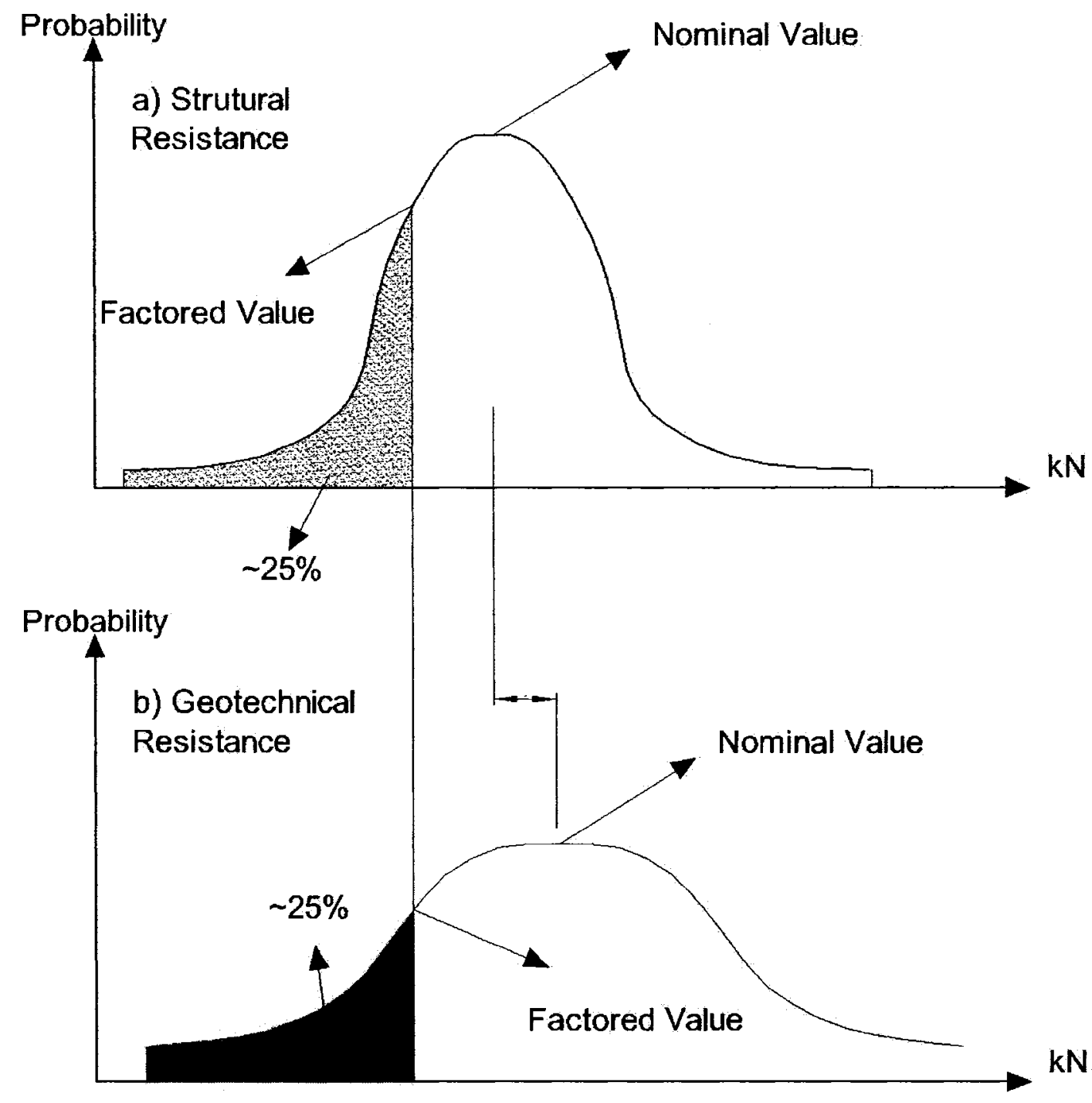

Figure 4-8: Nominal and factored resistance in structural and geotechnical systems

In Figure 4-8, the criterion to estimate the factored value from the mean value was arbitrary plotted to be $75 \%$ of exceedance; this criterion may be changed, but the concept will remain unchanged. There are two differences between the base shear design in structural systems and the retaining walls seismic design. First, because the uncertainties 
are different the nominal value for the geotechnical systems is higher than that for structural systems. Second, because static forces such as coming from dead loads are resisted by the same horizontal resistance, i.e., the friction and passive pressure, the load factors (like dead load) will increase the $R_{\varphi}$ in geotechnical systems.

After this illustration of the geotechnical resistance in retaining walls design, and in light of the fact that the 2005 NBCC recommends a value of 1.18 for concrete, it is reasonable to set $R_{\varphi}$ to be 1.4 in retaining walls.

\subsubsection{3. $\mathrm{R}_{\mathrm{sh}}$}

This factor accounts for the strain hardening phenomenon in structural elements as illustrated in Section 4.4.1.4. Because passive pressure requires large strain to build up and therefore higher partial safety factor is often applied in design. This is significant, because the available strength increases with the increase in deformation similar to the strain hardening process. The 2005 NBCC assigns values of up to 1.25 for $R_{\text {sh }}$ in ductile shear walls. It is suggested here that $R_{s h}$ in gravity walls may take 1.2 for sliding failure and 1.05 for overturning failure. Therefore, it is important to indicate this component of the overstrength is a best estimate, and it may change under different assumption.

\subsubsection{4. $\mathrm{R}_{\text {yield }}$}

This factor accounts for the fact that the specified strength, i.e., set by the manufacturer standards is evaluated below the actual strength. In geotechnical resistance, this matter is also applicable, but it needs statistical analysis to be precisely evaluated. 
The 2005 NBCC recommends 1.1 for steel and 1.05 for concrete resistance structures. A value of 1.05 may be applied for both the sliding and the bearing capacity failure.

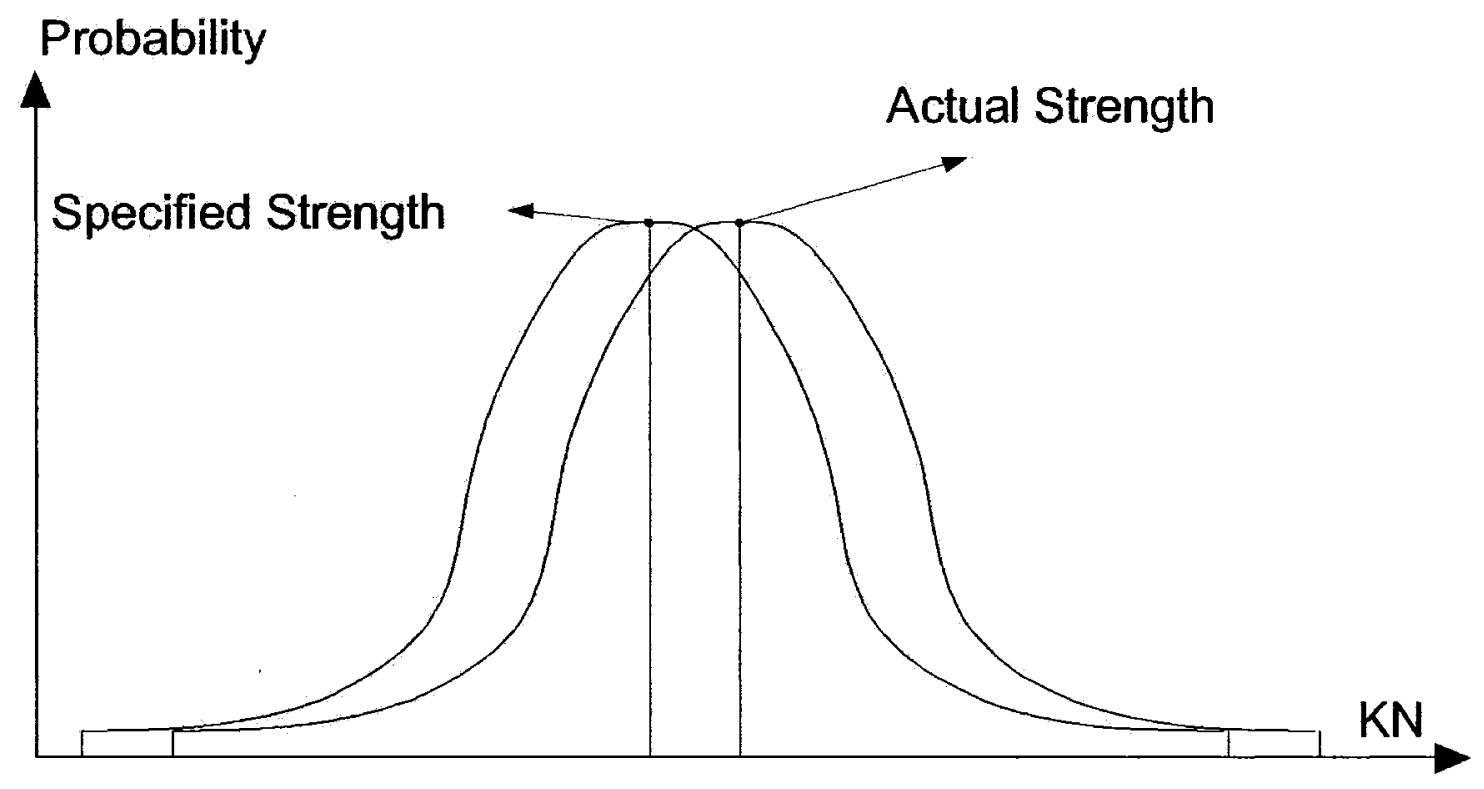

Figure 4-9: "Nominal and actual resistance at the 50\% value"

In Figure 4-9, both the specified or nominal strength and the actual strength have been plotted. Both curves have the same distribution function with an offset. On the other hand, the specified strength has been arbitrary set to be at the mean value (50\%).

\subsubsection{5. $\mathrm{R}_{\text {mech }}$ (Failure Mechanism)}

This modification factor is introduced to account for the sequence failure mechanisms in the systems of beams and columns (Mitchell et al. 2003). For most geotechnical resistance mechanism, $R_{\text {mech }}$ is not applicable. Therefore, $R_{\text {mech }}$ may be set to 1.0 . 
Other factors in retaining wall resistant systems, not existing in structural systems, may create an extra strength in these systems. Some of these factors are discussed in the following sections.

\subsubsection{Correlation Relationships}

Most of the geotechnical design models use the cohesion, the internal friction angle, and effective stresses as the main parameters for evaluating the strength. Strength may also be evaluated using field tests like SPT, CPT, shear wave velocity, or even the surface wave testing like MASW (Model Analysis of Surface Waves) introduced by Lefebvre (2006). These correlation equations will most likely underestimate the soil strength. It might be difficult to estimate the overstrength gained from this factor, and that is beyond the scope of this study.

\subsubsection{Friction Angle Rounding off is One Degree}

The friction angle $(\varphi)$ round off will contribute to the overstrength in two ways. First, because of the high uncertainty, some geotechnical technical reports will not report any portion of the degree that may exist in $\varphi$. For instance, $\varphi=31.459^{\circ}$ may be taken as $31^{\circ}$

Second, any tolerance of the friction angle number will have higher tolerance on the strength. The following numerical example will be used to explain the second reason. An increase of one degree of $\varphi$ from 35 to 36 is only $2.9 \%$ increase, but the $N \gamma$ (in bearing capacity strength) will increase from 48.03 to 56.31 which is $17.2 \%$ increase. 


\subsubsection{Soil Suction}

In saturated soil mechanics, the pore water pressure is either positive or zero. Several studies related to unsaturated soils have shown that the shear strength increases due to the soil suction. The increase of strength from suction is an extra strength which is not counted in classical soil mechanics. The soil suction may become an important part of the strength. The loss of suction leading to strength decrease is responsible for many landslides during and after rainfall around the world.

\subsubsection{Load Factor Effect}

As discussed earlier in this thesis, the load factors such as the dead load factor will increase the performance level of the gravity retaining wall. Later in this study, the discussion will reveal that the performance of the retaining wall seismic design will increase from the presence of the static loads.

\subsubsection{Vegetation Cover}

During the long lifetime of a retaining wall, the vegetation growth will reinforce the top part of the backfill increasing the soil shear strength there. Figure 4-10 shows a joint sliding failure happened during Chi-Chi earthquake in Taiwan (1999) with a dense vegetated backfill. 


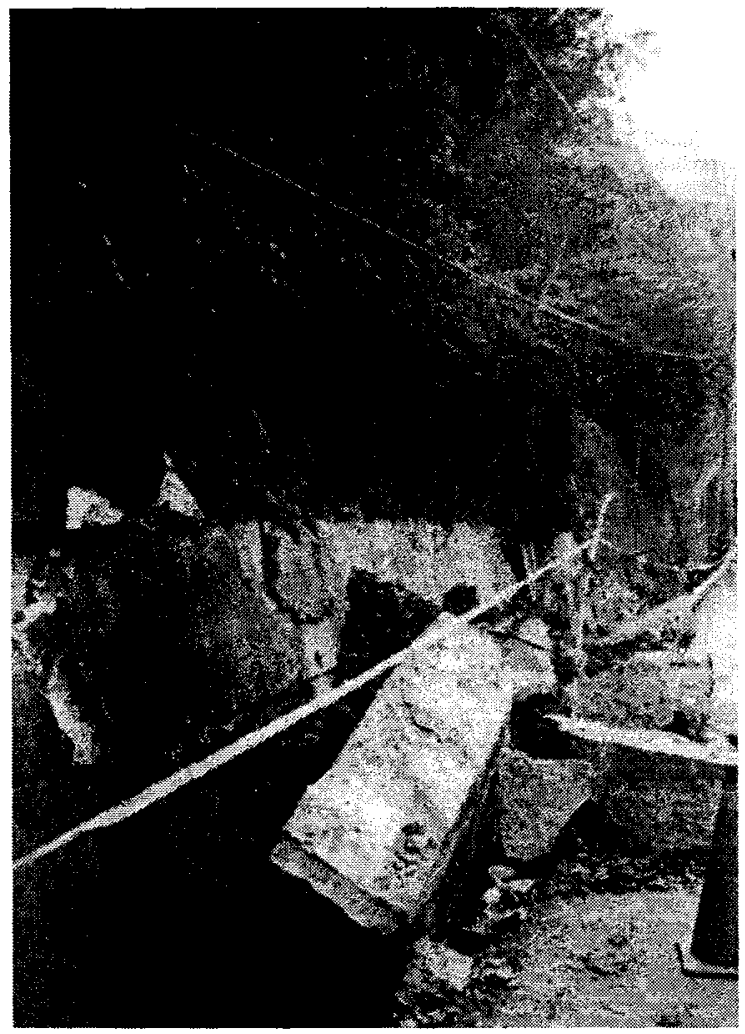

Figure 4-10: Chi-Chi Earthquake construction joint failure (Fang et al. 2003)

Although the soil behind the wall was pure sand (laboratory tests conducted by Fang et al. (2003) revealed that the strength parameters were $C=0.8 \mathrm{kPa}, \varphi=35.7^{\circ}$ ), the vegetation prevented the sand from sliding after the partial failure of the wall. Another effect of the vegetation cover is to increase the suction in the soil. Some plants are able to generate tension in the pore water (suction) up to $2 \mathrm{MPa}$ (Taylor and Ashcroft 1972).

\subsubsection{Semi-Cyclic Loading}

Shear stresses in retaining wall backfill do not mostly change their signs during seismic loading which means no stress reversal, unlike the structural resistant systems like columns that swing from extreme right to extreme left crossing the neutral state. The static earth pressure from dead load and live loads will prevent the stress reversal, and 
will limit the swing in a small range. As a result of the semi-cyclic loading, the yield range will relatively increase. In Figure 4-11, two different yield ranges were proposed: one for a semi-cyclic yielding and the other for a full-cycle yielding.
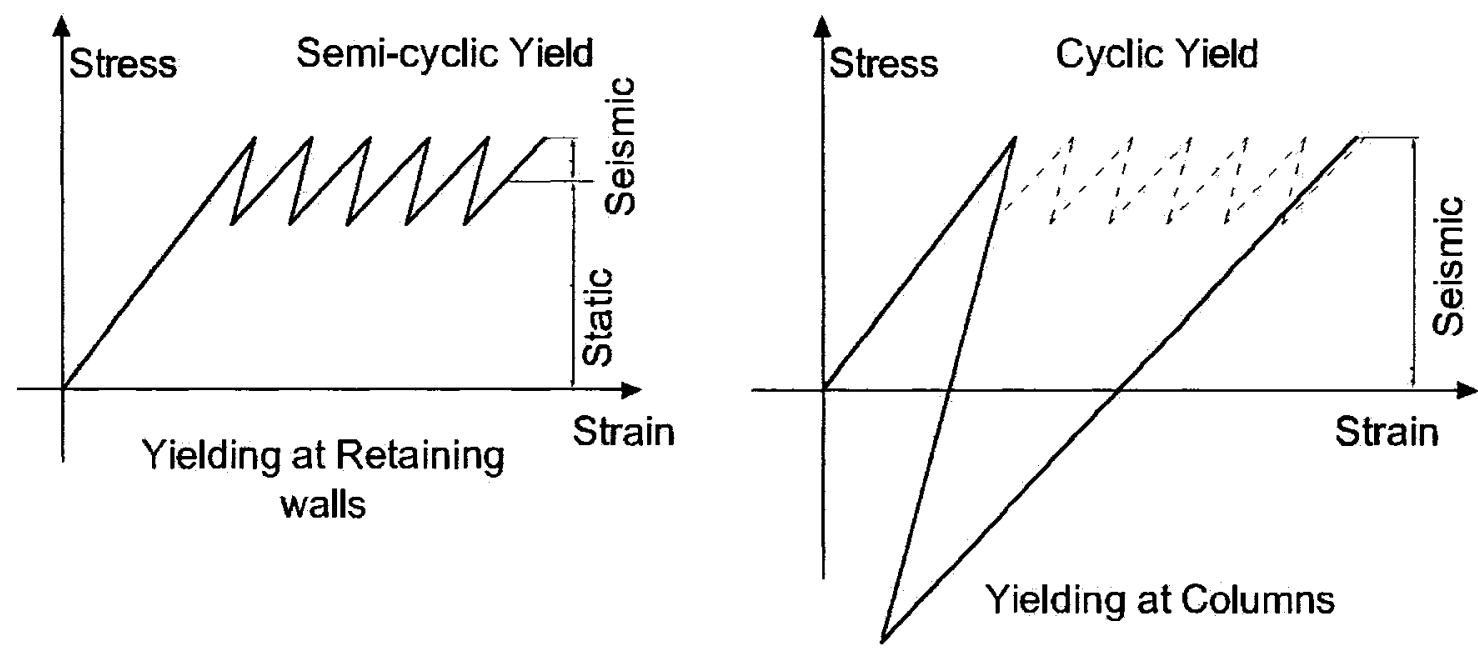

Figure 4-11: Yielding differences between a structural system and a retaining wall system

In the proposed example, the resultant yield at one cycle of loading in columns is equivalent to six cycles of loading in semi-cyclic yield system that proposed at Figure 4-11. Finally, the contribution of this factor to the overstrength is still under discussion because of the lack of supporting studies to quantify the precise amount that the yield will contribute to the overstrength.

\subsubsection{Fast Loading Effect}

During earthquake, the loading rate is relatively fast compared to static loads. In addition, practical experiments on soils have indicated that in fast shearing tests, soils will fail at relatively high strength. Therefore, the fast application of seismic forces will be resisted by higher strength. 


\subsubsection{Summary and Discussion on Overstrength}

In summary for the overstrength in geotechnical systems and especially in retaining walls seismic resistance, the possible applicable overstrength factors are outlined in Tables 4-3 and 4-4 as follows:

Table 4-3: Overstrength Factors for Cantilever Retaining Walls

\begin{tabular}{|c|c|c|c|c|}
\hline & Overturning & Sliding & Bearing Capacity & 2005 NBCC \\
\hline Rsize & 1.09 & 1.09 & 1.09 & $1.05-1.1$ \\
\hline $\mathrm{R} \varphi$ & 1.4 & 1.4 & 1.5 & 1.18 \\
\hline Ryield & 1.0 & 1.05 & 1.05 & 1.1 \\
\hline Rsh & 1.05 & 1.2 & 1.05 & $1.05-1.15$ \\
\hline Rmech & Not applicable & Not applicable & Not applicable & $1.0-1.1$ \\
\hline Total Ro & 1.6 & 1.92 & 1.8 & $1.28-1.63$ \\
\hline
\end{tabular}

Most of the factors of the overstrength suggested in Tables 4-3 and 4-4 represent the best estimate introduced in Sections 4.4.3.1 through 4.4.3.5.

For gravity retaining walls:

Table 4-4: Overstrength Factors for Gravity Retaining Walls

\begin{tabular}{|c|c|c|c|c|}
\hline & Overturning & Sliding & Bearing Capacity & 2005 NBCC \\
\hline Rsize & 1.05 & 1.05 & 1.05 & $1.05-1.1$ \\
\hline $\mathrm{R} \varphi$ & 1.4 & 1.4 & 1.5 & 1.18 \\
\hline Ryield & 1.0 & 1.05 & 1.05 & 1.1 \\
\hline Rsh & 1.05 & 1.2 & 1.05 & $1.05-1.15$ \\
\hline Rmech & Not applicable & Not applicable & Not applicable & $1.0-1.1$ \\
\hline Total Ro & 1.55 & 1.85 & 1.75 & $1.28-1.63$ \\
\hline
\end{tabular}


All other eight factors from Sec. 6.4.3.6 thru Sec. 6.4.3.13 will positively increase the overstrength reserved in the cantilever retaining walls design, but the precise determination of these factors is beyond the scope of this study. Finally the numerical impact of the partial overstrength factors on the performance level will be discussed in the next chapter in a parametric study.

\subsubsection{The Overstrength in NEHRP Recommended Provisions}

As previously stated in Section 2.3.2, the NEHRP provisions have been adopted a low probability level ( $2 \% / 50$ years), which is different from the design level. The corresponding overstrength in a structural design has been estimated for different lateral resistant systems. Overall overstrength has been classified into three categories: design overstrength, material overstrength, and system overstrength. Table 4-5 presents some proposed ranges for the previous categories of overstrength and for various lateral resistant systems.

Table 4-5: Typical Range for Overstrength for Various Systems (NEHRP Commentary 2003)

\begin{tabular}{|l|c|c|c|c|}
\hline \multicolumn{1}{|c|}{ Structural System } & $\begin{array}{c}\text { Design } \\
\text { Overstrength } \\
\Omega_{\text {I }}\end{array}$ & $\begin{array}{c}\text { Material } \\
\text { Overstrength } \\
\Omega_{\text {MI }}\end{array}$ & $\begin{array}{c}\text { System } \\
\text { Overstrength } \\
\Omega_{S}\end{array}$ & $\Omega_{0}$ \\
\hline Special moment frames (steel, concrete) & $1.5-2.5$ & $1.2-1.6$ & $1.0-1.5$ & $2-3.5$ \\
\hline Intermediate moment frames (steel, concrete) & $1.0-2.0$ & $1.2-1.6$ & $1.0-2.0$ & $2-3.5$ \\
\hline Ordinary moment frames (steel, concrete) & $1.0-1.5$ & $1.2-1.6$ & $1.5-2.5$ & $2-3.5$ \\
\hline Masonry wall frames & $1.0-2.0$ & $1.2-1.6$ & $1.0-1.5$ & $2-2.5$ \\
\hline Braced frames & $1.5-2.0$ & $1.2-1.6$ & $1.0-1.5$ & $1.5-2$ \\
\hline Reinforced bearing wall & $1.0-1.5$ & $1.2-1.6$ & $1.0-1.5$ & $1.5-2.5$ \\
\hline Reinforced infill wall & $1.0-1.5$ & $1.2-1.6$ & $1.0-1.5$ & $1.5-2.5$ \\
\hline Unreinforced bearing wall & $1.0-2.0$ & $0.8-2.0$ & $1.0-2.0$ & $2-3$ \\
\hline Unreinforced infill wall & $1.0-2.0$ & $0.8-2.0$ & $1.0-2.0$ & $2-3$ \\
\hline Dual system bracing and frame & $1.1-1.75$ & $1.2-1.6$ & $1.0-1.5$ & $1.5-2.5$ \\
\hline Light bearing wall systems & $1.0-0.5$ & $1.2-2.0$ & $1.0-2.0$ & $2.5-3.5$ \\
\hline
\end{tabular}


An overstrength factor of 1.5 is suggested to be used to reduce the spectral values. This value is based on some experience, but is largely outside the ranges listed in Table 4-5. In fact, the 1.5 factor represents the performance level vs. the design level of San Francisco city (Adams 2006, personal communications). Furthermore, from Figure 2-1, the seismic hazard curve of San Francisco city has a normalized value equals to $1.0 \mathrm{~g}$ at $2 \%$ in 50 years (Performance level), and an approximate value of $0.66(1 / 1.5)$ at $10 \%$ in 50 years.

On the other hand, in Canada and in light of the American approach, the value of the overstrength factor may be reflected by the ratio of the increase in the PGA of the major cities from the $1995 \mathrm{NBCC}$ to $2005 \mathrm{NBCC}$. Table 4-6 lists these increases and the increase ratios which may be used to judge the appropriate overstrength in design. The average increase ratio is 2.70 , but the minimum value is 1.95 from Québec city.

Table 4-6: Increase Ratio of the PGA values in the 2005 NBCC

\begin{tabular}{|c|c|c|c|}
\hline PGA(g) & 1995 NBCC & $2005 \mathrm{NBCC}$ & Increase ratio \\
\hline Québec & $0.19(\mathrm{~g})$ & $0.37(\mathrm{~g})$ & 1.95 \\
\hline Toronto & 0.056 & 0.20 & 3.57 \\
\hline Vancouver & 0.23 & 0.48 & 2.09 \\
\hline Calgary & 0.019 & 0.088 & 4.63 \\
\hline Ottawa & 0.20 & 0.42 & 2.1 \\
\hline Halifax & 0.056 & 0.12 & 2.14 \\
\hline Montréal & 0.18 & 0.43 & 2.39 \\
\hline
\end{tabular}


If the rationale that is incorporated in the NEHRP provisions is used to judge the overstrength factor, the appropriate overstrength factor may be chosen at 1.95 . The use of this value from Québec city will maintain the design values in normalize the performances in the nation to Québec city as will discussed later in the next chapter.

Moreover, values higher than 1.95 may be used to judge the overstrength, but this will lead to a reduction in the design PGAs in some cities. This reduction may lead to a reduction in the safety level of the design, but in structural design, there was a reduction in the design base shear in some cases. This may justify any possible reduction of the PGA in geotechnical design. Figure 4-12 illustrates the base shear coefficient $(V / W)$ under certain conditions for both editions of the NBCC.

(a)

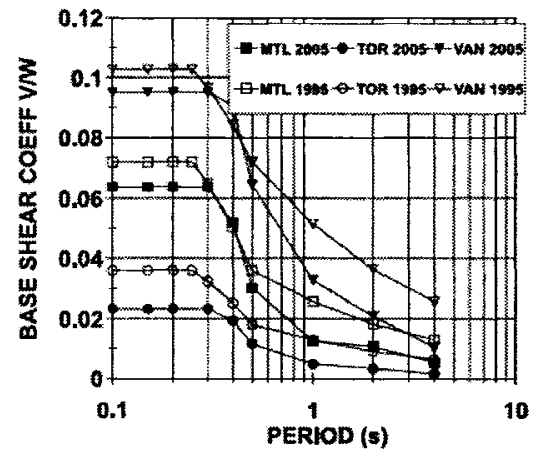

(b)

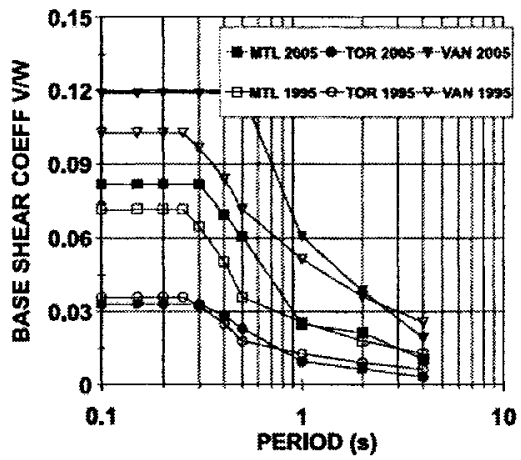

(c)

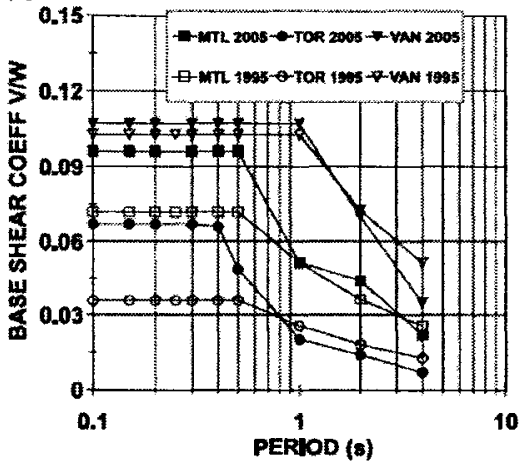

Figure 4-12: Base shear coefficients for reinforced concrete ductile shear-wall (1995 NBCC case 12): (a) hard rock (site $A$ ); (b) very dense soil and soft rock (site $C$ ); and (c) soft soil (site E) from Heidebrecht (2003) 
As illustrated in Figure 4-12, for long-period structures, the recommended base shear in the $2005 \mathrm{NBCC}$ is relatively lower than that of the $1995 \mathrm{NBCC}$, but for shortperiod structures, the new code coefficients are larger than those of the 1995 NBCC. This fact applies for all soil conditions.

\subsection{Practical Implications}

The use of 1.95 overstrength factor will bring the PGA of Quebec City back to its original safety level incorporated in the $1995 \mathrm{NBCC}$, so there will be no improvement of the safety level for the this part of the country. The use of 1.55 overstrength will maintain uniform performance in various parts of the country, and will bring about an improvement of the safety level performance for retaining walls.

In keeping with the provisions of the $2005 \mathrm{NBCC}$ and to achieve an improved safety level, it is therefore, recommended for design purposes, the PGAs of the $2 \%$ in 50 years event should be adopted with an overstrength factor of 1.55. The resultant PGAs for design will then be equal to the PGAs from the 2005 NBCC divided by the overstrength factor. This resultant PGAs can be used directly in common design formulae for retaining walls.

\subsection{Summary}

There will be significant developments in the seismic design of retaining walls. The performance consistency between structural and geotechnical designs has initiated the need for these developments. Some of the facts about these new developments are summarized in the following: 
- The new earthquake data and the new simulation models used by seismologists to generate the new hazard maps will have the same benefits on the design of retaining walls as they have had on buildings designs.

- In any design, the performance level always has to exceed the design level within some range, i.e., introduced by safety factors. These safety factors have different forms in different design approaches such as the LSD or the WSD.

- The difference in strength between the design level and the performance level is responsible for the extra strength in the design system.

- Similar to the structural systems, the seismic resistance of the gravity retaining walls possesses overstrength inherent in the design techniques used in practice.

- Because of the similarities between the retaining walls and the structural resistant systems, most of the overstrength factors that are incorporated in the base shear equation are applicable to the retaining wall structural design.

- There are other factors that will positively contribute to the overstrength, but the numerical determination of these factors is beyond the scope of this study.

- Because overstrength is a consequence of lowering the probability level, the range that the overall overstrength will take, will be limited to the rise in the hazard values.

- The analogy between the two previous systems has led to partial overstrength values that range from 1.55 in an overturning failure mode for gravity wall system to as high as 1.92 in a sliding failure mode for a cantilever retaining wall system. 


\section{Chapter 5 Average Peak Ground Acceleration (APGA)}

In geotechnical design, the main parameter of seismic hazard widely implemented in design formulae like Cyclic Stress Ratio (CSR) that represents liquefaction susceptibility is the peak ground acceleration (PGA). PGA is a poor representative number to represent earthquake ground motions because it will only describe the peak value. Therefore, there is a need to define a different parameter to represent ground motion time histories.

In the literature, several parameters were developed to describe ground motion time history with a single number. For instance, Effective Acceleration which was initially proposed by Kennedy (1980), is defined to be $25 \%$ greater than the third highest peak acceleration. In this study, a new parameter will be introduced and the quality of the new parameter will be estimated.

\subsection{Definition}

A new parameter which will be called Average Peak Ground Acceleration (APGA) is introduced to characterize ground motions for geotechnical seismic design purposes. Initial results have shown that the soil profile appears to be less sensitive to the variations in ground motion characteristics while keeping the APGA constant. The proposed technique to obtain an APGA is summarized as follows:

1. Extract all the absolute peaks from the time history. 
2. First level of filtering is to filter out the low peaks that fall within a certain threshold range as illustrated in Figure 5-1. For instance, this threshold range may be chosen as $30 \%$ of PGA.

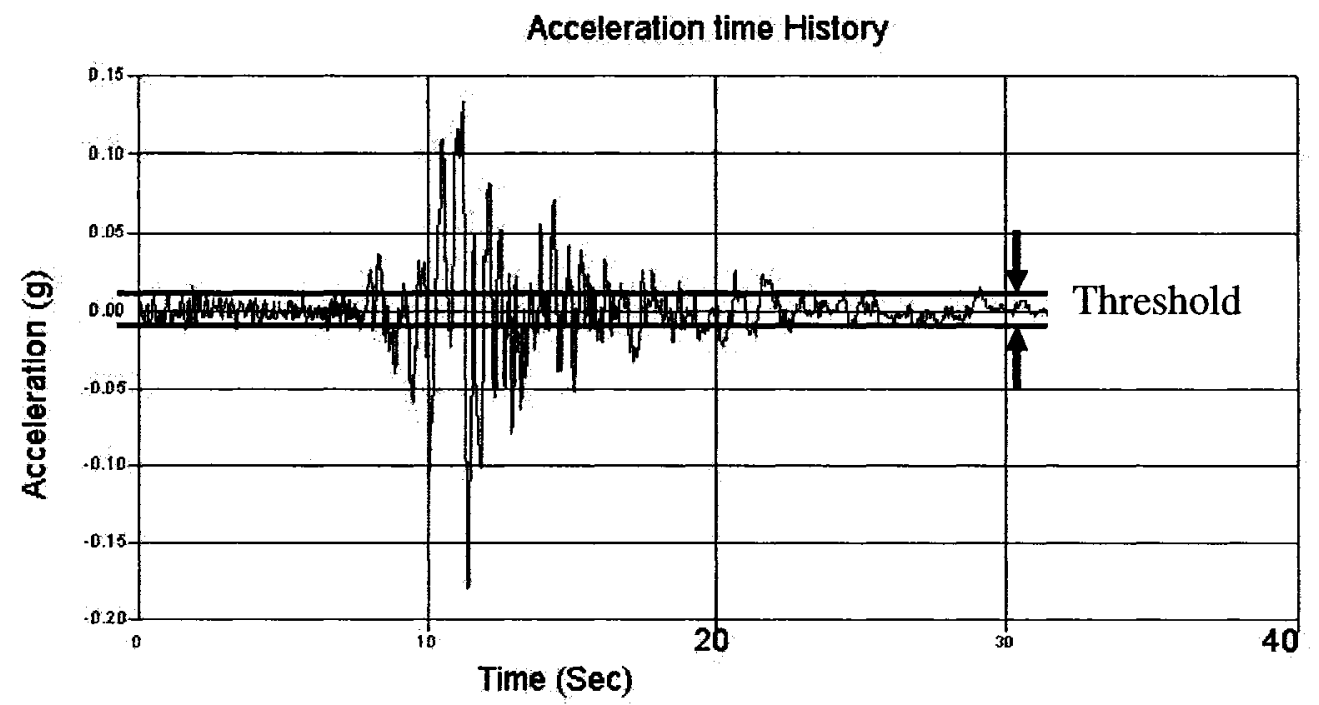

Figure 5-1: Filtering Technique

3. The second level of filtering is to consider only the top peaks, e.g., the top $20 \%$ of the remaining peaks after first filtering.

4. The last step is to extract a single number out of the last set of peaks. The average would be the simplest approach. Other techniques which could implement more weight to the larger peaks should be more appropriate because the influence on the non-linearity in soil response will be larger in those peaks.

The previous steps can be easily implemented in a programming code. Python is used for this purpose. In the next section, Python code will be introduced with an example of its results. 


\subsection{Python Programming}

Like any programming language, a set of orders called code will be executed each time the program runs. The actual code used to load the ground motion record and execute two levels of filtering is as the following:

- Start:

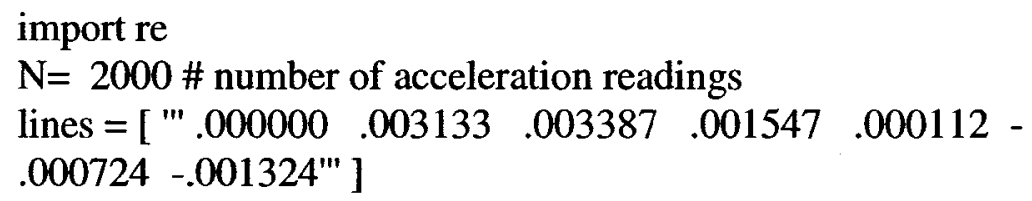

- transfer the record to CSV (comma separated values) format and obtain the absolute peaks:

for line in lines:

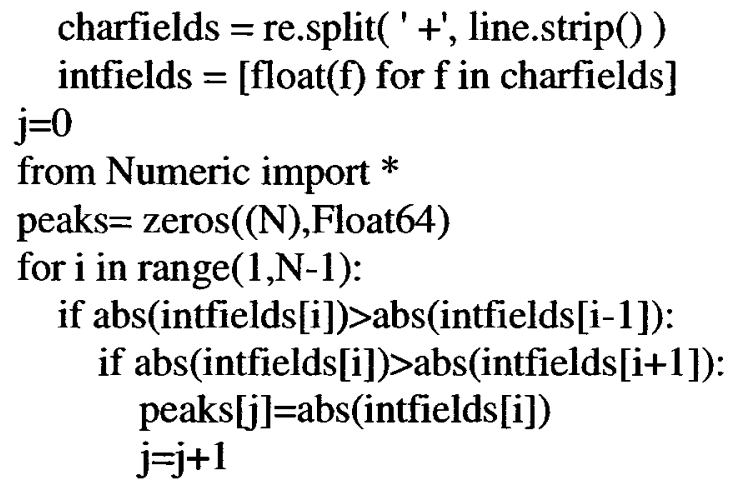

- organize the peaks from Max value to min value:

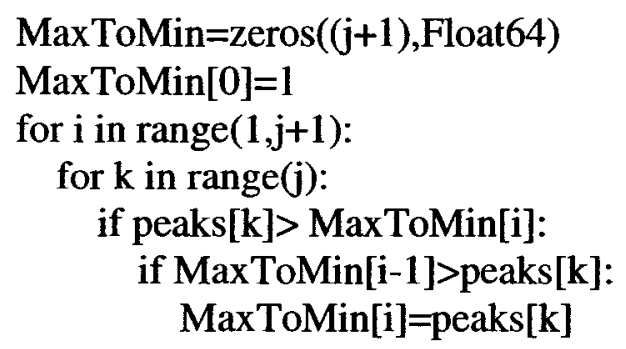


- First level of filtering:

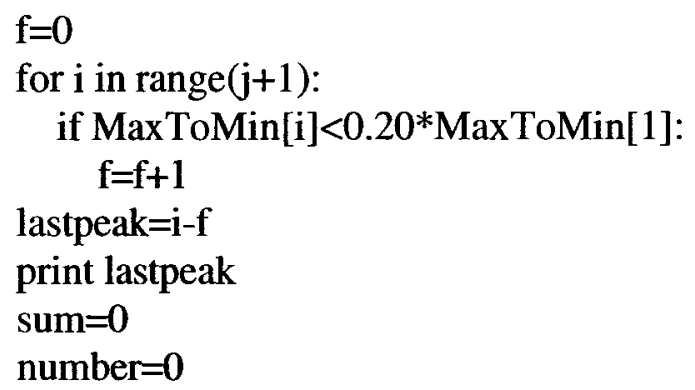

- Second level of filtering:

for $t$ in range $\left(1, \operatorname{int}\left((\text { lastpeak-1 })^{*} 0.1+2.5\right)\right)$ :

sum=sum+MaxToMin[t]

number=number +1

- The suggested average peak ground acceleration:

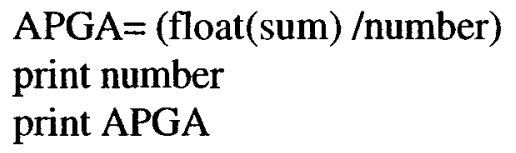

\subsection{Example}

The previous steps will be performed on El Centro earthquake which has 4187 timesteps in $0.02 \mathrm{~s}$ intervals. The PGA of El Centro earthquake is $0.3435 \mathrm{~g}$. The APGA of El Centro earthquake will be found as the following:

- Number of peaks in both directions (positive and negative) is 490 peaks.

- The remaining peaks after first level of filtering (threshold of $30 \%$ of the PGA) are 52 peaks.

- The next step of filtering will eliminate almost $80 \%$ i.e. given value, of the peaks. The remaining peaks are 11 .

- The last step is to combine the values of the rest. The mean or the root mean square (RMS) is one way to combine these peaks. 
- The final value would be $0.2746 \mathrm{~g}$.

\subsection{Numerical Evaluation Method}

Most of the developed techniques to represent ground motions that are available in the literature did not undergo any process to evaluate the validity of these techniques. Indeed, it is quite difficult to evaluate the consistency of a factor describing ground motion time history. The evaluation method is simply by normalizing a set of ground motions to the same APGA, and study the nonlinear soil responses on a given soil profile. Then, second to perform the same responses using PGA to normalize the previous ground motions. The deviation of the normalized responses will determine the quality of the normalization which is in turn representing the quality of the new numerical parameter (APGA).

\subsection{Analysis Characteristics}

In this parametric study, six different ground motions will be used Elcentro (1940), Taft Kern County earthquake (1952), Treasure (Loma Prieta 1989), and Yerba Buena Island (Loma Prieta 1989), Petrolia Cape Mendocino earthquake (1992), and Topanga Northridge Earthquake (1994). Shake computer program (EduShake 2002) which is a simple finite element one dimensional program, will be used to conduct equivalent linear seismic analysis. Equivalent linear soil model will be used to simulate the nonlinearity in soil seismic response. 


\subsubsection{Ground Motions Characteristics}

The time histories of the ground motions that will be used in the analysis have different characteristics. The PGA, number of readings, duration, and other characteristics of these motions are randomly distributed. Table 5-1 outlines the main characteristics of these motions as follows:

Table 5-1: Ground motion characteristics

\begin{tabular}{|c|c|c|}
\hline Earthquake and the station & \# of readings & PGA (g) \\
\hline ElCentro & 4187 & 0.34352 \\
\hline Petrolia & 5879 & 0.42193 \\
\hline TAFT & 4220 & 0.18522 \\
\hline Topanga & 5872 & 0.32894 \\
\hline Treasure & 2000 & 0.1571 \\
\hline Yerba & 2000 & 0.06505 \\
\hline
\end{tabular}

The range of the PGAs extends from $0.065 \mathrm{~g}$ to $0.42 \mathrm{~g}$.

\subsubsection{Soil Profile}

Soil profile also has an influence on the response results, so it is better to keep the same soil profile throughout the study in order to eliminate the influence of the soil profile. Figure 5-2 illustrates the changes in the shear modulus and unit weight of the proposed soil profile: 


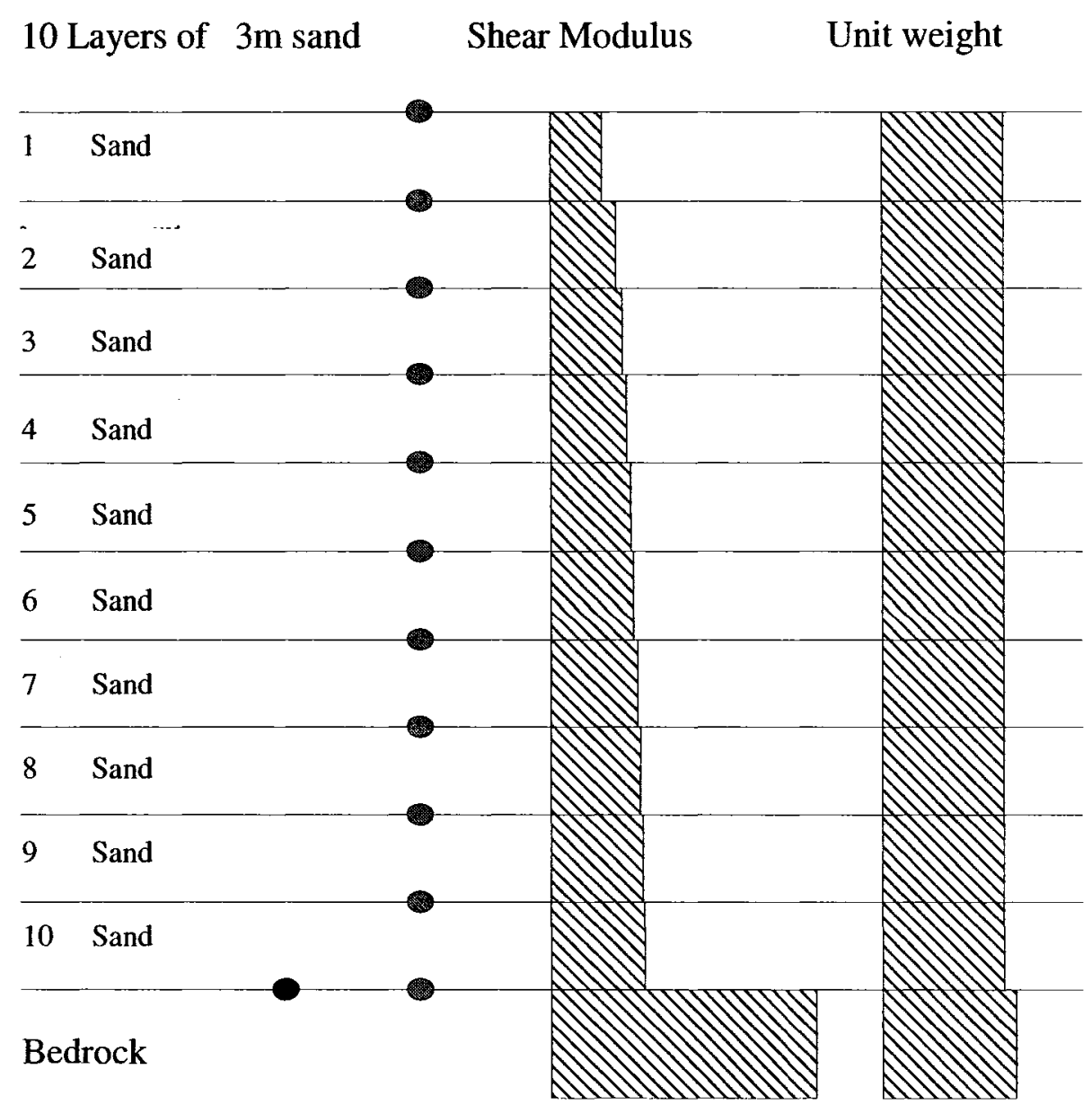

Figure 5-2: Soil Profile consists of 10 layer of $3 \mathrm{~m}$ thick laid on bedrock

\subsubsection{Nonlinear Effect}

Nonlinearity effect which is simulated by the modulus reduction function and the increase of damping with strain, will determine major part of the soil response during earthquake. Typical functions for modulus and damping reductions versus strain are illustrated in Figures 5-3 and 5-4. 


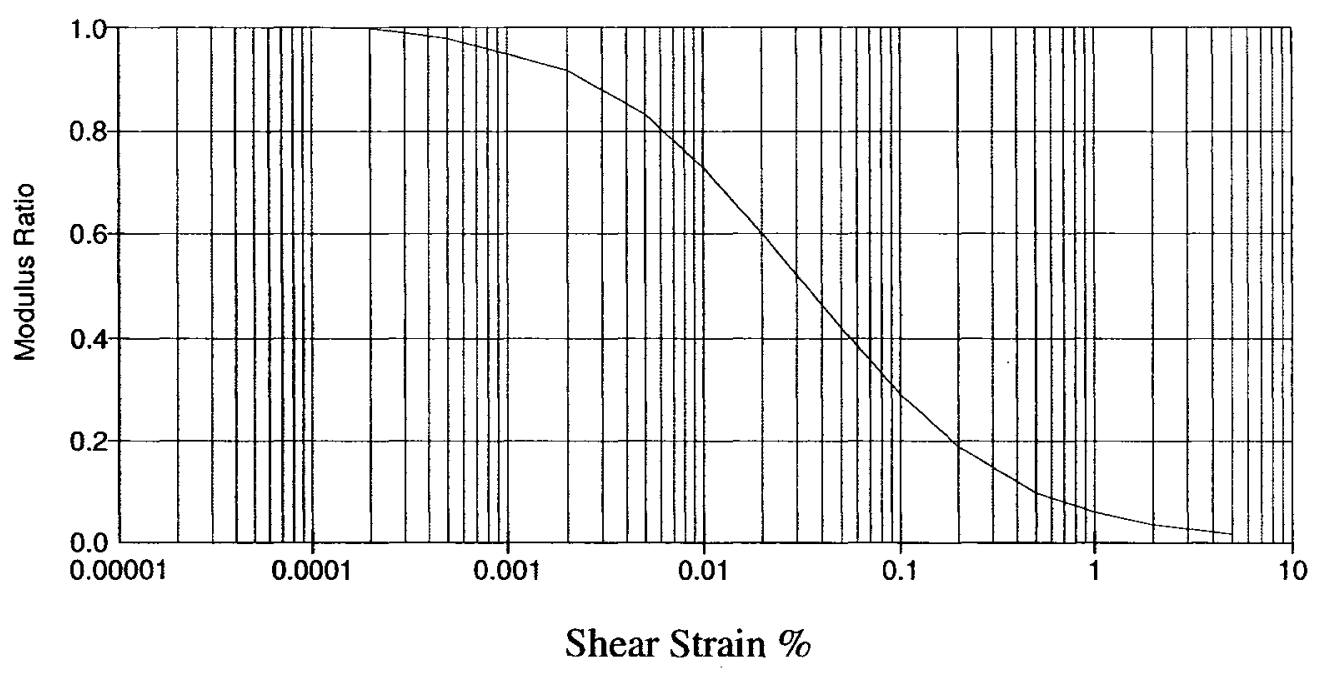

Figure 5-3: Typical Modulus reduction function for sand (Seed and Idriss 1970)

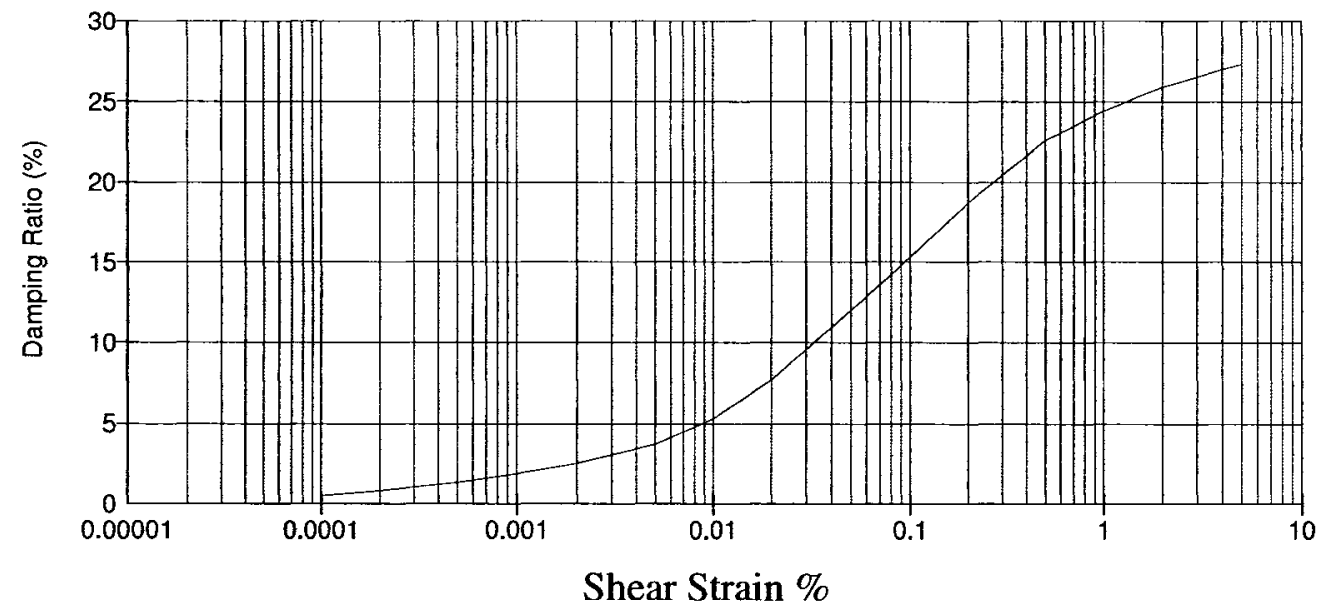

Figure 5-4: Typical Damping function (Seed and Idriss 1970)

The equivalent-linear model may not represent the exact cyclic behavior of the soil profile, but the application of this model is widely used in soil seismic analysis.

\subsection{Analysis and Results}

The analyses of nonlinear responses of the soil profile have been examined under three cases in which the criteria to define the APGA have changed. 


\subsubsection{Threshold Level of $6 \%$, top $10 \%$ Peaks with Simple Mean Value}

The average peak ground accelerations of the previous ground motions before any normalization are calculated upon the previous conditions (6\% threshold and top $10 \%$ ) and listed in Table 5-2. Column \# 4 in Table 5-2 represents the corresponding PGAs of the ground motions if these motions were normalized to APGA equal $0.2 \mathrm{~g}$. Column \# 4 is presented because in Shake, ground motions may only be normalized based on their PGAs.

Table 5-2: Average Peak Ground Accelerations

\begin{tabular}{|c|c|c|c|}
\hline Earthquake and the station & APGA & $\begin{array}{c}\text { Normalized } \\
\text { APGA }\end{array}$ & $\begin{array}{c}\text { Normalized PGA } \\
(\mathrm{g})\end{array}$ \\
\hline ElCentro & 0.2254 & 0.2 & 0.3048 \\
\hline Petrolia & 0.2530 & 0.2 & 0.3335 \\
\hline TAFT & 0.1044 & 0.2 & 0.3548 \\
\hline Topanga & 0.1995 & 0.2 & 0.3297 \\
\hline Treasure & 0.1355 & 0.2 & 0.2319 \\
\hline Yerba & 0.04072 & 0.2 & 0.3195 \\
\hline
\end{tabular}

The average of the previous normalized PGAs is 0.3124 . This value will be used in the second part of the study to normalize the ground motions and then compare the two responses.

To quantify the deviation of the response between different ground motions, the standard deviation of the response among them will be calculated for both cases with normalized APGA 0.2 and the average of the normalized PGAs. As an example of the result, the peak ground displacement is presented in Table 5-3. The first part of the table 
is for the case of normalized APGAs $(0.2 \mathrm{~g})$, and the second part is for the case of normalized PGAs (0.3124g).

Table 5-3: Soil responses with depth for the six ground motions

\begin{tabular}{|c|c|c|c|c|c|c|c|c|c|}
\hline & & \multicolumn{6}{|c|}{ Peak Displacement (m) from normalized APGA } & \multirow[b]{2}{*}{$\begin{array}{c}\text { Std } \\
\text { Deviation }\end{array}$} & \\
\hline $\begin{array}{l}\text { Depth } \\
\text { (m) }\end{array}$ & ElCentro & Yerba & Topanga & Petrolia & TAFT & Treasure & Mean & & \\
\hline-1.5 & 0.118872 & 0.2896 & 0.04572 & 0.2957 & 0.1280 & 0.2591 & 0.18948 & 0.10542 & \\
\hline-4.5 & 0.118872 & 0.2896 & 0.04572 & 0.2926 & 0.1280 & 0.2591 & 0.188976 & 0.104809 & \\
\hline-7.5 & 0.118872 & 0.2865 & 0.04267 & 0.2835 & 0.1280 & 0.2560 & 0.185928 & 0.102876 & \\
\hline-10.5 & 0.115824 & 0.2774 & 0.03962 & 0.2682 & 0.1280 & 0.2469 & 0.179324 & 0.098246 & \\
\hline-13.5 & 0.112776 & 0.2682 & 0.03658 & 0.2377 & 0.1280 & 0.2347 & 0.169672 & 0.090842 & \\
\hline-16.5 & 0.112776 & 0.2530 & 0.03658 & 0.2134 & 0.1250 & 0.2164 & 0.159512 & 0.081688 & \\
\hline-19.5 & 0.109728 & 0.2316 & 0.03962 & 0.2073 & 0.1250 & 0.2012 & 0.1524 & 0.073431 & \\
\hline-22.5 & 0.10668 & 0.2073 & 0.03962 & 0.2012 & 0.1250 & 0.1890 & 0.14478 & 0.066241 & \\
\hline-25.5 & 0.103632 & 0.1981 & 0.03962 & 0.1981 & 0.1219 & 0.1859 & 0.141224 & 0.064158 & \\
\hline-28.5 & 0.100584 & 0.1951 & 0.03962 & 0.1981 & 0.1219 & 0.1829 & 0.1397 & 0.063569 & \\
\hline-30.0 & 0.097536 & 0.1890 & 0.04267 & 0.1951 & 0.1189 & 0.1768 & 0.136652 & 0.060728 & \\
\hline & & \multicolumn{7}{|c|}{ Peak Displacement (m) from normalized PGA } & \\
\hline $\begin{array}{c}\text { Depth } \\
\text { (m) }\end{array}$ & ElCentro & Yerba & Topanga & Petrolia & TAFT & Treasure & Mean & $\begin{array}{c}\text { Std } \\
\text { Deviation }\end{array}$ & $\begin{array}{c}\text { Improvement } \\
\%\end{array}$ \\
\hline-1.5 & 0.12192 & 0.28346 & 0.042672 & 0.27737 & 0.11278 & 0.35052 & 0.19812 & 0.121691 & 13.37 \\
\hline-4.5 & 0.12192 & 0.28042 & 0.042672 & 0.27432 & 0.11278 & 0.35052 & 0.19710 & 0.120874 & 13.29 \\
\hline-7.5 & 0.12192 & 0.27737 & 0.042672 & 0.26822 & 0.10973 & 0.344424 & 0.19405 & 0.118562 & 13.23 \\
\hline-10.5 & 0.118872 & 0.27127 & 0.039624 & 0.25298 & 0.10973 & 0.329184 & 0.18694 & 0.113141 & 13.16 \\
\hline-13.5 & 0.115824 & 0.25908 & 0.036576 & 0.22555 & 0.10973 & 0.307848 & 0.17577 & 0.104109 & 12.74 \\
\hline-16.5 & 0.112776 & 0.24384 & 0.036576 & 0.20117 & 0.10973 & 0.280416 & 0.16408 & 0.09286 & 12.03 \\
\hline-19.5 & 0.109728 & 0.22555 & 0.036576 & 0.19507 & 0.10973 & 0.262128 & 0.15646 & 0.085053 & 13.66 \\
\hline-22.5 & 0.10668 & 0.20117 & 0.036576 & 0.18898 & 0.10668 & 0.256032 & 0.14935 & 0.079995 & 17.19 \\
\hline-25.5 & \begin{tabular}{|l|}
0.10668 \\
\end{tabular} & 0.19202 & 0.036576 & 0.18593 & 0.10668 & 0.249936 & 0.14630 & 0.076916 & 16.59 \\
\hline-28.5 & 0.103632 & 0.18898 & 0.039624 & 0.18593 & 0.10668 & 0.24384 & 0.14478 & 0.07438 & 14.54 \\
\hline-30.0 & 0.100584 & 0.18593 & 0.039624 & 0.18288 & 0.10363 & 0.237744 & 0.14173 & 0.072713 & 16.48 \\
\hline
\end{tabular}

An improvement of up to $17 \%$ has been achieved. However, when considering more response parameters which are peak shear strain, peak shear stress, peak displacement, and peak velocity the average improvement will be close to $5.5 \%$. As a result, a moderate but positive improvement has been achieved by using APGA of $6 \%$ threshold and top $10 \%$ criteria as a tool to normalize different ground motions. 


\subsubsection{Threshold Level of $20 \%$, top $10 \%$ Peaks with Simple Mean Value}

The average peak ground accelerations of the previous ground motions before any normalization are calculated upon these conditions (20\% threshold and top 10\%) and introduced in Table 5-4. Column \# 4 in Table 5-4 represents the corresponding PGAs of the ground motions if these motions were normalized to APGA equal 0.3g.

Table 5-4: Average Peak Ground Accelerations

\begin{tabular}{|c|c|c|c|}
\hline Earthquake & APGA & $\begin{array}{c}\text { Normalized } \\
\text { APGA }\end{array}$ & Normalized PGA (g) \\
\hline ElCentro & 0.2758741 & 0.3 & 0.373563 \\
\hline Petrolia & 0.353019 & 0.3 & 0.358564 \\
\hline TAFT & 0.131199 & 0.3 & 0.42352 \\
\hline Topanga & 0.234835 & 0.3 & 0.420222 \\
\hline Treasure & 0.144865 & 0.3 & 0.32534 \\
\hline Yerba & 0.0517623 & 0.3 & 0.377023 \\
\hline
\end{tabular}

The average of the previous normalized PGAs is $0.3797 \mathrm{~g}$. Similarly, this value will be used in the second part of the study to normalize the ground motions and then study the two responses.

The standard deviation of the response among them will be calculated for both cases with normalized APGA 0.3 and the average of the normalized PGAs. As an example of the result, Peak Shear Strain is presented in Table 5-5. First part of the table is for the case of normalized APGAs (0.3g), and the second part is for the case of normalized PGAs $(0.3797 \mathrm{~g})$. 
Table 5-5: Soil responses (Peak Shear Strain) with depth for the six ground motions

\begin{tabular}{|c|c|c|c|c|c|c|c|c|c|}
\hline \multicolumn{10}{|c|}{ Peak Shear Strain (\%) from normalized APGA } \\
\hline $\begin{array}{c}\text { Depth } \\
\text { (m) }\end{array}$ & ElCentro & Yerba & Topanga & Petrolia & TAFT & Treasure & Mean & $\begin{array}{c}\text { Std } \\
\text { Deviation }\end{array}$ & \\
\hline-1.5 & 0.0485 & 0.0472 & 0.0573 & 0.0755 & 0.0724 & 0.0656 & 0.061083 & 0.012014 & \\
\hline-4.5 & 0.149 & 0.1721 & 0.1444 & 0.3029 & 0.2659 & 0.2607 & 0.215833 & 0.068677 & \\
\hline-7.5 & 0.2538 & 0.3694 & 0.1767 & 0.6729 & 0.4935 & 0.5815 & 0.424633 & 0.192194 & \\
\hline-10.5 & 0.3513 & 0.5652 & 0.1686 & 1.0708 & 0.5903 & 0.9905 & 0.622783 & 0.352219 & \\
\hline-13.5 & 0.3747 & 0.8214 & 0.1616 & 1.292 & 0.5298 & 1.3015 & 0.746833 & 0.477181 & \\
\hline-16.5 & 0.3777 & 0.998 & 0.1338 & 1.3401 & 0.436 & 1.4813 & 0.794483 & 0.556696 & \\
\hline-19.5 & 0.4026 & 1.1673 & 0.1329 & 1.2118 & 0.3998 & 1.552 & 0.811067 & 0.571378 & \\
\hline-22.5 & 0.4018 & 1.3134 & 0.1603 & 1.1342 & 0.3978 & 1.571 & 0.82975 & 0.582056 & \\
\hline-25.5 & 0.38 & 1.479 & 0.1802 & 1.2177 & $0 . \overline{4504}$ & 1.5576 & 0.877483 & 0.609298 & \\
\hline-28.5 & 0.3665 & 1.6478 & 0.186 & 1.2648 & 0.517 & 1.5257 & 0.917967 & 0.636075 & \\
\hline-30.0 & 0.007 & 0.0114 & 0.0053 & 0.0095 & 0.0085 & 0.0103 & 0.008667 & 0.002235 & \\
\hline \multicolumn{10}{|c|}{ Peak Shear Strain (\%) from normalized PGA } \\
\hline $\begin{array}{c}\text { Depth } \\
\text { (m) }\end{array}$ & ElCentro & Yerba & Topanga & Petrolia & TAFT & Treasure & Mean & $\begin{array}{c}\text { Std } \\
\text { Deviation }\end{array}$ & $\begin{array}{c}\text { Improvement } \\
\%\end{array}$ \\
\hline-1.5 & 0.0515 & 0.0474 & 0.0544 & 0.08 & 0.0665 & 0.0814 & 0.063533 & 0.014749 & 18.5424 \\
\hline-4.5 & 0.1557 & 0.173 & 0.135 & 0.3223 & \begin{tabular}{|l|}
0.2328 \\
\end{tabular} & 0.34 & 0.226467 & 0.087575 & 21.57959 \\
\hline-7.5 & 0.268 & 0.3713 & 0.168 & 0.7624 & 0.4428 & 0.8434 & 0.475983 & 0.270998 & 29.07939 \\
\hline-10.5 & 0.356 & 0.5724 & 0.1572 & 1.1393 & 0.5338 & 1.3126 & 0.67855 & 0.452189 & 22.10802 \\
\hline-13.5 & 0.3784 & 0.8371 & 0.1496 & 1.3722 & 0.4858 & 1.7057 & 0.821467 & 0.607586 & 21.4629 \\
\hline-16.5 & 0.379 & 1.0118 & 0.1254 & 1.4047 & $0 . \overline{4001}$ & 1.8645 & 0.86425 & 0.679876 & 18.11798 \\
\hline-19.5 & 0.4039 & 1.1801 & 0.1154 & 1.2409 & 0.363 & 1.9013 & 0.867433 & 0.684250 & 16.49562 \\
\hline-22.5 & 0.404 & 1.3341 & 0.1396 & 1.2381 & 0.3554 & 1.9311 & 0.900383 & 0.705228 & 17.46563 \\
\hline-25.5 & 0.3947 & 1.5038 & 0.1598 & 1.3527 & \begin{tabular}{|l|}
0.3591 \\
\end{tabular} & 1.929 & 0.94985 & 0.736103 & 17.22651 \\
\hline-28.5 & 0.3783 & 1.6806 & 0.1654 & 1.3938 & 0.389 & 1.8469 & 0.975667 & 0.746776 & 14.82388 \\
\hline-30.0 & 0.007 & 0.0115 & 0.005 & 0.0099 & \begin{tabular}{|l|}
0.0082 \\
\end{tabular} & 0.0111 & 0.008783 & 0.002523 & 11.42089 \\
\hline
\end{tabular}

An improvement of up to $29 \%$ have been achieved in the Shear Strain, but the average improve will increase to be close to $14 \%$ rising from $5.5 \%$ in the previous case.

As a result, a reduction in standard deviation has been achieved by using APGA of $20 \%$ threshold and top $10 \%$ criteria as a tool to normalize different ground motions. 


\subsubsection{Threshold Level of 20\%, top $10 \%$ Peaks with RMS Combination}

\section{Technique}

This case is similar to the previous case, but the difference is in the combination of the resulted second filtration. To give more weight to the higher acceleration peaks, the square root of the average of the squares is used to represent the APGA. In Table 5-6, the average peak ground accelerations of the previous ground motions before any normalization are calculated upon the previous conditions (20\% threshold and top $10 \%+$ RMS combination rule), and introduced.

Table 5-6: Average Peak Ground Accelerations

\begin{tabular}{|c|c|c|c|}
\hline Earthquake & APGA & $\begin{array}{c}\text { Normalized } \\
\text { APGA }\end{array}$ & $\begin{array}{c}\text { Normalized PGA } \\
(\mathrm{g})\end{array}$ \\
\hline ElCentro & 0.27461 & 0.3 & 0.37528 \\
\hline Petrolia & 0.34728 & 0.3 & 0.36448 \\
\hline TAFT & 0.13096 & 0.3 & 0.42431 \\
\hline Topanga & 0.23374 & 0.3 & 0.42219 \\
\hline Treasure & 0.13647 & 0.3 & 0.34534 \\
\hline Yerba & 0.049786 & 0.3 & 0.39198 \\
\hline
\end{tabular}

The average of the previous normalized PGAs is $0.387263 \mathrm{~g}$. Similarly, this value will be used in the second part of the study to normalize the ground motions and then study the two responses.

The standard deviation of the response among them will be calculated for both cases with normalized APGA 0.3 and the average of the normalized PGAs. As an example of the result, the peak shear strain is presented in Table 5-7. First part of the 
table is for the case of normalized APGAs $(0.3 \mathrm{~g})$, and the second part is for the case of normalized PGAs (0.38726g).

Table 5-7: Soil responses (Peak Shear Strain) with depth for the six ground motions

\begin{tabular}{|c|c|c|c|c|c|c|c|c|c|}
\hline \multicolumn{9}{|c|}{ Peak Shear Strain (\%) from normalized APGA } \\
\hline $\begin{array}{c}\text { Depth } \\
\text { (m) }\end{array}$ & ElCentro & Yerba & Topanga & Petrolia & TAFT & Treasure & Mean & $\begin{array}{c}\text { Std } \\
\text { Deviation }\end{array}$ & \\
\hline-1.5 & 0.0487 & 0.0481 & 0.0574 & 0.0768 & 0.0725 & 0.0709 & 0.0624 & 0.012640 & \\
\hline-4.5 & 0.1499 & 0.1773 & 0.1448 & 0.3085 & 0.2663 & 0.2925 & 0.223217 & 0.074246 & \\
\hline-7.5 & 0.2563 & 0.3869 & 0.177 & 0.6968 & 0.4942 & 0.6657 & 0.44615 & 0.212288 & \\
\hline-10.5 & 0.3536 & 0.6185 & 0.1693 & 1.091 & 0.5911 & 1.1055 & 0.654833 & 0.380843 & \\
\hline-13.5 & 0.3769 & 0.8998 & 0.1622 & 1.3152 & 0.5305 & 1.4459 & 0.788417 & 0.519655 & \\
\hline-16.5 & 0.3792 & 1.0787 & 0.1343 & 1.3591 & 0.4366 & 1.6399 & 0.837967 & 0.606521 & \\
\hline-19.5 & 0.4037 & 1.2489 & 0.1338 & 1.2208 & 0.4005 & 1.6858 & 0.848917 & 0.617955 & \\
\hline-22.5 & 0.4026 & 1.4316 & 0.1613 & 1.1623 & 0.3984 & 1.693 & 0.874867 & 0.635790 & \\
\hline-25.5 & 0.3828 & 1.6204 & 0.1812 & 1.2544 & 0.4529 & 1.7071 & 0.933133 & 0.67431 & \\
\hline-28.5 & 0.3677 & 1.828 & 0.187 & 1.3002 & 0.5196 & 1.6645 & 0.977833 & 0.707937 & \\
\hline-30.0 & 0.007 & 0.0119 & 0.0054 & 0.0096 & 0.0085 & 0.0105 & 0.008817 & 0.002368 & \\
\hline & & & Peak Shear Strain (\%) from normalized PGA & & \\
\hline \begin{tabular}{c|c|c|c|c|c|c|c|c|c|}
\hline \\
Depth
\end{tabular} & ElCentro & Yerba & Topanga & Petrolia & TAFT & Treasure & Mean & Std & Improvement \\
\hline-1.5 & 0.0523 & 0.0479 & 0.055 & 0.0814 & 0.0677 & 0.0835 & 0.064633 & 0.015306 & 17.42 \\
\hline-4.5 & 0.1584 & 0.1755 & 0.1365 & 0.3284 & 0.2388 & 0.3502 & 0.2313 & 0.090595 & 18.05 \\
\hline-7.5 & 0.2773 & 0.3803 & 0.1701 & 0.7921 & 0.4525 & 0.8754 & 0.491283 & 0.283127 & 25.02 \\
\hline-10.5 & 0.3645 & 0.5991 & 0.1594 & 1.1608 & 0.5451 & 1.3554 & 0.697383 & 0.464936 & 18.09 \\
\hline-13.5 & 0.3861 & 0.8755 & 0.1516 & 1.397 & 0.4937 & 1.7548 & 0.843117 & 0.624204 & 16.75 \\
\hline-16.5 & 0.3846 & 1.0518 & 0.1268 & 1.4236 & 0.4061 & 1.9135 & 0.8844 & 0.697185 & 13.00 \\
\hline-19.5 & 0.4091 & 1.219 & 0.1184 & 1.2472 & 0.3697 & 1.956 & 0.886567 & 0.702775 & 12.07 \\
\hline-22.5 & 0.4119 & 1.3934 & 0.1437 & 1.287 & 0.363 & 1.9857 & 0.930783 & 0.730051 & 12.91 \\
\hline-25.5 & 0.4065 & 1.5748 & 0.1634 & 1.4024 & 0.3666 & 1.9802 & 0.982317 & 0.762178 & 11.53 \\
\hline-28.5 & 0.3884 & 1.7783 & 0.169 & 1.441 & 0.4102 & 1.8873 & 1.012367 & 0.774480 & 8.59 \\
\hline-30.0 & 0.007 & 0.0118 & 0.0051 & 0.01 & 0.0083 & 0.0112 & 0.0089 & 0.002581 & 8.28 \\
\hline
\end{tabular}

A maximum improve of $25 \%$ has been achieved in the Shear Strain, but the average improve for the total response variables is $10 \%$. The reduction in the standard 
deviation of the current criteria is still positive, and the effects of the new combination technique (RMS) have negatively improved the APGA extraction method.

\subsection{Conclusions and Discussion}

In summary of the main conclusion that was discussed throughout study, some important conclusions may be derived as follows:

1. A moderate but positive reduction in the standard deviation is reached by considering an average value of certain peaks rather than the PGA.

2. The validity of the new numerical parameter changes if the combining method of the responses or the filtering criterion changes.

3. In the case of APGA, the given soil profile appears to be less sensitive to the variations in the ground motion characteristics while keeping the APGA constant.

4. For comparison, PGA may be easily replaced by APGA in the design formulas which are initially adapted for PGA by considering that APGA=0.79 PGA if the filtering criteria of $20 \%$ and top $10 \%$ was used (second case).

5. Although the final results always indicated positive reductions, but they were relatively low. The reasons may include:

a. Portion of the inconsistency in the soil response is related to the relative resonance influence between various ground motions.

b. Technical restrictions in the previous analyses such as the poor precision. In the educational version of Shake (EduShake), the results extracted from the FE analysis were sometimes represented in only two 
digits. This poor precision may fail to capture the variation between the ground motions.

c. The use of peak values i.e. peak shear strain, peak shear stress, peak displacement, peak cyclic stress ratio, and peak velocity to evaluate the geotechnical response, may not represent the entire response. These peaks which last only a fraction of a second and may not have the key element in safety. In addition, this study has proved the limitation of a peak to represent the entire time history.

d. Other factors should also be considered including duration of the earthquake. 


\section{Chapter 6 The Performance of Retaining Walls}

The new philosophy of seismic designs was introduced so that structural designs nationwide will achieve a uniform performance. This performance level was set to be at probability of exceedance of $2 \%$ in 50 years. The 1995 NBCC seismic provisions have provided a performance level close to the 2500 year return period; but it was not uniform nationwide. Previous seismic designs of retaining walls also possesses a performance level (non-uniform) higher than the design level, however this performance may and may not be the same as the building design which is at $2 \%$ in 50 years. To evaluate the performance level of the retaining walls, a numerical study will be conducted under the following criteria:

1. Gravity wall type will be used in this study.

2. Only two failure mechanisms will be considered: overturning and sliding.

3. The WSD approach will be used.

4. Overstrength factors will be used, but only partial overstrength factors from Tables 4-3 and 4-4 will be considered, knowing that those factors represent the best estimate of the overstrength.

5. To estimate the seismic thrust on retaining wall and for simplicity, simplified considerations will be used in design.

6. The performance level will be set to be the level at which the entire overstrength is used. 
7. For reference purposes, Ottawa will be used as a specified location for the wall where the PGA for Ottawa equals to $0.2 \mathrm{~g}$ (1995 NBCC).

Finally the performance level of the retaining walls seismic design will be compared with that of the structural design.

\subsection{Numerical Study on Performance of Gravity Wall}

Figure 6-1 presents a typical retaining wall located in Ottawa. To minimize any tolerance in the geometries, two independent geometries were presented $X 1$ and $X 2$. These unknown geometry parameters will be calculated based on the criteria that the safety factors for sliding and overturning equal to exactly the minimum design values.

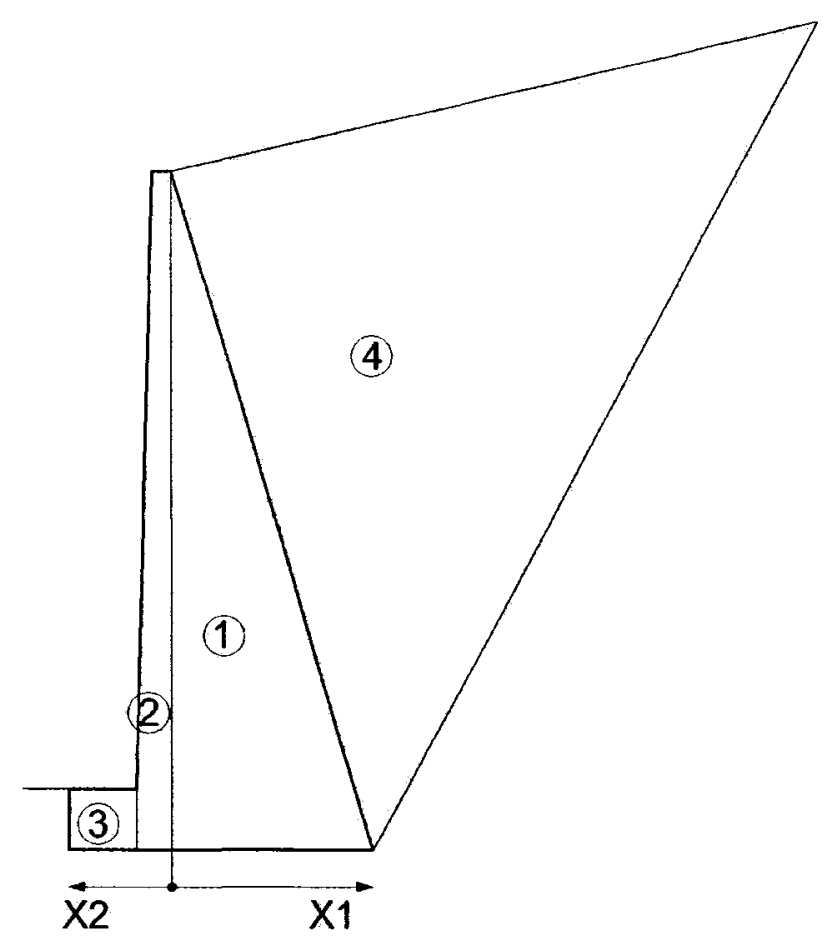

Figure 6-1: The wall sections 
First of all, the centroids of the model components need to be determined. Figure 6-2 illustrates these components, and in Table 6-1, the mechanical properties of these sections will be presented.

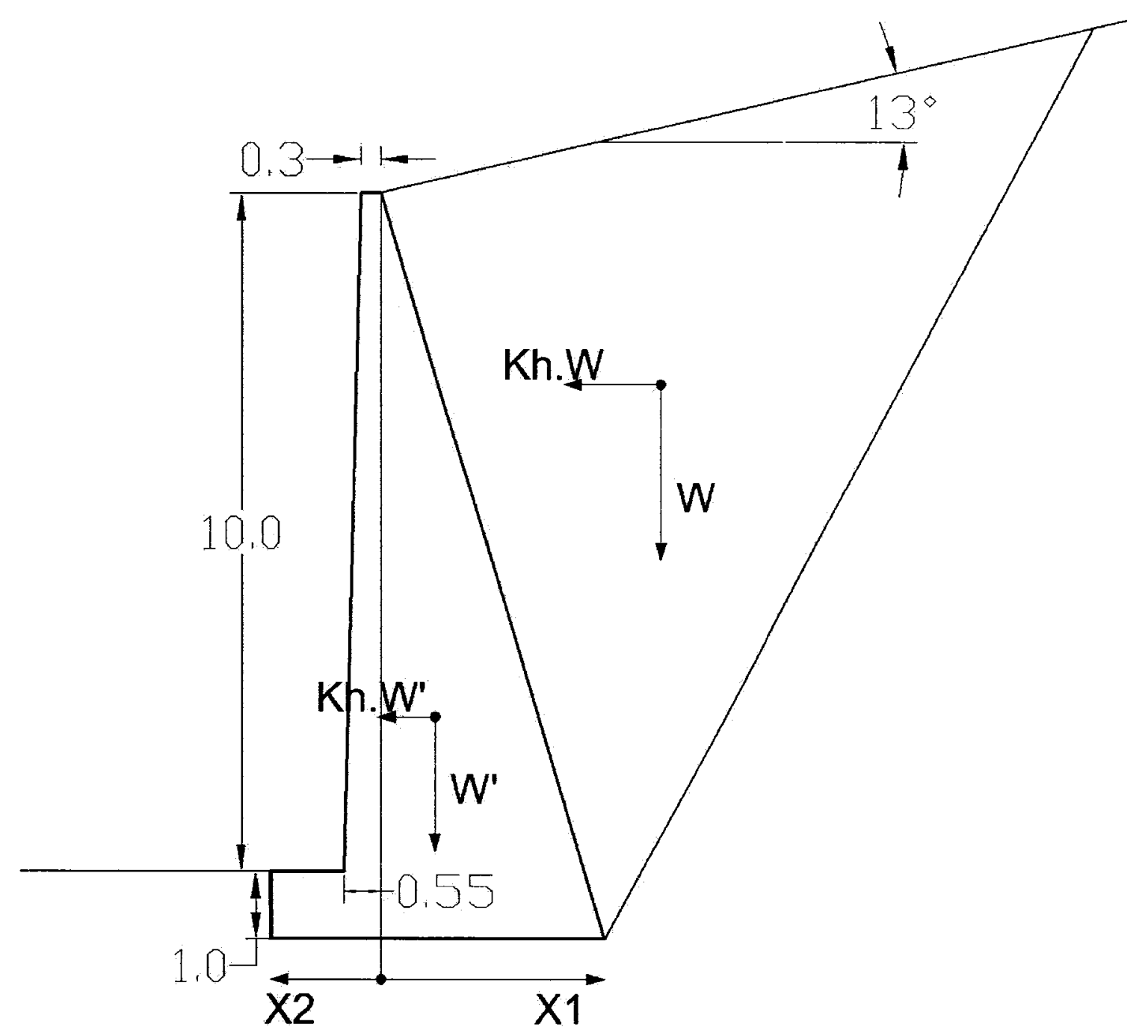

Figure 6-2: "A retaining wall designed based on M-O method"

For the wall body, a typical density of concrete will be used. For soil, a sand profile will be used:

$$
\gamma_{\text {concrete }}=24 \mathrm{kN} / \mathrm{m}^{3}, \gamma_{\text {sand }}=17.5 \mathrm{kN} / \mathrm{m}^{3}, \varphi=30^{\circ} \text { (backfill) }
$$


$\varphi_{\text {wallxsoil }}=\tan ^{-1}\left(0.75^{*} \tan 30\right)=23.4^{\circ}$, and $\varphi_{\text {soil } / \text { foundation }}=36^{\circ}($ foundation soil $)$

The stability of the wall will be determined based on the static and pseudo-static forces illustrated in Figure 5-2. The soil failure plane is assumed to be forming $45+\varphi / 2$ degrees from the horizontal plane. Safety factors will be taken as 1.5 for both sliding and overturning failure mechanisms (Canadian Foundation Engineering Manual 1993).

Table 6-1: Centroids and Weights of the wall sections

\begin{tabular}{|c|c|c|c|c|}
\hline Section & $\mathrm{X}_{\mathrm{G}}(\mathrm{m})$ & $\mathrm{Y}_{\mathrm{G}}(\mathrm{m})$ & $\mathrm{A}\left(\mathrm{m}^{2}\right)$ & $\mathrm{W}(\mathrm{KN})$ \\
\hline 1 & $\mathrm{X}_{1} / 3+\mathrm{X}_{2}$ & $11 / 3$ & $5.5 \mathrm{X}_{1}$ & $132 \mathrm{X}_{1}$ \\
\hline 2 & $\mathrm{X}_{2}-0.2251$ & 4.936 & 4.8 & 115.2 \\
\hline 3 & $\mathrm{X}_{2}-\left(\mathrm{X}_{2}+0.55\right) / 2$ & 0.5 & $\left(\mathrm{X}_{2}-0.55\right)$ & $24 \mathrm{Ar}_{3}$ \\
\hline 4 & $\mathrm{X}_{2}+2.4401+$ & $7.8931+0.08814 \mathrm{X}_{1}$ & $40.26+7.179 \mathrm{X}_{1}+0.1322 \mathrm{X}_{1}{ }^{2}$ & $17.5 \mathrm{Ar}_{4}$ \\
& $0.7176 \mathrm{X}_{1}$ & & & \\
\hline
\end{tabular}

The stability of both the wall and the failure wedge will be considered; therefore, the soil thrust will become an internal force. In conclusion, the external force system will consist of the following forces:

- Gravity forces: these forces are located at the centroids $\left(\mathrm{X}_{\mathrm{G}}\right)$.

- Pseudo-static M-O forces; these forces also located at the centroids $\left(\mathrm{X}_{\mathrm{G}}\right.$ and $\left.\mathrm{Y}_{\mathrm{G}}\right)$ and knowing that $\mathrm{K}_{\mathrm{h}}=1 / 3^{*}(\mathrm{PGA} / \mathrm{g})$ according to Marcuson (1981): $\mathrm{K}_{\mathrm{h}}=$ 0.06667 .

- By assuming that the vertical pseudo-static forces have minor effects on stability, they will not be considered. 
- Passive pressure at the toe. $P_{P}=1 / 2 \gamma H^{2} K_{P}=58.4 \mathrm{kN}: K_{P}=6.675$ for $\varphi=30^{\circ}$, $\varphi_{\text {wall } / \text { soil }}=23.4^{\circ}($ Coulomb 1776, quoted by Kaadan 2001$)$.

- Soil pressure along the soil wedge failure line $P w$ (assuming this force will not change after the pseudo-static loading). Figure 6-3 illustrates the rationale behind the estimation of $P_{W}$.

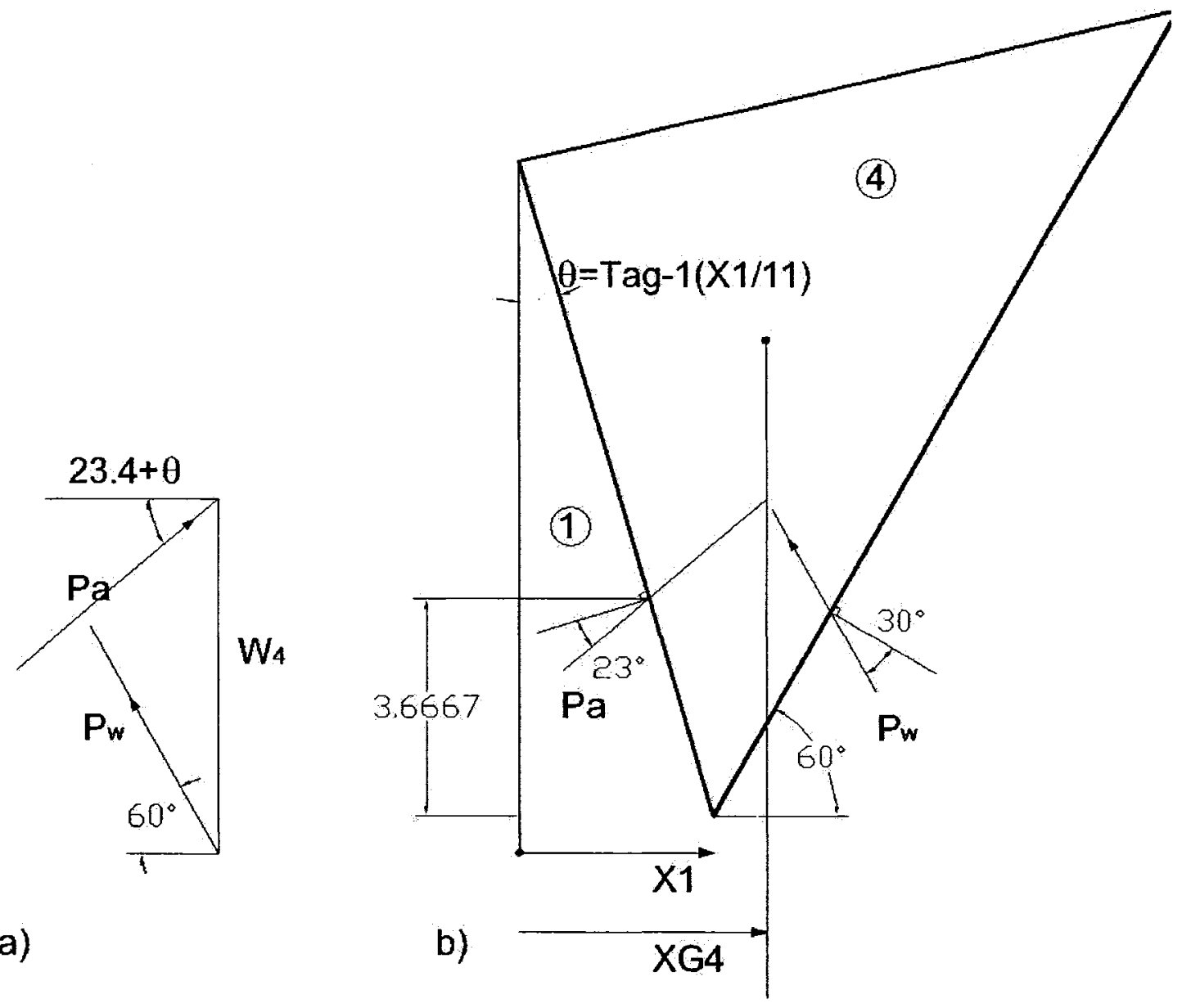

Figure 6-3: "The orientation and the value of $P w$ "

From Figure 6-3-a:

$\Sigma H=0: P w^{*} \cos 60=P a * \cos (23.4+\theta)$

$\sum V=0: P w^{*} \operatorname{Sin} 60+P a * \operatorname{Sin}(23.4+\theta)=W 4$ 


\subsubsection{Sliding Failure}

The free body diagram of the wall-backfill system is illustrated in Figure 6-4. The external forces were approximately plotted at their positions.

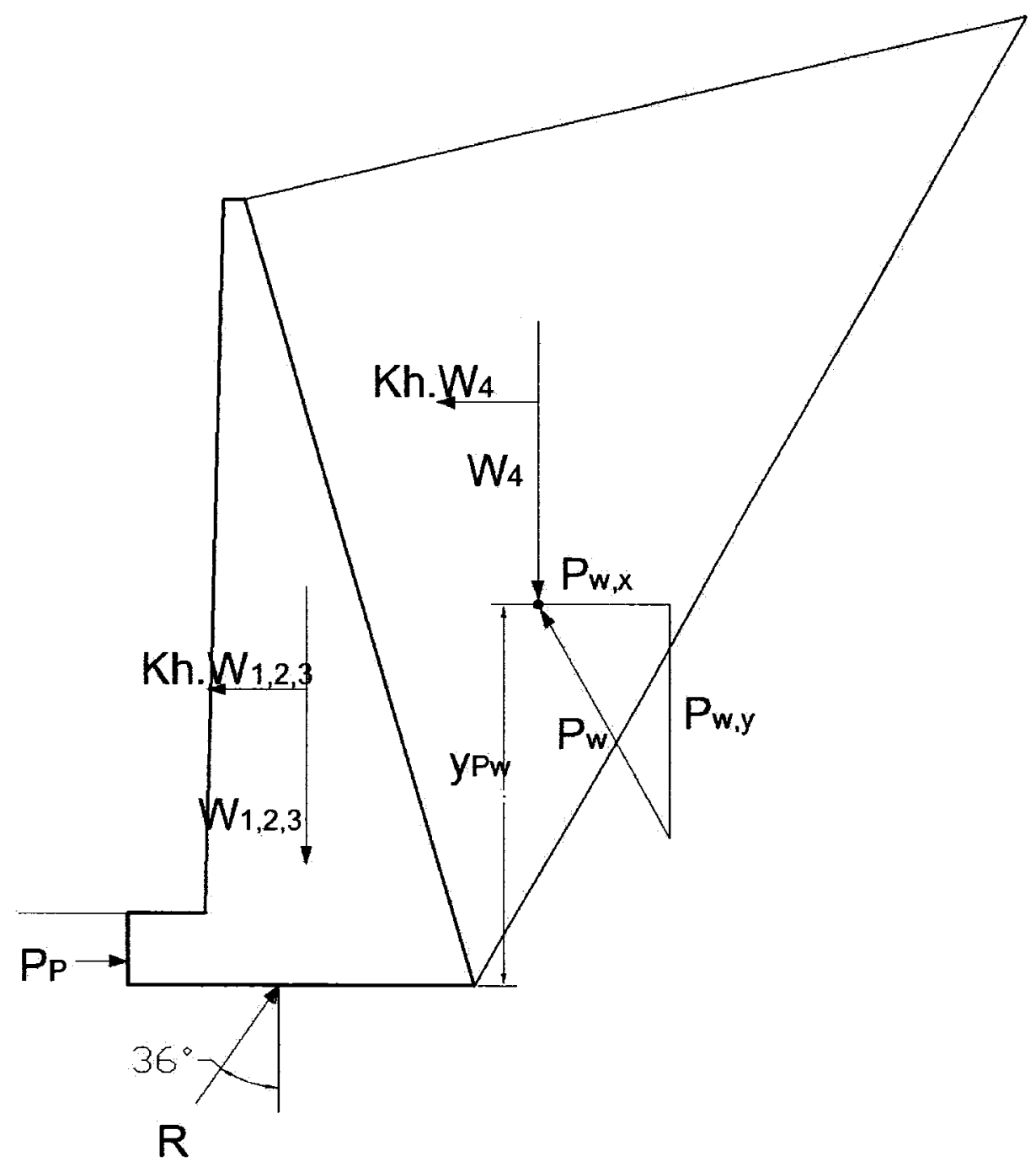

Figure 6-4: The wall-backfill external forces

$N=R \operatorname{Cos}\left(36^{\circ}\right)=\sum_{i=1}^{4} W_{i}-P_{w, y}$ 
Then the sliding safety factor:

$F s_{I}=\frac{P_{p}+N \cdot \operatorname{Tan}\left(36^{\circ}\right)}{K_{h} \cdot W_{(1,2,3, \text { and } 4)}+P_{W, X}}=1.5$

(No tolerance, first independent equation with two unknowns $X_{I}$ and $X_{2}$ ).

\subsubsection{Overturning Failure}

The safety factor for overturning failure will be chosen to be $F s_{2}=1.5$. (No tolerance, second independent equation with two unknowns $X_{1}$ and $X_{2}$ ). Finally, after solving the two equations of the safety factors, the variable will equal to $X_{I}=4.35 \mathrm{~m}$, $X_{2}=0.95 \mathrm{~m}$.

\subsubsection{The Performance of the Retaining Wall}

To estimate the performance level of the hazard (PGA), the overstrength factor should be applied to the strength, and then the corresponding hazard will represent the performance. In Section 4.4.3.13, the values, 1.55 and 1.85, were proposed for overturning and sliding. The performance level may be outlined in the following statement:

Performance resistance $=$ performance static loads + performance pseudo-static forces Design resistance $=$ design static loads + (performance pseudo-static loads/overstrength)

For sliding:

$\left\lfloor P_{p}+N \cdot \operatorname{Tan}\left(36^{\circ}\right)\right\rfloor=F_{S} *\left\lfloor K_{h}\left(\right.\right.$ Performance) $\left.W_{(1,2,3, \text { and } 4)} / R_{O}+P_{W, X}\right\rfloor: R_{o} \quad$ (overstrength factor) $=1.85$ in gravity walls and sliding failure

$\Rightarrow K_{h}=0.1233 \Rightarrow$ 
$\mathrm{PGA}($ performance $)=0.37 g: \mathrm{PGA}=3^{*} K_{h}$ (Marcuson 1981)

For overturning mechanism:

$\mathrm{R}_{\mathrm{o}}$ (overstrength factor) $=1.55$ in gravity walls and sliding failure $\Rightarrow K_{h}=0.1033 \Rightarrow$ $\operatorname{PGA}($ performance $)=0.31 \mathrm{~g}$.

The two performance PGAs are relatively comparable to the structural performance PGA $(0.42 \mathrm{~g})$. To find out the equivalent return periods of the performance of the gravity walls, the hazard curve should be plotted. On the $\log / \log$ scale of the hazard curve, i.e., PGA versus the return period; the hazard curve will be approximately a constant line. Using interpolation of the hazard curve, the return period of the performance level will be easily determined as illustrated in Figure 6-5 and outlined in Table 6-2.

Table 6-2: The performance return period of the wall

\begin{tabular}{|c|c|c|c|}
\hline PGA(g) & $\log (\mathrm{PGA})$ & $\log (\mathrm{T})$ & $\begin{array}{c}\text { Equivalent Return } \\
\text { period }\end{array}$ \\
\hline 0.2 & -0.69897 & 2.67669 & 475 \\
\hline 0.42 & -0.37675 & 3.39358 & 2475 \\
\hline 0.37 & -0.43180 & 3.2711 & 1867 \\
\hline 0.31 & -0.50864 & 3.1001 & 1259 \\
\hline
\end{tabular}

The seismic hazard curve versus return period on $\log / \log$ scale may not be a linear function, but for simplicity, it will be assumed to be a linear function. 


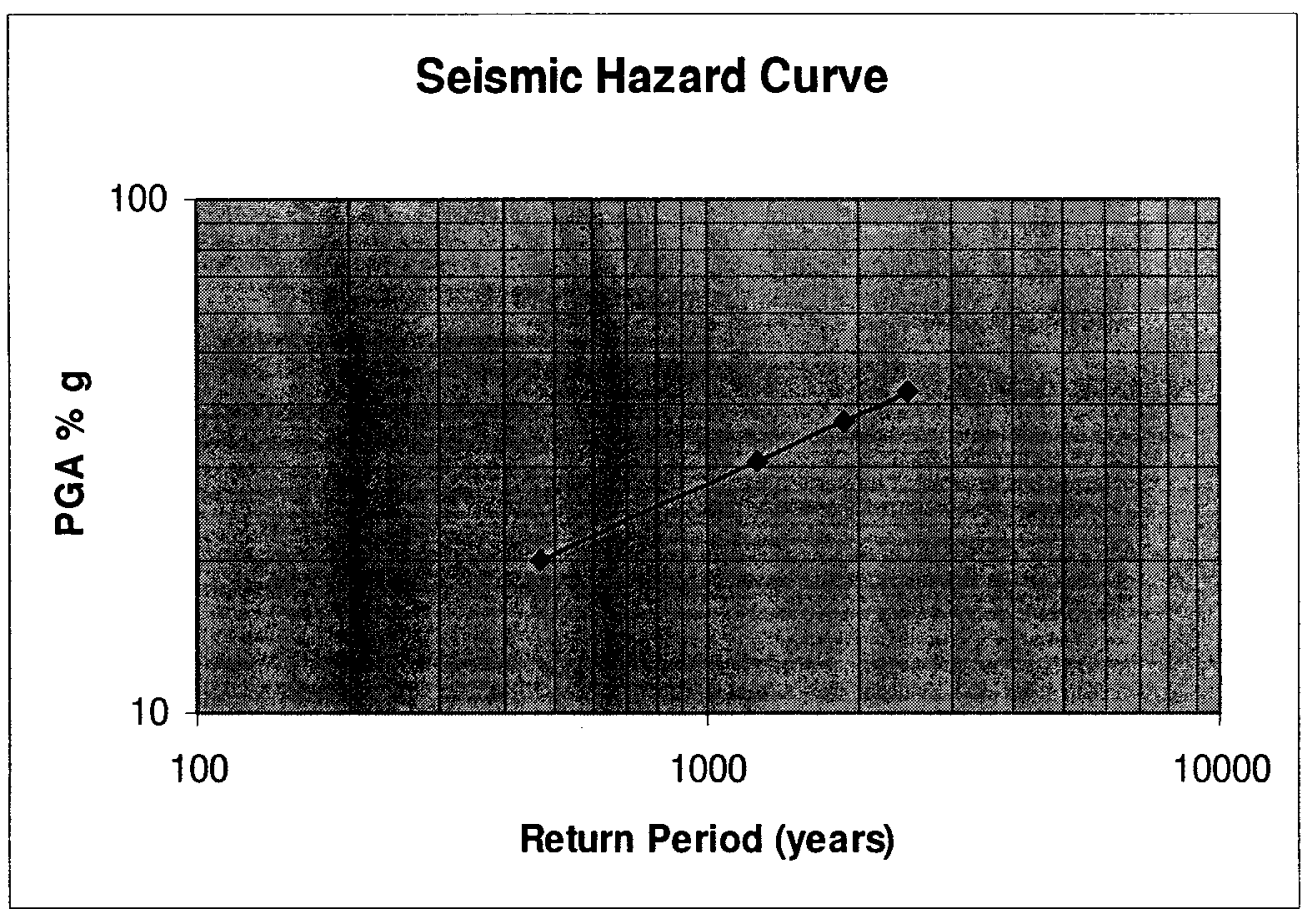

Figure 6-5: The performance return period of the retaining wall

The precise return period of the retaining wall performance may require the exact shape of the seismic hazard curve.

\subsection{Discussion on the Retaining Wall Performance}

The performance of this returning wall is in the same range of structural performance. Other sources of overstrength discussed in the previous chapter, will contribute to the performance of retaining walls in the life time of the walls. In addition, because the structural performance of the $2005 \mathrm{NBCC}$ is set at 2500 -year return period, the performance of the retaining walls needs to be adjusted to match that of the structural design.

Similar to Table 6-2, in Table 6-3, the performance return periods of several failure mechanisms in both types of the retaining walls will be as follows: 
Table 6-3: The performance return period of the retaining wall based on 1995 NBCC

\begin{tabular}{|c|c|c|c|}
\hline Failure type & Overstrength & Perform. PGA (g) & Return period \\
\hline Gravity sliding (G.S.) & 1.85 & 0.37 & 1867 \\
\hline Gravity overturning (G.O.) & 1.55 & 0.31 & 1259 \\
\hline Gravity Bearing capacity(G.B.C.) & 1.75 & 0.35 & 1650 \\
\hline Cantilever sliding (C.S.) & 1.92 & 0.384 & 2028 \\
\hline Canti. Overturning(C.O.) & 1.6 & 0.32 & 1352 \\
\hline Canti. Bearing capacity(C.B.C.) & 1.8 & 0.36 & 1756 \\
\hline
\end{tabular}

For the other major cities in Canada, similar work will reveal that the performance PGAs for different failure mechanisms will be close to the those given be the 2005 NBCC. Table 6-4 and Figure 6-6 introduce the performance PGAs for different cities and different failure mechanisms.

Table 6-4: Performance PGAs for Different cities and different failure mechanisms based on 1995 NBCC

\begin{tabular}{|c|c|c|c|c|c|c|c|}
\hline \multirow{2}{*}{ Failure } & \multicolumn{7}{|c|}{ Performance PGA (g) } \\
\cline { 2 - 8 } & Ottawa & Quebec & Toronto & Halifax & Vancouver & Calgary & Montréal \\
\hline G.S. & 0.37 & 0.3515 & 0.104 & 0.104 & 0.3885 & 0.03515 & 0.333 \\
\hline G.O. & 0.31 & 0.2945 & 0.0868 & 0.0868 & 0.3255 & 0.02945 & 0.279 \\
\hline G.B.C. & 0.35 & 0.3325 & 0.098 & 0.098 & 0.3675 & 0.03325 & 0.315 \\
\hline C.S. & 0.384 & 0.3648 & 0.108 & 0.108 & 0.4032 & 0.03648 & 0.3456 \\
\hline C.O. & 0.32 & 0.304 & 0.0896 & 0.0896 & 0.336 & 0.0304 & 0.288 \\
\hline C.B.C. & 0.36 & 0.342 & 0.101 & 0.101 & 0.378 & 0.0342 & 0.324 \\
\hline
\end{tabular}




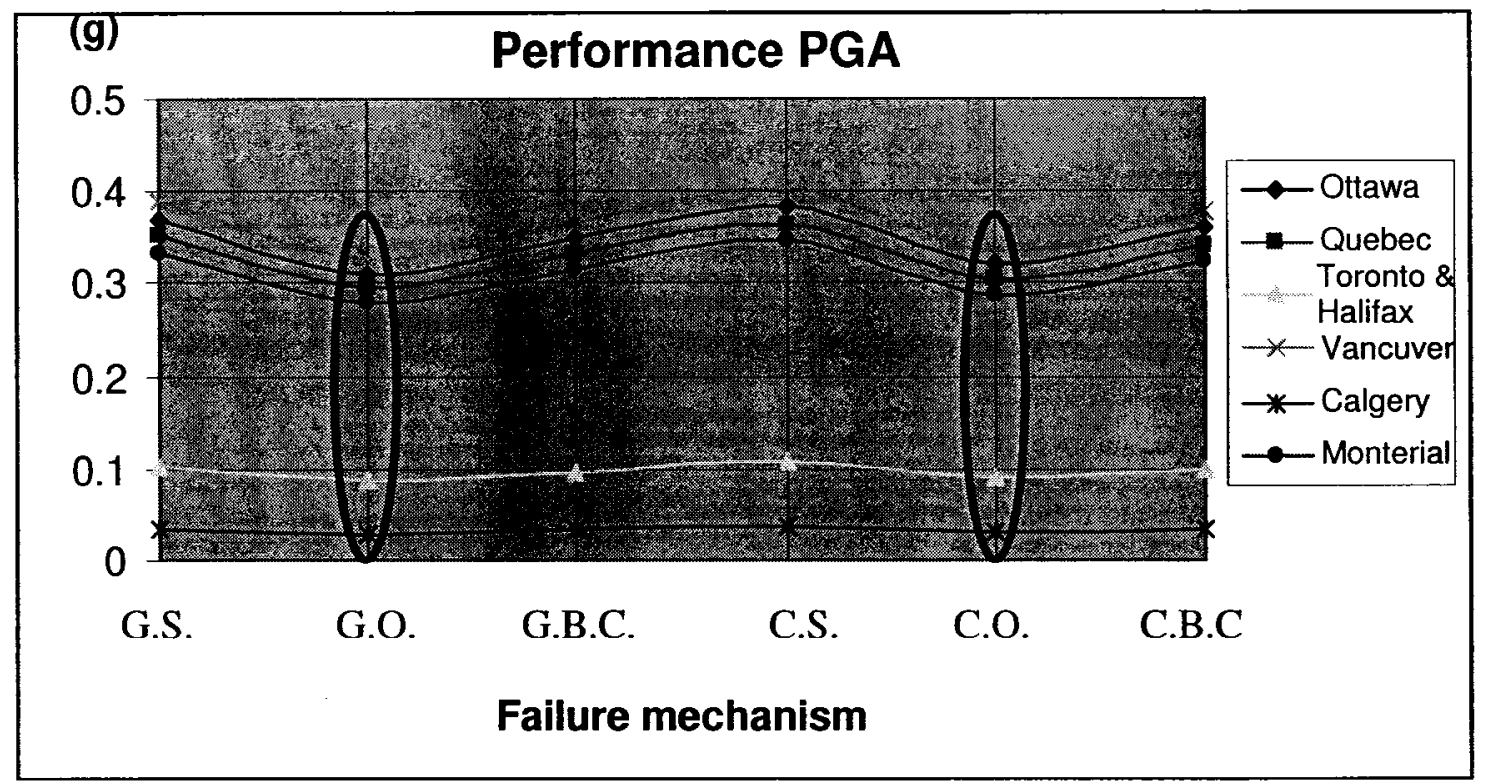

Figure 6-6: Performance PGAs for Different cities and different failure mechanisms, the first letter of G.S. is for wall type (gravity) and the second is for the failure type (sliding)

From Figure 6-6, the seven curves that represent the performance PGAs of the major seven cities in Canada in the $1995 \mathrm{NBCC}$, indicate that overturning failure mechanism is the lowest performance. Therefore, the performance of the retaining walls is most likely to have an overstrength factor equals 1.55 .

\subsection{Uniform Performance According to 2005 NBCC}

Retaining walls have different performances due to different failure mechanisms. To achieve uniform performance between different cities in Canada and in accordance with the 2005 NBCC return period, the design should be accomplished in such a way that the performance is 2500 years.

After referring to Figure 3-11, the design PGAs that will achieve uniform performance at 2500 year for all cities in Canada will be at ratio equals to $R_{O}=1.55$ lower than the $2 \%$ in 50 year probability as they are introduced in Table 6-5: 
Table 6-5: Design and performance PGAs for retaining walls in the 1995 NBCC and the 2005 NBCC, the ratio is the introduced design PGA in the 2005 to the 1995 design PGA

\begin{tabular}{|c|c|c|c|c|c|}
\hline \multirow{2}{*}{ PGA(g) } & $\begin{array}{c}1995 \\
\text { NBCC }\end{array}$ & 1995 NBCC & 2005 NBCC & $\begin{array}{c}2005 \\
\text { NBCC }\end{array}$ & Ratio \\
\cline { 2 - 6 } & Design & Performance & Performance & Design & Design \\
\hline Québec & 0.19 & 0.295 & 0.37 & 0.239 & $126 \%$ \\
\hline Toronto & 0.056 & 0.0868 & 0.2 & 0.129 & $230 \%$ \\
\hline Vancouver & 0.23 & 0.357 & 0.48 & 0.310 & $135 \%$ \\
\hline Halifax & 0.056 & 0.0868 & 0.12 & 0.0774 & $138 \%$ \\
\hline Calgary & 0.019 & 0.0295 & 0.088 & 0.0568 & $299 \%$ \\
\hline Ottawa & 0.2 & 0.31 & 0.42 & 0.271 & $135 \%$ \\
\hline Montréal & 0.18 & 0.279 & 0.43 & 0.277 & $154 \%$ \\
\hline
\end{tabular}

Finally, it is important to indicate that the design values of PGA introduced in Table 6-5 dependent on the overstrength of retaining walls which is chosen to be 1.55 . The exact value of the overstrength requires evaluation of the other overstrength contributing factors discussed in Section 4.4.3. 


\section{Chapter 7 Conclusions and Recommendations}

Several conclusions could be derived from this study. The developments of the seismic provisions pertaining to seismological, geotechnical and structural are thoroughly evaluated. The developments introduced for the structural design are applied to the seismic design of gravity retaining walls. In light of this application, a factor of overstrength for a gravity retaining wall is obtained. The use of 1.55 overstrength will maintain uniform performance in various parts of the country, and will bring about an improvement of the safety level performance for retaining walls.

\subsection{Results and Conclusions}

The following conclusions can be derived from this study:

1. This study shows that designers can avoid the use of $2 \%$ in 50 years peak ground acceleration directly in design, and be consistent with the new safety level recommended by the $2005 \mathrm{NBCC}$.

2. There is an overstrength inherited in the seismic design of retaining walls. A reasonable value of overstrength factor of 1.55 is estimated. The use of 1.55 overstrength will maintain uniform performance in various parts of the country, and will bring about an improvement of the safety level performance for retaining walls.

3. In keeping with the provisions of the $2005 \mathrm{NBCC}$ and to achieve an improved safety level, it is therefore, recommended for design purposes, the PGAs of the $2 \%$ in 50 years event should be adopted with an overstrength factor of 1.55 . The 
resultant PGAs for design will then be equal to the PGAs from the 2005 NBCC divided by the overstrength factor. This resultant PGAs can be used directly in common design formulae.

4. Based on the proposed values of the overstrength factors, the performance of the retaining wall seismic design based on the 1995 NBCC provisions (475-year return period) is close to resisting a 1500 -year event.

5. For design consistent with safety level adopted in the $2005 \mathrm{NBCC}$, an overstrength factor equal to 1.55 can be used on the working stress approach with a safety factor of 1.5 .

6. Because of the unique characteristics of geotechnical design, the overstrength reserved in the design system might come from various factors such as vegetation cover which are only applicable to the geotechnical strength.

7. The differences in the performance of structures designed for different cities inherent in the $1995 \mathrm{NBCC}$ seismic design were not only due to the differences of the slopes of the seismic hazards existed between the east and the west but also due to the differences in the seismicity level existed between cities in the same region.

8. It seems that the philosophy of seismic design has changed in the recent American and Canadian building codes from designing a structure to resist 475 -year event (1995 NBCC) to designing a structure that will survive 2500 year event (2005 NBCC). 


\subsection{Remarkable Contributions}

After this presentation of the main research conclusions, two remarkable contributions will be summarized:

\subsubsection{Uniform Performance}

As discussed in Section 3.1.4 and illustrated in Figure 3-10, the change of the probability level from $10 \%$ to $2 \%$ in 50 years have unified and normalized the seismic design performance not only between the east coast and the west coast regions as noted by Adams and Atkinson (2003), but also between cities in the same seismic zone. This benefit is discovered through Figure 3-10. This contribution will be useful for the geotechnical design as well as for all other civil engineering designs that require an earthquake assessment.

Furthermore, in other countries, the seismic design of civil engineering structures may also benefit from this contribution. In the United States, the NEHRP recommended provisions have not yet addressed the extended benefits of the new change in probability level although those provisions had been adopted to the new probability level since 1997 . According to this effect, the $2 / 3$ factor that was chosen to calibrate the new PGAs may need to be changed to accommodate the new performances.

Finally, the designs for other natural disasters such as hurricanes or storms that possess time dependent exposure functions like earthquakes will be susceptible to nonuniform performances because of the differences in the exposure levels. To achieve 
uniform performance for these designs, they have to be recalibrated just like how it was illustrated in Figure 3-11.

\subsubsection{Average PGA}

The APGA introduced in the Chapter 5 is a single number that quantify the ground motion time history. This number has a potential advantage over PGA, and may be used to normalize different time histories. In the geotechnical design, design methods used in practice (like Cyclic Stress Ratio in liquefaction assessment) have incorporated a single number (PGA) in their structures which could be easily replaced by an APGA. For reference purposes, APGA is equal to 0.64 PGA and is obtained by taking the average of the top $10 \%$ peak accelerations after filtering out the bottom $6 \%$ peaks.

\subsection{Future Work}

The following investigation can be conducted to extend the work described in this thesis.

1. For the analyses of seismic forces on gravity retaining walls, there is an opportunity to obtain a simple pseudo-static method (like M-O method) that employs the Average Peak Ground Acceleration (APGA), the resonance effect, and the inertia forces of the wall mass in one composite equation for seismic thrust.

2. Possible improvements may be achieved if different combination methods are applied and/or different filtering criteria are considered in establishing the value 
of APGA. Other factors could be incorporated such as giving a weight to the duration.

3. There is still a need for post earthquake reports on retaining wall failures. As discussed in Section 2.4.8, only full reports are valuable, and they are in short supply.

4. The overstrength factors discussed in Section 4.4 .2 are a best estimate. Statistical studies are strongly recommended to evaluate and estimate the precise values of the overstrength factors. After the statistical studies are conducted, the seismic performance of retaining walls needs to be independently estimated.

5. From the performance level that will be determined, a new overstrength factor could be obtained. 


\section{References}

Adams, J. (2006) "A Discussion at the One-Day Workshop on the 2005 NBCC Seismic Design Requirements". University of Ottawa, Ottawa, ON.

Adams, J. and Atkinson, G. (2003) "Development of Seismic Hazard Maps for the Proposed 2005 Edition of the National Building Code of Canada". Canadian J. of Civil Engineering, 30(2): 255-271.

Adams, J., Weichert, D.H., and Halchuk, S. (1999) "Lowering the Probability Level Fourth Generation Seismic Hazard Results for Canada at the $2 \%$ in 50 Year Probability Level". Proceedings of the $8^{\text {th }}$ Canadian Conference on Earthquake Engineering, Vancouver, B.C., 83-88.

Allen, D.E. (1975) “Limit States Design: a Probabilistic Study”. Canadian J. of Civil Engineering, 2(1): 36-49.

Allen, D.E. (1991) "Limit States Criteria for Structural Evaluation of Existing Buildings”. Canadian J. of Civil Engineering, 18(6): 995-1004.

Brinch Hansen, J. (1953) "Earth Pressure Calculation". Institution of Danish Civil Engineers, Copenhagen, Denmark.

Brinch Hansen, J. (1956) "Limit States and Safety Factors in Soil Mechanics". Danish Geotechnical Institute, Copenhagen, Denmark. 
Caltabiano, S., Cascone, E., and Maugeri, M. (1999) "Sliding Response of Rigid Retaining Walls". Proceedings of the $2^{\text {nd }}$ International Conference on Earthquake Geotechnical Engineering, Lisbon, Portugal, 285-290.

Caltabiano, S., Cascone, E., and Maugeri, M. (2000) "Seismic Stability of Retaining Walls with Surcharge". Soil Dynamics and Earthquake Engineering, 20: 469-476.

Canadian Foundation Engineering Manual (1992) $3^{\text {rd }}$ Edition, Canadian Geotechnical Society, BiTech Publishers, Vancouver, B.C.

Chugh, A.K. (2005) "A Counterfort versus a Cantilever Retaining Wall (a Seismic Equivalence)". J. for Numerical and Analytical Methods in Geomechanics, 29: 897-917.

Concrete Design CSA Standard A23.3 (1994), Canadian Standards Association, Code for the Design of Concrete Structures for Buildings, Rexdale, Toronto, ON.

Cornell, C.A. (1996) "Reliability-Based Earthquake-Resistant Design: The Future". Proceedings of the $11^{\text {th }}$ World Conference on Earthquake Engineering, Acapulco, Mexico, 2166.

Crespellani, T., Madiai, C., and Vannucchi, G. (1994) "Earthquake Destructiveness Potential Factor and Permanent Displacements of Gravity Retaining Walls". Proceedings of the Conference on Analysis and Design of Retaining Structures Against Earthquakes, 124-133.

Day, R.W. (2002) "Geotechnical Earthquake Engineering Handbook". McGraw-Hill, New York. 
EduShake (2002) "One dimensional Computer Program for Earthquake Response Analysis of Horizontally Layered Profile". Earthquake Engineering Research Center, University of California, Berkeley.

Ellingwood, B.R. (1994) "Probability-Based Codified Design: Past Accomplishments and Future Challenges". Structural Safety, 13(3): 159-176.

Engineer Manual (1989) "Engineer Manual, Retaining and Flood Walls". U.S. Army Corps of Engineers, Washington, D.C.

Fang, Y.S., Yang, Y.C., and Chen, T.J. (2003) "Retaining Walls Damaged in the Chi-Chi Earthquake". Canadian Geotechnical J., 40: 1142-1153.

Glen, W. (1975) “Continental Drift and Plate Tectonic”. Merrill, Columbus, Ohio.

Green, R.A., Olgun, C.G., Ebeling, R.M., and Cameron, W.I. (2003) "Seismically Induced Lateral Earth Pressures on a Cantilever Retaining Wall". Proceedings of the $6^{\text {th }}$ U.S. Conference and Workshop on Lifeline Earthquake Engineering, Long Beach, CA, 946-955.

Gubbins, D. (1990) "Seismology and Plate Tectonics". Cambridge University Press, Cambridge, U.K.

Hager, B.H. (1978) "Oceanic Plate Driven by Lithospheric Thickening and Subducted Slabs". Nature, 276: 156-159. 
Heidebrecht, A.C. (2003) "Overview of Seismic Provisions of the Proposed 2005 Edition of the National Building Code of Canada". Canadian J. of Civil Engineering, 30: 241254.

Heidebrecht, A.C. and Tso, W.K. (1985) "Seismic Loading Provisions Changes in the National Building Code of Canada”. Canadian J. of Civil Engineering, 12: 653-660.

Humar, J. (2006) “A Discussion at the One-day Workshop on the 2005 NBCC Seismic Design Requirements". University of Ottawa, Ottawa, ON.

Kaadan, A. (2001) "Foundation Engineering”. Ray Publishing \& Science, Aleppo, Syria.

Kearey, P. and Vine, F.J. (1990) “Global Tectonics”. Blackwell, Oxford.

Kennedy, R.P. (1980) "Ground Motion Parameters Useful in Structural Design". Proceedings of the Conference on Evaluation of Regional Seismic Hazards and Risk, Santa Fe, New Mexico.

Kennedy, R.P., Short, A.S., McDonald, R.R., McCann, M.W., Murray, R.C., and Hill, J.R. (1994) “Natural Phenomena Hazards Design and Evaluation Criteria for Department of Energy Facilities". U.S. Department of Energy, Washington, D.C.

Kim, S.R., Kwon, O.S., and Kim, M.M. (2004) "Evaluation of Force Components Acting on Gravity Type Quay Walls During Earthquakes". Soil Dynamics and Earthquake Engineering, 24(11): 853-866. 
Kramer, S.L. (1996) “Geotechnical Earthquake Engineering”. Pearson Education, Upper Saddle River, N.J.

Law, K.T. (2005) “Advanced Soil Mechanics”. Discussion and Class Notes, Carleton University, Ottawa, ON.

Law, K.T., Allen, D.E., Evison, S., Bartlett, M., and St. Louis, M. (1991) "Workshop on Limit States Design for Foundations". Institute for Research in Construction (NRC), Ottawa, ON.

Lee, C.J. (2005) "Centrifuge Modeling of the Behaviour of Caisson-Type Quay Walls during Earthquake”. Soil Dynamics and Earthquake Engineering, 25(2): 117-131.

Lefebvre, G. (2006) “Surface Wave Testing in Geotechnical Investigations”. Luncheon Presentation, Ottawa Geotechnical Group (OGG), Ottawa, ON.

Ling, H.I., Liu, H., and Mohri, Y. (2005) "Parametric Studies on the Behavior of Reinforced Soil Retaining Walls under Earthquake Loading". J. of Engineering Mechanics, 131(10): 1056-1065.

Malhotra, P.K. (1997) "Dynamics of Seismic Impacts in Base-Isolated Buildings". Earthquake Engineering and Structural Dynamics, 26: 797-813.

Marcuson, W.F. (1981) 'Moderator's Report for Session on Earth Dams and Stability of Slopes under Dynamic Loads". Proceedings of the International Conference on Recent Advances in Geotechnical Earthquake Engineering and Soil Dynamics, St. Louis, Missouri, 1175. 
Meyerhof, G.G. (1993) “Development of Geotechnical Limit State Design”. Proceedings of the International Symposium on Limit State Design in Geotechnical Engineering, Copenhagen, Denmark, 1-12.

Meyerhof, G.G. (1995) "Development of Geotechnical Limit State Design". Canadian Geotechnical J., 32: 128-136.

Mononobe, N. and Matsuo, H. (1929) "On the Determination of Earth Pressure During Earthquake". Proceedings of the World Engineering Congress, Tokyo 9(1): 177-185.

Nadim, F. (1982) “A Numerical Model for Evaluation of Seismic Behavior of Gravity Retaining Walls". Ph.D. Thesis, Department of Civil Engineering, Massachusetts Institute of Technology (MIT), Cambridge, MA.

Nadim, F. and Whitman, R.V. (1983) "Seismically Induced Movement of Retaining Walls”. J. of Geotechnical Engineering, 109(7): 915-931.

Nadim, F. and Whitman, R.V. (1984) "Coupled Sliding and Tilting of Gravity Walls during Earthquakes". Proceedings of the $8^{\text {th }}$ World Conference on Earthquake Engineering, Washington, D.C., 477-484.

Navarro, C. and Samartín, A. (1988) "Seismic Earth Thrust Against Massive Building Walls". International J. for Numerical and Analytical Methods in Geomechanics, 13(4): 347-357. 
Noson, L.L., Qamar, A., and Thorsen, G.W. (1988) "Washington State Earthquake Hazards". Washington Division of Geology and Earth Resources Information Circular, Olympia, WA.

Okabe, S. (1926) “General Theory of Earth Pressure and Seismic Stability of Retaining Wall and Dam”. J. of the Japanese Society of Civil Engineering, 12(1): 123-134.

Ostadan, F. (2005) "Seismic Soil Pressure for Building Walls: An Updated Approach". Proceedings of the $11^{\text {th }}$ International Conference on Soil Dynamics and Earthquake Engineering, Berkeley, CA, 785-793.

Ostadan, F. and White, W.H. (1998) "Lateral Seismic Soil Pressure: An updated Approach". Proceedings of the Workshop on Soil-Structure Interaction, Menlo Park, California, 2-36.

Prakash, S. (1996) “Analysis And Design Of Retaining Structures Against Earthquakes”. Book, ASCE, Washington, D.C.

Psarropoulos, P., Klonaris, G., and Gazetas, G. (2005) "Seismic Earth Pressures on Rigid and Flexible Retaining Walls". Soil Dynamics and Earthquake Engineering, 25:795-809.

Richards, R. and Elms, D.G. (1979) "Seismic Behaviour of Gravity Retaining Walls". J. of Geotechnical Engineering, 105(4): 449-64.

Saatcioglu, M. (2004) "Earthquake Engineering". Discussion and Class Notes, Ottawa University, Ottawa, ON. 
Saatcioglu, M. (2006) “A Discussion at the One-Day Workshop on the 2005 NBCC Seismic Design Requirements”. University of Ottawa, Ottawa, ON.

Seed, H.B. and Idriss, I.M. (1970) "Soil Moduli and Damping Factors for Dynamic Response Analyses”. Report No EERC 70-10, Earthquake Engineering Research Center, University of California, Berkeley.

Sherif, M.A. and Fang, Y.S. (1984) "Dynamic Earth Pressures on Wall Rotating about the Base". Proceedings of the $8^{\text {th }}$ World Conference on Earthquake Engineering, San Francisco, CA, 993-1000.

Sherif, M.A. and Fang, Y.S. (1984) "Dynamic Earth Pressures on Wall Rotating about the Top". Soil and Foundation, 24(4): 109-117.

Sherif, M.A., Ishibashi, I., and Lee, C.D. (1982) "Earth Pressure Against Rigid Retaining Walls". J. of Geotechnical Engineering, 108(5): 679-695.

Siddharthan, R. and Maragakis, E.M. (1988) "Performance of Flexible Retaining Walls Supporting Dry Cohesionless Soils Under Cyclic Loads”. International J. for Numerical and Analytical Methods in Geomechanics, 13(3): 309-326.

Siddharthan, R., Ara, S., and Norris, G.M. (1992) "Simple Rigid Plastic Model for Seismic Tilting of Rigid Walls". J. of Structural Engineering, 118(22): 469-487.

Sivathayalan, S. (2005) "Geotechnical Earthquake Engineering”. Discussion and Class Notes, Carleton University, Ottawa, ON. 
Steedman, R.S. and Zeng, X. (1990) “The Seismic Response of Waterfront Retaining Walls". Proceedings of the ASCE Specialty Conference on Design and Performance of Earth Retaining Structures, New York, NY, 872-886.

Taylor, F.B. (1910) "Bearing of the Tertiary Mountain Belt on the Origin of the Earth's Plan”. Bulletin of the Geotechnical Society of America, 21: 179-226.

Taylor, S.A. and Ashcroft, G.L. (1972) "Physical Edaphology: the Physics of Irrigated and Non-Irrigated Soils". W.H. Freeman, San Francisco, CA.

Terzaghi, K. and Peck, R.P. (1967) "Soil Mechanics in Engineering Practice". $2^{\text {nd }}$ Edition, John Wiley \& Sons, New York.

Tso, W.K. (1992) "Overview of Seismic Provision Changes in National Building Code of Canada”. Canadian J. of Civil Engineering, 19(3): 383-388.

Vanapalli, S.K. (2005) "Shear Strength in Unsaturated Soil Mechanics". Class Notes, Ottawa University, Ottawa, ON.

Veletsos, A.S. and Younan, A. (1997) "Dynamic Response of Cantilever Retaining Walls". J. Geotechnical and GeoEnvironmental Engineering, 123(2): 161-172.

Verney, P. (1979) “The Earthquake Handbook”. Paddington Press, New York.

Whitman, R.V. (1990) "Seismic Design and Behavior of Gravity Retaining Walls". Proceedings of the ASCE Specialty Conference on Design and Performance of Earth Retaining Structures, 817-842. 
Whitman, R.V. and Liao, S. (1985) “Seismic Design of Retaining Walls”. Miscellaneous Paper GL-85-1, U.S. Army Engineer Waterways Experiment Station, Vicksburg, Mississippi.

Wood, J.H. (1973) "Earthquake-Induced Soil Pressures on Structures". Ph.D. Thesis, California Institute of Technology, Pasadena, California.

Wu, G. and Finn, W.D.L. (1999) "Seismic Lateral Pressures for Design of Rigid Walls". Canadian Geotechnical J., 33: 509-522.

Younan, A. and Veletsos, A.S. (2000) "Dynamic Response of Flexible Retaining Walls". Earthquake Engineering and Structural Dynamics, 29(12): 1815-1844. 